San Jose State University

SJSU ScholarWorks

Master's Theses

Master's Theses and Graduate Research

Spring 2012

\title{
Effectiveness of a San Francisco Bay Area Community Education Program on Reducing Home Energy Use
}

Ellen M. Wilkinson

San Jose State University

Follow this and additional works at: https://scholarworks.sjsu.edu/etd_theses

\section{Recommended Citation}

Wilkinson, Ellen M., "Effectiveness of a San Francisco Bay Area Community Education Program on Reducing Home Energy Use" (2012). Master's Theses. 4182.

DOI: https://doi.org/10.31979/etd.rhtg-vj3x

https://scholarworks.sjsu.edu/etd_theses/4182

This Thesis is brought to you for free and open access by the Master's Theses and Graduate Research at SJSU ScholarWorks. It has been accepted for inclusion in Master's Theses by an authorized administrator of SJSU ScholarWorks. For more information, please contact scholarworks@sjsu.edu. 


\title{
EFFECTIVENESS OF A SAN FRANCISCO BAY AREA COMMUNITY EDUCATION PROGRAM ON REDUCING HOME ENERGY USE
}

\author{
A Thesis \\ Presented to \\ The Faculty of the Department of Environmental Studies \\ San José State University \\ In Partial Fulfillment \\ of the Requirements for the Degree \\ Master of Science
}

by

Ellen M. Wilkinson

May 2012 
(C) 2012

Ellen M. Wilkinson

ALL RIGHTS RESERVED 
The Designated Thesis Committee Approves the Thesis Titled

\section{EFFECTIVENESS OF A SAN FRANCISCO BAY AREA COMMUNITY EDUCATION PROGRAM ON REDUCING HOME ENERGY USE}

by

Ellen M. Wilkinson

APPROVED FOR THE DEPARMENT OF ENVIRONMENTAL STUDIES

SAN JOSÉ STATE UNIVERSITY

May 2012

Dr. William H. Russell Department of Environmental Studies

Dr. Clifton Oyamot Department of Psychology

Dr. Anne Marie Todd Department of Communication Studies 


\section{ABSTRACT \\ EFFECTIVENESS OF A SAN FRANCISCO BAY AREA COMMUNITY EDUCATION PROGRAM ON REDUCING HOME ENERGY USE}

by Ellen M. Wilkinson

In order to promote the adoption of home energy reduction practices and mitigate the climate impact of the collective greenhouse gas emissions generated by consumers, it is critical to identify an effective educational approach. A community-based educational intervention model that employs norms, information, commitment, feedback, and face-toface communication strategies was examined for its ability to motivate changes in everyday energy-use behavior in two communities compared to a control group. A follow up study was also conducted to evaluate whether behaviors adopted as a result of the intervention were long lasting, and whether the community-focused features of the intervention were motivating to participants. Results showed that a greater number of individuals participated in the intervention over its five-month duration, reported significantly higher numbers of adopted behaviors, and maintained more adopted behaviors post-intervention than did people in the control group. In addition, intervention participants reported that some of the community-based features of the intervention motivated their behavior changes. These findings lend support to a number of social and community psychology theories about how to design effective interventions by leveraging social awareness and support. 


\section{Table of Contents}

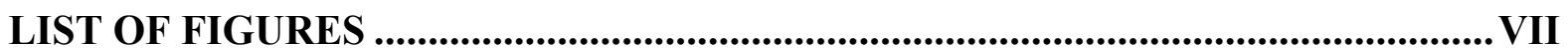

LIST OF TABLES ................................................................................................................ IX

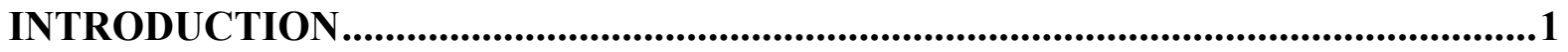

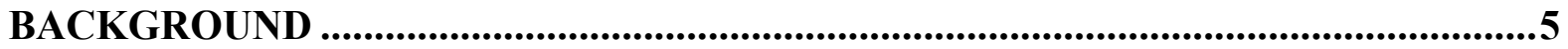

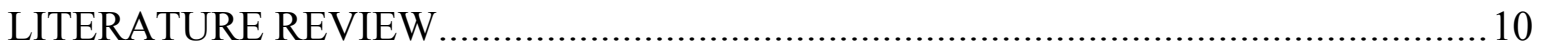

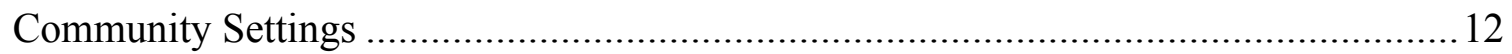

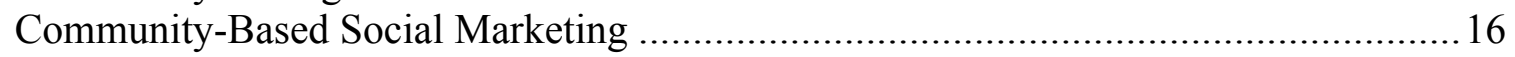

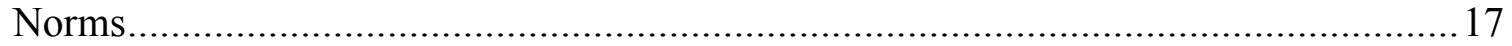

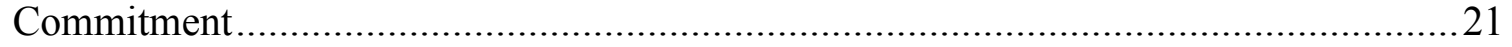

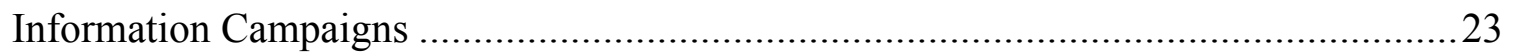

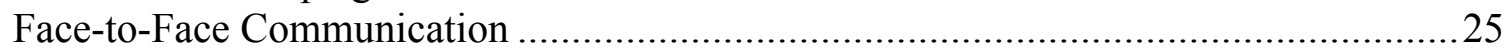

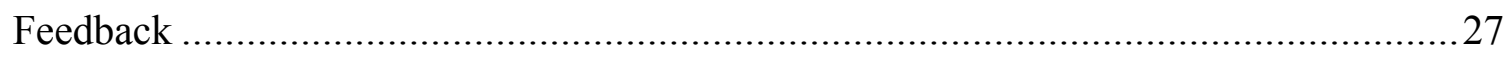

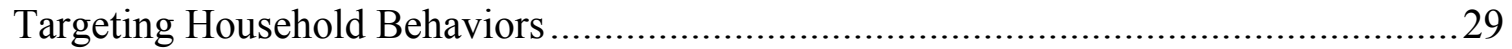

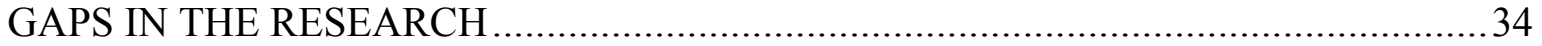

Long Term Effectiveness of Behavior Change Interventions.........................................34

Examples of a Community-based Intervention ................................................................ 35

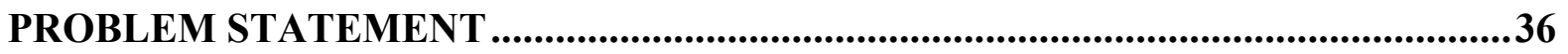

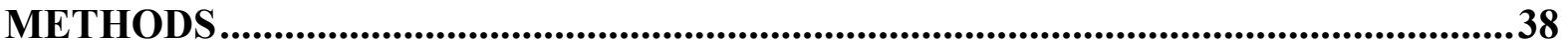

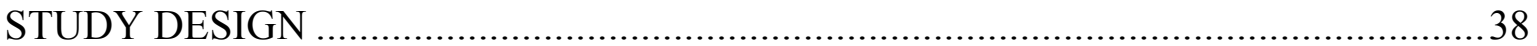

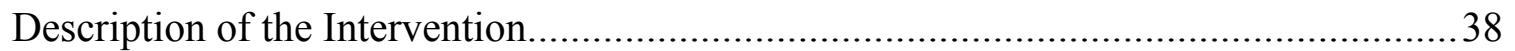

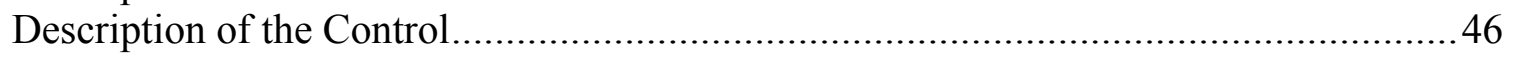

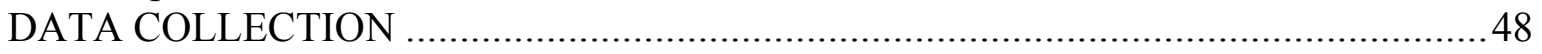

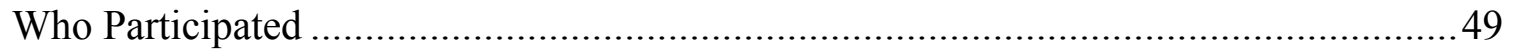

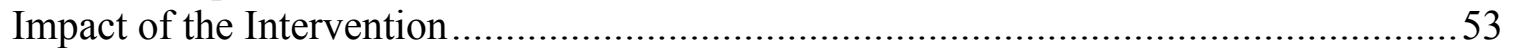

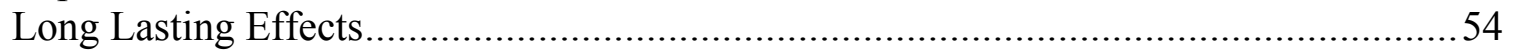

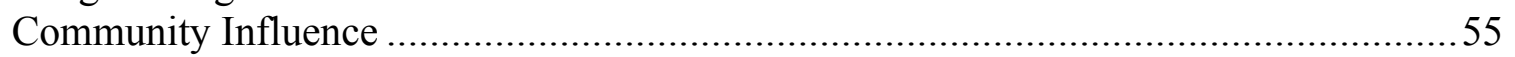

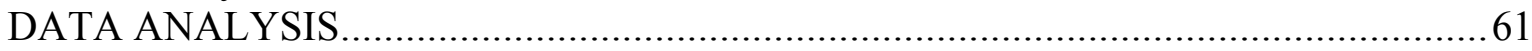

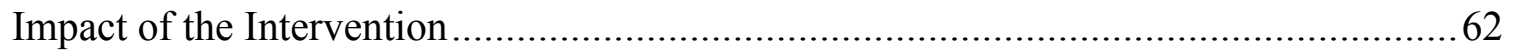

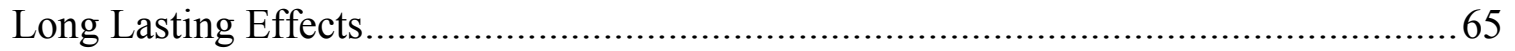

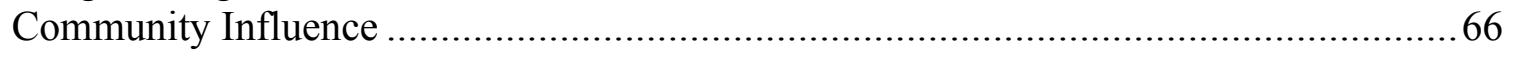

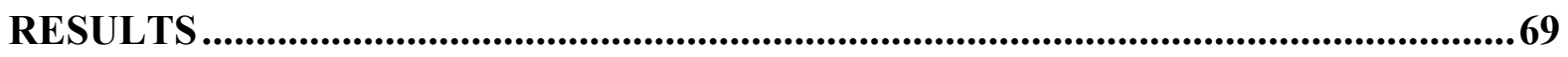

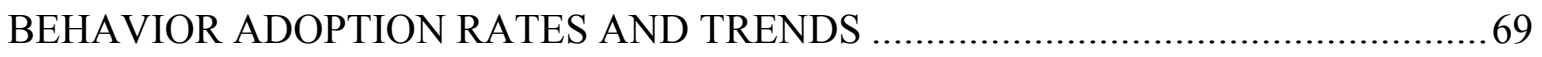

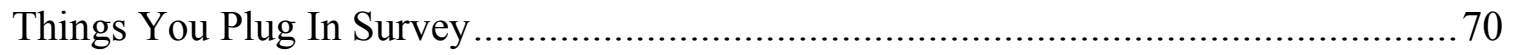

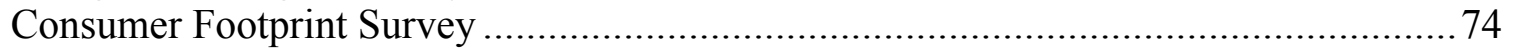




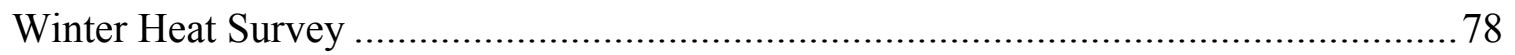

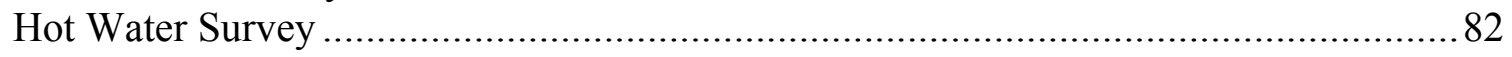

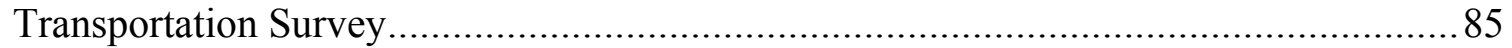

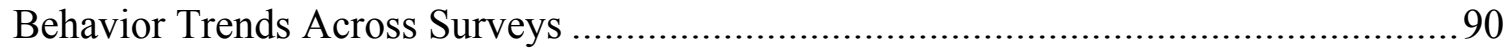

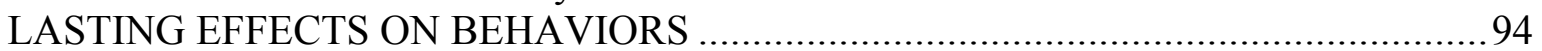

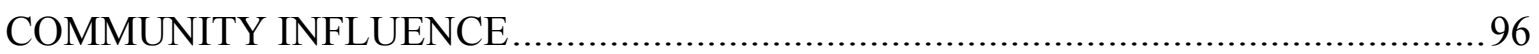

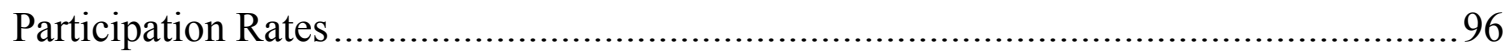

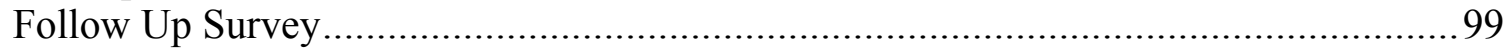

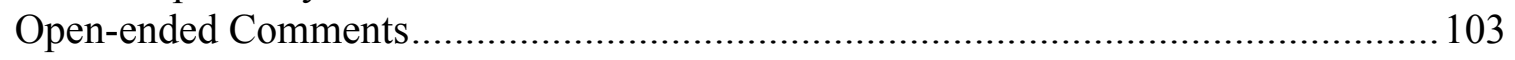

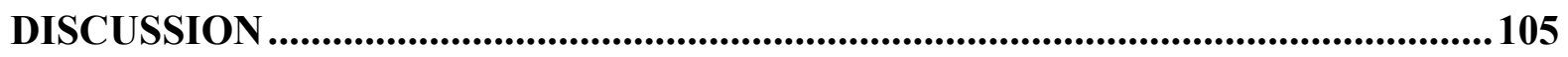

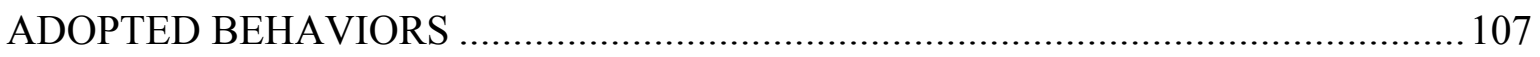

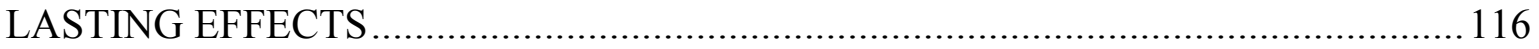

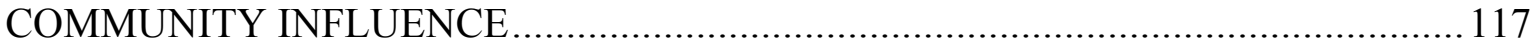

VALUE OF A COMMUNITY-BASED INTERVENTION APPROACH.......................124

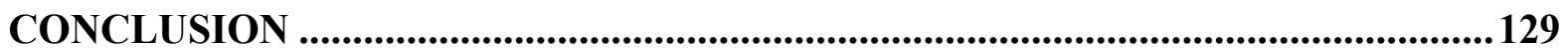

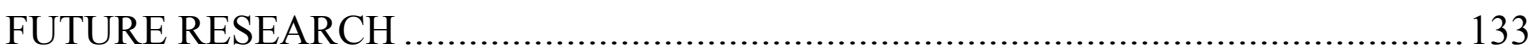

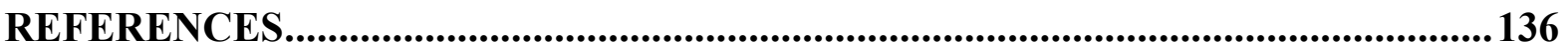

APPENDIX A INTERVENTION SURVEY QUESTIONS BY TOPIC AND TYPE...142

APPENDIX B FIRST MONTHLY SURVEY ................................................................145

APPENDIX C MONTHLY SURVEY RESULTS GRAPH .............................................149

APPENDIX D FOLLOW UP SURVEY FOR INTERVENTION GROUP...................150

APPENDIX E OPEN-ENDED COMMENTS FROM ALL SURVEYS ..........................155 


\section{List of Figures}

Figure 1. Screen capture of webpage from a campaign website.

Figure 2. Left: Intervention Group 1's launch day; right, Their community pledge display ..57

Figure 3. Comparison of Things You Plug In Survey responses. 70

Figure 4. Comparison of previously adopted behaviors reported in the Things You Plug In Survey. .71

Figure 5. Comparison of the most adopted behaviors reported in the Things You Plug In Survey. 73

Figure 6. Comparison of Consumer Footprint Survey responses. 74

Figure 7. Comparison of previously adopted behaviors reported in the Consumer Footprint Survey. 76

Figure 8. Comparison of the most adopted behaviors reported in the Consumer Footprint Survey.

Figure 9. Comparison of Winter Heat Survey responses .79

Figure 10. Comparison of the previously adopted behaviors reported in the Winter Heat Survey 80

Figure 11. Comparison of most adopted behaviors reported in the Winter Heat Survey.......81

Figure 12. Comparison of Hot Water Survey responses .......................................... 83

Figure 13. Comparison of previously adopted behaviors reported in the Hot Water Survey.. 83

Figure 14. Comparison of most adopted behaviors reported in the Hot Water Survey..........84

Figure 15. Comparison of Transportation Survey responses. ..................................... 86

Figure 16. Comparison of previously adopted behaviors reported in the Transportation Survey.

Figure 17. Comparison of most adopted behaviors reported in the Transportation Survey. .. 88 
Figure 18. Top 25 newly adopted behaviors by the intervention group, by percentage of respondents

Figure 19. Top 25 newly adopted behaviors because of the intervention by 3 pilot study communities.

Figure 20. Left, Comparison of the mean rank of continued behaviors seven months postintervention and post-study; right, Behaviors adopted seven months postintervention/study.

Figure 21. Comparison of pledge participation rates

Figure 22. Comparison of survey response trends over five monthly surveys. The intervention survey participation rate was calculated using total number of pledged households. The control survey participation rate was calculated using total number of households that took the first month's survey

Figure 23. Average rank given for the question "How much did your [intervention] [study] motivate you to change your habits to reduce your home energy use?"

Figure 24. Average rank given for the question "How much did the knowledge that [your community was united in a campaign to reduce their energy use][friends and/or family members have begun reducing their energy use] motivate you to change your energy habits?"

Figure 25. The average rank of community-based intervention features by respondents, using a 1-5 Likert scale, to the survey question "To the best of your memory, how much did each of the following motivate you to adopt energy reduction behaviors during the Campaign?" 


\section{List of Tables}

Table 1. Frameworks and strategies used by the intervention....................................... 11

Table 2. Demographic data of three case study communities ......................................51

Table 3. Comparison of environmental attitudes ................................................52

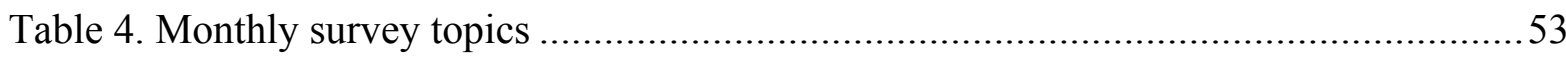

Table 5. Comparison of average percent of endorsement by response type per survey for two intervention groups that took the surveys from one to seven months apart in time.

Table 6. Comparison of average percent of endorsement, by response type, for the intervention group and 3 pilot study communities who also underwent the intervention.

Table 7. Participation rates for three pilot study intervention communities

Table 8. Summary of independent t-test results for "Did it" and "Already" responses for

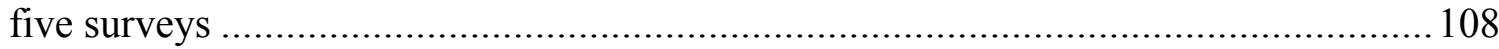




\section{INTRODUCTION}

Climate change is a problem that has been capturing worldwide attention as scientists work to measure and understand it, and governments, corporations, and industry try to identify policies and practices to mitigate its impacts on environmental, economic, and human health. While climate scientists have established (Solomon 2007) and a majority of Americans believe that global warming is happening and that human activities contribute to the greenhouse gas (GHG) emissions that are a major cause of it (Krosnick and MacInnis 2011), finding effective human-made solutions is proving to be a slow and challenging process. Government, corporations, and industry may be capable of effecting larger reductions on global greenhouse gas emissions than individuals can, and a majority of Americans are expecting them to do more about it (Leiserowitz et al. 2011c, 4), but unfortunately they are not moving quickly enough. Recent reports that GHG emissions have jumped by an alarming amount in 2010 indicate that more needs to be done to slow warming so that we "avoid the most dangerous aspects of climate change such as widespread water stress and sea level rise, and increases in extreme climate events" (Peters et al. 2011, 3). With planet and human health at stake, we cannot afford to rely solely on governments, corporations, and industry to take action against climate change; developing ways to harness the power of individuals working collectively to reduce their energy use deserves equal attention.

The confirmation of the link between climate change and anthropogenic activities, noted by Hegerl et al., makes it all the more urgent that we identify ways to change human behavior (Hegerl et al. 2007, 665). A majority of Americans look to government 
to generate policy solutions to the problems caused by climate change, from limiting air pollution and greenhouse gases that business can produce, to giving companies tax breaks for producing more renewable energy sources (Krosnick 2010, 3). But for its part, the U.S. Congress has struggled and ultimately failed to reach agreement on a variety of legislative proposals that seek to reduce GHG emissions. International efforts have likewise been widely seen as not having done enough to curb climate change either, as is evidenced by the continuing inability of world governments and coalitions to form a comprehensive international climate change treaty (Carmichael 2012). Therefore, while looking to government, corporations, and industry to pursue a meaningful reduction in greenhouse gas emissions is logical, the ongoing delays in developing climate change policies make it prudent to pursue a parallel effort to teach people how to reduce their immense, collective contribution to the buildup of greenhouse gases in the atmosphere as well.

According to Gardner and Stern, "by changing their selection and use of household and motor vehicle technologies, without waiting for new technologies to appear, making major economic sacrifices, or losing a sense of well-being, households can reduce energy consumption by almost 30 percent-about 11 percent of total U.S. consumption" (Gardner and Stern 2008, 13). Moreover, American attitudes toward climate change indicate that they have sufficient awareness and concern about it that they may be ready to play a more direct role in trying to fight it. A $2007 \mathrm{ABC}$ News/Washington Post/Stanford Poll found that "nearly 94 percent of all Americans say they're willing to make changes in their lives in order to help the environment generally" 
(Krosnick 2007, 3). According to more recent polls, a majority of Americans think that global warming is happening, feel fairly well informed about it, and believe it is caused partly or mostly by human activities (Leiserowitz et al. 2011b, 5; Krosnick and MacInnis 2011, 5). Further, Americans believe a single individual can make some difference in fighting climate change and that widespread collective action could be even more effective; fifty percent of survey respondents thought that taking specific energy-reducing actions for twelve months would reduce their personal contribution to global warming only "a little," whereas if most people in the U.S. did them or, even better, most people in industrialized countries did the same actions in that time period, the majority of respondents believed that would reduce global warming "some" or even "a lot" (Leiserowitz et al. 2011a, 6). What seems to be missing from conversations about how to fight climate change then is an educational approach that could engage the masses collectively in knowing which everyday actions to take that would be most effective in reducing our contribution of GHG emissions to the atmosphere.

Luckily, pro-environmental behavior change solutions have been studied since the advent of the modern environmental movement and great strides have been made in understanding what makes the effective ones work, many are discussed in detail, below (Berk, Schulman, McKeever, and Freeman 1993; Syme, Nancarrow and Seligman 2000; Henry and Gordon 2003; Staats, Harland and Wilke 2005; Abrahamse, Steg, Vlek, and Rothengatter 2005; Grodzinska-Jurczaka et al. 2006; Nolan et al. 2008; Griskevicius, Cialdini and Goldstein 2008; Dietz et al. 2009). In particular, using a behavioral approach is gaining recognition as a valuable short-term option to achieve substantial 
carbon emissions reduction (Dietz et al. 2009, 18452). Yet, despite the advances scientists have made in understanding what motivates behavior change, a comprehensive, targeted approach to convince the public to examine and change the lifestyle behaviors of each household that contribute to greenhouse gas emissions has not been achieved. What is needed, according to Wilke and Speer, is to define an effective model "that empowers individuals to create positive and lasting change in our environments ... this is of paramount importance to researchers and practitioners alike" (Wilke and Speer 2011, 973). To date, there have been few studies demonstrating an educational model that successfully motivates lasting change of a wide range of household behaviors. Moreover, very few studies focus on campaigns designed to motivate groups of people collectively; the target of most campaigns has been on individuals, acting in isolation from others. What has been missing is the power of community-based efforts that unite individuals around a shared vision and sense of purpose, one that provides credible information, effectively reinforced, about which actions everyone can take that will make the most difference in the fight against climate change. This study seeks to demonstrate a new type of educational model that operates at a community level and focuses on motivating change around a large number of household behaviors to determine whether this model can successfully empower and motivate individuals to take action to fight climate change. 


\section{BACKGROUND}

The study of what motivates individuals to change behaviors that negatively impact the environment has been a focus of academic research for decades. In recent years, increasing concerns about climate change have helped focus international attention on understanding its causes in an effort to identify effective methods to mitigate its impacts through the reduction of GHG emissions. This goal is supported by research conducted around the world, and notably by the International Panel on Climate Change (IPCC) and the National Research Council, that has lead to strengthened scientific understanding that climate change is, in large part, caused by human activities that result in the burning of fossil fuels (Solomon et al. 2007, 728; Committee on America's Climate Choices 2011, 16). Given the causal link between human energy use and climate change, and the resulting threat this poses to planet and human health, the need to identify strategies that will motivate people to reduce fossil fuel grows increasingly urgent.

Existing research in various scientific fields focuses on numerous approaches that attempt to identify variables that designers of future interventions can employ to influence people to practice environmentally responsible behaviors, or ERBs. However, I found few examples of programs that aspire to motivate entire communities to change their energy-use habits. For example, a December 2011 review I conducted of Internet resources using the search terms "reducing household energy use," "community-based household energy campaigns," and "grassroots household energy use campaigns" revealed only three grassroots efforts that leverage relationships with neighbors or explicitly rely on social marketing tools to spread awareness about and encourage 
participation in adopting specific behaviors. Examples include replacing incandescent light bulbs with compact fluorescent ones, competing with neighboring communities in water conservation efforts, or in supporting a county campaign that offered educational workshops. There were also a variety of grassroots campaigns that focused on mobilizing people to support environmental legislation in their counties or state. In contrast, conducting an Internet search using the term "how to save household energy" directed me to websites that promote lists of energy-saving actions alongside statistics on the rate of energy saved by each action, often coupled with emissions calculators. These websites are produced and promoted by government agencies, such as the U.S. Department of Energy, the National Resources Defense Council, and the Environmental Protection Agency; educational and environmental organizations that are less well known such as CarbonRally.com; and municipalities and utility companies that often couple their initiatives with financial rebates for consumers who adopt costly but highly energyefficient strategies, such as installing house insulation or water-conservation devices. While clearly this review of Internet resources was far from exhaustive, it nevertheless showed that overall, outside of interventions designed for academic research, information campaigns that promote lists of energy-saving measures are the most popular type of intervention employed around the nation. This study was undertaken to demonstrate that a grassroots, community-based education program to reduce household energy use is a more effective model to emulate than information-only campaigns, especially because it holds numerous advantages over the more impersonal types of information campaigns currently being relied on around the country. 
In 2006 I developed the intervention — defined as an "outside process that has the effect of modifying an individual's behavior, cognition, or emotional state," as indicated by the Encyclopedia of Mental Disorders' website - at the heart of this study to explore whether a community-based approach would lead to a greater adoption of energyreduction behaviors at home. Working with a $\mathrm{K}-8$ school community that I had engaged with previously in a leadership capacity, I pulled together a team of parents eager to take action to support the environment, developed a website describing effective energyreducing actions people could adopt at home, and designed an interactive approach to talking with the community about participating in a campaign to fight climate change. Our "Green Team" brainstormed a special launch event where we spoke to the driver of each car that drove onto campus on launch day, gave them a rock, a printed invitation, a 10-second speech inviting them to join the campaign, and asked them to signal their interest in participating by putting the rock in an oversized clear jar on the front porch of the school. The invitation provided an overview of the campaign, the website address, and the schedule of monthly surveys they would be asked to take online. We introduced a set of actions to adopt the first month, and new sets of actions each subsequent month for a total of five months. We encouraged participants to focus on any one or more action that interested them, knowing that their fellow participants were likely working on the same actions, in the hope that it would encourage more conversation and sharing of ideas and support among participants. Our Green Team kept the community informed via messages to the email group, posted each month's survey results around campus, held various outreach events so participants could gather to talk about environmental issues 
generally or the campaign in particular, and worked hard to serve as role models and cheerleaders to fellow parents who were eager to share their own efforts to save energy and seemed appreciative of someone to talk with about it. The response to our campaign was immediate and overwhelming; seventy-five percent of the community's households joined our campaign in the first few weeks after our launch event. Before the campaign ended five months later, I was approached to develop the campaign into a full program that other communities could adopt as well. The opportunity to focus my master's thesis research on the campaign arose after it had evolved into a formal program, sponsored by a local environmental organization, that was implemented by a dozen communities over a 3-year period.

The educational intervention I developed is unusual for two reasons. First, it emphasizes the importance of both targeting an entire community as the audience for the intervention and using the social dynamic of the community to drive participation and deepen each households' commitment to the environmental goals the effort is promoting. Second, it employs a wide variety of strategies to influence behavior change, any one or combination of which may account for its overall effectiveness, including communitybased social marketing, norms, information campaigns, commitment, feedback, and faceto-face communications. While the theories behind each component part used in the intervention is examined, below, it is not the focus of this study to conclusively prove the effectiveness of these component parts of the intervention for their motivational impact, but rather to assess the impact of the intervention as a whole, in all of its complexity. In other words, the intervention itself is the independent variable being tested. 
In addition to evaluating the effectiveness of the intervention, I hope to contribute new understanding of the value in using a community-based approach to influence proenvironmental behaviors. To that end, the community psychology concept of empowering community settings will also be discussed as it provides a useful lens through which to view the intervention and help explain its effectiveness. In so doing, I hope the intervention may serve as a model for others to build on, thereby reaching increasing numbers of individuals, motivating them to reduce greenhouse gas generating activities and, ultimately, help mitigate climate change impacts. 


\section{LITERATURE REVIEW}

To assist the reader in understanding the possible component value of the many features used in the intervention at the heart of this study, I examined the research that explains why each one may be effective in its own right in motivating behavior change. The defining feature of the intervention is that it relies on the unique dynamics of a community setting to reinforce the shared goal of fighting climate change to effect social change, and employs some of the techniques associated with community-based social marketing (CBSM) as well. Underpinning a number of the strategies employed by the intervention is the activation of social norms, which helps to explain why and how the manipulation of our human desire to conform to rules, standards, or behaviors established by our social group can be such a powerful tool for eliciting behavior change. Using a commitment strategy is one such strategy, as it provides a way to effectively capture people's initial intentions to perform specific actions and motivate them to follow through on them. The intervention is primarily an information campaign, one of the most popular approaches used to elicit changed behavior. Information campaigns can be made more effective if information is packaged and presented in specific ways that describe social norms for the audience, and can be further enhanced by incorporating face-to-face communication techniques, which have been proven to be remarkably effective at influencing behaviors because communicators bring social norms directly into play during their interactions. Similarly, feedback about the impact a person's or a group's behavior has on a desired result can play an important role in reinforcing an individual's 
interest in adopting new behaviors by inspiring awareness of the effects of their actions, a sense of competition, and identification with and interest in supporting one's social group. Finally, the intervention focuses on changing a large number of specific types of household energy behaviors considered to be most effective at reducing energy use, instead of only a few behaviors, as is common among most other environmental education programs. This wide behavioral scope is used in order to have as broad of an impact as possible, to maximize the energy saving potential of each household, and to reinforce the level of commitment required to participate in an effort to effect social change. The strategies employed by the intervention, and a description of how they were employed, are presented in table 1.

Table 1. Frameworks and strategies used by the intervention

\begin{tabular}{|c|c|}
\hline Strategy & Description \\
\hline Community setting & $\begin{array}{l}\text { A framework for empowering organizations to achieve individual growth, } \\
\text { community betterment and social change that relies on the following: a group- } \\
\text { based belief system (campaign goals), engaging learning activities (behavior } \\
\text { challenges), a relational environment (community approach), opportunities for } \\
\text { participants to contribute unique skills to the effort, and shared and delegated } \\
\text { leadership (Green Team define their own roles and share leadership) }\end{array}$ \\
\hline $\begin{array}{l}\text { Community-based } \\
\text { social marketing }\end{array}$ & $\begin{array}{l}\text { A framework to motivate environmentally responsible behavior that consists of } \\
\text { the following guided steps: fostering shared group identity around fighting climate } \\
\text { change (campaign goals), fostering effective group interactions that encourage } \\
\text { participation (launch and pledge gesture), creating effective messages (simple and } \\
\text { directive messages via launch invitation, website, email and newsletter), } \\
\text { promoting opportunities for social support through Green Teams interactions } \\
\text { (outreach events). }\end{array}$ \\
\hline Norms & $\begin{array}{l}\text { Established and activated positive social norms by rallying community around the } \\
\text { shared goal of taking action and fighting climate change, used Green Team to } \\
\text { serve as role models and issue reminders and encouragement of community effort } \\
\text { to motivate household behavior change effort, provided monthly reports on } \\
\text { community's progress }\end{array}$ \\
\hline $\begin{array}{l}\text { Information } \\
\text { Campaigns }\end{array}$ & $\begin{array}{l}\text { An information-based effort that relied on effective messaging strategies using } \\
\text { newsletters, emails, posted signage, website to educate, inform, inspire, build } \\
\text { awareness, offer encouragement and motivation }\end{array}$ \\
\hline Commitment & $\begin{array}{l}\text { Solicited written commitment statements from participating households to reduce } \\
\text { their energy use, in addition to a pledge gesture }\end{array}$ \\
\hline
\end{tabular}


Table 1 continued

\begin{tabular}{ll}
\hline Strategy & Description \\
\hline Feedback & $\begin{array}{l}\text { Information about the community's interest in the climate change campaign was } \\
\text { presented in a public display of the community's collective pledge gestures, the } \\
\text { impact of household behavior change was presented through monthly reports that } \\
\text { provided a review of collective survey results }\end{array}$ \\
$\begin{array}{l}\text { Face-to-face } \\
\text { communications }\end{array}$ & $\begin{array}{l}\text { Opportunities to socialize, discuss behaviors and encourage participation came via } \\
\text { Green team solicitation of participants to join the campaign, and the creation of }\end{array}$ \\
outreach events that provided opportunities for discussion and social support \\
Targeted numerous household actions as the focus of the behavior change effort \\
that comprise each household's lifestyle habits, instead of a select few behaviors \\
only
\end{tabular}

\section{Community Settings}

The most unique feature of the intervention is its use of a community setting to organize and influence participants around a shared goal of reducing their collective energy use. When individuals feel overwhelmed with their concern about the environment, finding social support for taking action to address that concern can make all the difference. The theme of using social support to influence behavior arises repeatedly in the academic literature and perhaps holds the most important key to understanding the effectiveness of a community-based intervention such as the one at the heart of this study (Staats, Harlan and Wilke 2004, 344; Christens, Peterson and Speer 2011, 343). In the community psychology literature, Maton examined the nature of "empowering community settings" and how they can play an important role in "impact[ing] individual growth, community betterment and social change" (Maton 2008, 5). He distilled multiple definitions of empowerment found in academic literature to one that defines empowerment as "a participatory-developmental process-occurring over time, involving active and sustained engagement, and resulting in growth in awareness and capacity" that 
is elastic enough to occur at both the individual and collective level (Maton 2008, 6). Wilke and Speer, in their review of similar research on the subject, extended the definition of empowerment to include its ability to help "individuals, organizations, and communities gain greater control, efficacy, and social justice regarding issues of concern to them" (Wilke and Speer 2011, 973). While developed primarily to help "marginalized or oppressed individuals and groups gain greater control over their lives and environment," the defining characteristics of empowering community settings have the potential to be of invaluable service to the needs of any organization seeking to change society (Maton 2008, 5).

Maton's approach is identified by six organizational characteristics (Maton 2008, 8-14), which include:

1. Having a group-based belief system that helps to set the culture, and inspires change through "a shared vision and larger purpose" that helps direct focus "beyond the self."

2. Core activities that are engaging in nature, require active learning and are of high quality.

3. A relational environment that is made up of an encompassing support system, caring relationships with peers and mentors, and a sense of community.

4. Opportunity role structure, which provides participants of varying skill levels and ambition with a large variety of highly accessible and meaningful roles to play.

5. Leadership that is shared and delegated, that takes responsibility of a setting and that both inspires (by articulating a vision and serving as a role model) and motivates members to participate. 
6. Mechanisms for setting maintenance and change that enables a community to adapt to challenges that come from within or outside of the community, and thereby contributes to its sustainability.

In reviewing the literature, Maton found that where all six of these characteristics are found in a community setting, they "in effect function as viable and vital relational communities" that have great potential to empower its members.

Similarly, Wilke and Speer discussed the role of individual empowerment processes in attaining organizational empowerment outcomes (Wilke and Speer 2011, 976-983). They divided personal empowerment into two components, the intrapersonal and interactional. Intrapersonal (or emotional) empowerment is "the manner in which individuals think about themselves and their capacities to successfully intervene upon the world," and is reciprocally related to participation in community groups and activities, while interactional (or cognitive) empowerment "comprises an individual's ability to develop a critical understanding of the forces that shape his/her environment and a knowledge of resources and methods, most often collective power, that can be used to produce social change." One important new finding from Wilke and Speer's study about both what types of organizations contribute to personal empowerment and what mediating effects they had, was that a sense of community was enhanced by the presence of certain empowering organizational characteristics, such as social support and groupbased belief systems. In other words, if an organization hoping to promote social change meets the criteria of an empowering community setting and it does not have a political orientation — which they found has a significantly negative mediating effect—-then it has 
great potential to build both strong personal empowerment and a sense of community that can serve well the organization's interest in promoting social change. It is exactly this potential of empowering community settings that this study's intervention sought to exploit in the service of reducing household greenhouse gas emissions.

The relevance of Maton's research to this study and the reasons it may best describe its effectiveness as an intervention deserve further elaboration. The external impacts of empowering community settings show the promise of interventions to influence community betterment and social change (Maton 2007, 14-16). The ability for empowered community members to radiate influence to "family members and social network[s], to institutional attitudes and program development of organizations to national policy," is particularly compelling for environmental initiatives that can serve a critical role in influencing the national political debate that shapes our energy future. In addition, Maton noted that there is promise in the improved well-being that occurs when an intervention provides both a sense of purpose and specific actions to perform. That sense of purpose can be particularly valuable to individuals working toward reducing energy use with an eye on solving the larger crisis of climate change, because that sense of well-being helps relieve the feelings of despair many have over the bleak future that the climate crisis presents. If it is true that empowered community members show themselves to have higher levels of "political efficacy, civic skills, leadership, and community engagement," as Maton maintained, this bodes well for the future of the environmental movement where communities choose to devote their considerable efforts to promoting environmental change. 


\section{Community-Based Social Marketing}

When people take an interest in effecting social change in a group or within a community around environmental issues, a useful model has emerged that can help them leverage community affiliation and introduce effective strategies to achieve their goals. Throughout recent decades, research into how to motivate ERBs has circled around a familiar list of diverse inter-disciplinary approaches that show promise, including incentives, consequences, feedback, communications, goal-setting, commitment, attitudes, and media exposure. When viewed through the prism of social psychology, interventions that exploit social norms, conformity, compliance, and modeling (to name a few) offer compelling evidence that targeting the behavior change of a group can be more effective than targeting an individual. De Young, for example, argued that "durable proenvironmental changes can be facilitated by devising techniques that combine (a) detailed procedural information, (b) feedback about one's performance, and (c) a supportive social environment" (De Young 1996, as cited by Staats et al. 2004, 343).

This approach was expanded upon by McKenzie-Mohr who developed the community-based social marketing (CBSM) model (McKenzie-Mohr 1999). CBSM encourages sustainable practices and activities within the social network of a community. Social marketing of sustainable goals are achieved by following a guided series of steps, which include uncovering barriers and benefits of an intervention, fostering effective group interactions that encourage group participation, investing in the forging of a shared group identity, promoting positive social norms, creating effective messages, and designing incentives for desired behaviors. The intervention at the heart of this study 
employs many of these criteria, marking it as an example of CBSM; it offers detailed information about recommended behaviors, supplies comparative feedback about behavior adoption performance, and provides a supportive social environment. CBSM is a useful model to follow for individuals or groups that seek to initiate a proenvironmental behavior change effort in their community and would benefit from the clear set of planning guidelines it provides.

\section{Norms}

Almost any initiative that seeks to influence the behavior of a group of people will be engaging the existing social norms of that group. There is a sizable body of social psychological research, extending back to the 1930s, that has documented how normative social influence impacts human behavior (Nolan et al. 2008, 913; Cialdini and Goldstein 2004, 597-598). There is also a considerable volume of research that has demonstrated how norms can be employed to promote ERBs in particular, including a number of fresh insights into the moderating effects of various features of social interactions that have come to light in recent years and hold great promise for the environmental movement. Social norms, as defined by Cialdini and Trost, are "rules and standards that are understood by members of a group, and that guide and/or constrain social behavior without the force of laws" (Cialdini and Trost 1998, 152). For example, witnessing our neighbors regularly recycling newspapers, bottles, and cans may influence us to adopt those same behaviors. Gôckeritz et al. studied the correlation between norms and behavior and also found strong evidence that "efforts to conserve energy are significantly 
related to one's belief about how often others conserve energy" (Gôckeritz et al. 2009, 520).

Norms originate in the thinking or beliefs of each individual, who convey them in a variety of ways. In order to understand the moderating effects that beliefs have on one's behavior, some researchers have found it necessary to differentiate between “descriptive normative beliefs, which refer to what an individual thinks others do in a particular situation, and injunctive normative beliefs, which describe what an individual thinks others approve or disapprove of" (Gôckeritz et al. 2010, 515). Nolan et al. studied the persuasive impact and detectability of descriptive normative social influence and found that normative appeals (e.g. encouraging people to save energy because it is common in their neighborhood) spurred people to conserve nearly twice as much energy compared to more standard appeals (e.g. encouraging people to save energy because it is good for society, good for the environment, or could save money) (Nolan et al. 2008, 921-922). Interestingly, their research also found that people were surprisingly poor at understanding what motivated their conservation behavior, and rated the influence of their peers' behaviors as the "least likely to motivate their own conservation behavior." In other words, people are persuaded by descriptive normative appeals but do not think they are.

In a review of Nolan's study and others, Griskevicius, Cialdini, and Goldstein argued it is precisely because people are so poor at ascribing the influence of their peers' behaviors as motivators of their own that the use of social norms, if employed properly, has the potential to be especially effective at motivating conservation behaviors 
(Griskevicius, Cialdini, and Goldstein 2008, 7-11). In other words, the use of social norms in promoting environmentally friendly behavior is both underestimated and not used widely enough. Further, they contended that it is possible to "optimize the power of social norms" in order to influence ERBs by using them under conditions when recipients are experiencing uncertainty and tend to look to others to act, and that invoking social norms is even more influential when they look to others who most resemble them, such as members of one's own community. Gôckeritz et al., whose findings also showed that descriptive norms were effective in motivating conservation behavior, found that it was not only an individual's belief that other people performed the conservation behavior that spurred them to conserve themselves (Gôckeritz et al. 2010, 520). They found that the individual's belief that others also highly approved of performing those conservation behaviors spurred them to conserve even more. Therefore, for an intervention designed to promote environmentally responsible behavior to be as successful as possible, participants must both be made aware that others in their peer group were performing the desirable behaviors and also understand clearly that their peer group highly approves of these behaviors.

Norms have an additional role to play in encouraging environmentally friendly behavior when viewed through the lens of moral viewpoints. Stern distilled a number of important theories into his value-belief-norm (VBN) theory that contends that "personal moral norms are the main basis for individuals' general predispositions to proenvironmental action," and that "the consequences that matter in activating personal norms are adverse consequences to whatever the individual values" (Stern 2000, 413). 
By framing an energy conservation effort around the goal of preserving the earth for future generations and encouraging specific behaviors to adopt that will help accomplish this goal, such an effort helps establish social norms around exhibiting ERBs and, in asking for participants to commit to the effort, it activates the value-belief-norms as well. An important assumption underpinning the intervention model used in this study is that a general deepening of environmental values and a subsequent readiness to take personal responsibility for acting in a benevolent manner toward the environment will occur when a community is acting together based on shared values. This cooperative understanding, in turn, is what helps foster increased attention toward energy consumption that individuals can incorporate in their everyday behaviors. In support of this assumption, numerous studies have shown that "cooperation in large-scale social dilemmas involving a large social group of anonymous others, such as other commuters using the same roads or other householders using the same landfill ... is more likely to be guided by values such as social justice, equality, and protecting the environment" (Schwartz, 2005; Thøgersen and Olander 2002, as cited by Biel and Thøgersen 2007, 102). While this intervention works at a community level where individuals have the opportunity to know one another and are not necessarily anonymous, they do share responsibility for the consequences of burning fossil fuels that supply energy to their homes, and do share the wider global concern of protecting the planet from the ravages of climate change. Note that while norms can provide a useful measure of what triggers pro-environmental behavior, why such behavior is triggered is not a focus of this study. 


\section{Commitment}

There are many ways to activate norms to effect social change. One way is to ask people to make a commitment or promise to perform a particular behavior or set of behaviors, an approach that numerous social scientists assert can be an effective strategy to induce behavior change, especially when coupled with goal-setting or feedback (Cialdini and Goldstein 2004, 604; Staats, Harland and Wilke 2004, 345; Shippee and Gregory 1982, 82; Abrahamse et al. 2007, 266). What type of commitment to solicit is an important consideration for researchers. Shippee and Gregory found that mild public commitments, where participants were publicly acknowledged in a local newspaper advertisement thanking them for their participation in an energy conservation program, was more effective in reducing participants' energy use than strong public commitments, where participants were both publicly acknowledged and their actual energy use was published as well (Shippee and Gregory 1982, 81-89). The researchers found that instead of being motivated to preserve their positive community image by reducing their energy use, participants in the strong public commitment group reported that they "felt trapped" and as a result they ultimately conserved less energy. The researchers speculated that participants resisted conservation and instead consumed more because "their freedom to consume had been threatened by the strong commitment intervention." As a result, the milder commitment approach proved to be more effective.

Looking at personal commitment strategies, Werner et al. found that written commitments (to the researcher) to recycle were significantly more effective in changing behavior than face-to-face appeals (verbal commitment) or information-only appeals 
(Werner et al. 1995, 206). Moreover they found that the written commitment-based behaviors were continued over time and were translated into attitudes changes as well. Leon and Fuqua uncovered some interesting results when combining types of commitments or mixing a commitment strategy with other approaches (Leon and Fuqua 1995, 249). They found that combining a personal written commitment (to the researcher) with a public commitment to curbside paper recycling (permission to publish their names in a local newspaper) did not effect an increase in the amount of recycled paper in the groups studied. However they did find that combining a public commitment with feedback about the pounds of recycled paper produced by their group increased the weight of recycled paper by $40 \%$, a significant result.

There are other, more subtle forms of commitment that can be invoked in interventions that focus on social contact. Biel and Thogersen discussed the importance of communication between participants for cooperation, and demonstrated how group communication can be an effective way to elicit a commitment norm (Biel and Thogersen 2006, 102). For instance, providing an email group to serve both as a forum for participants to exchange ideas and to give and receive support for their behavior change efforts introduces an important channel of social contact for participants, many of whom may not interact on a regular basis, if at all.

If an intervention, therefore, is designed to use a commitment strategy effectively program designers should consider asking participants to make mild public commitments, and/or a written personal commitment that is combined with feedback about which behaviors their peers are adopting. Then, to tie it all together they should make use of 
communication opportunities that connect participants to one another and, in so doing, strengthen the commitment norm that keeps the goal of adopting behaviors central in everyone's mind.

\section{Information Campaigns}

At the heart of any educational intervention lies the need to convey information about the issue at hand. Information campaigns are used to build awareness, excite, motivate, and ultimately connect people to new ideas, and they are used widely and often. According to Staats, Harlan, and Wilke information "is one of the most widely used means to promote pro-environmental behavior change" (Staats, Harlan, and Wilke 2004, 343). However, information campaigns used to change behavior must be carefully designed in order to be effective. When seeking to educate the public, established communication methods dictate that messages be simple, clear, and directive (Henry and Gordon 2003, 53). Providing sources for information that have high credibility can make a tremendous difference in how messages are received (Vedung 1999, 246-247; and Henry and Gordon 2003, 47).

As to the purpose of information wielded to influence ERB, Pelletier asserted that in regard to influencing new behaviors, communicators should be strategic in how they tailor messages to the different phases of behavior change (detecting that a problem exists; making a decision to act; determining when, where, and how to implement a new behavior) (Pelletier 2008, 214-215). In particular, attending to intrinsic motives (i.e., health, personal growth), rather than extrinsic motives (i.e., financial incentives, rewards) 
when goal framing can lead to "deeper engagement in an activity, deeper processing of the information related to an activity, and more persistence," or maintenance of the behavior once it has been adopted (Pelletier 2008, 214-215). Siero found that where the public and private interests coincide - where what is good for a person personally also serves the national community—such as occurs around efforts promoting the adoption of energy conservation behaviors, there are some useful guidelines to follow for designing persuasive messages for information campaigns, namely: reference the national interest to trigger - but not create — certain motives toward performing behaviors; tailor the messages to the needs of the target group, in particular offer specific and practical advice about which actions are most profitable from an economic standpoint; and use a positive frame around the problem instead of a negative frame (for instance use "energy efficiency" instead of "energy saving") to produce a more consequential impact (Siero 1999, 246-247). A negative frame for a behavior, such as "saving," can imply sacrifice whereas "efficiency" may align with a personal goal to support the environment, eliciting positive feelings that can in turn result in proactive behavior. Staats et al. also reported that information could be used to give practical advice, as well as to increase awareness about problems that need to be solved, or to call attention to others' efforts (Staats et al. 2004, 343). Moreover, Griskevicius et al. demonstrated that using descriptive social norms - "what is commonly done in a situation"-when designing communications to influence environmentally friendly behaviors can be a highly effective strategy (Griskevicius et al. 2008, 6-15). Specifically, they asserted, designing messages that promote a set of desirable behaviors and emphasize that many others are engaged in those 
behaviors, and in particular others who are like the consumers of the message (such as members of their own community) will be more powerful and effective than messages that simply convey the importance of adopting the behaviors alone. In doing so, this type of messaging essentially activates and reinforces the social norms of the target audience. The researchers also noted that "tapping into the actions of others can provide a goldmine of persuasive resources" when designing communication appeals to encourage people to fight climate change (Griskevicius et al. 2008, 6-15). Finally, Gardener and Stern lamented that the common approach to promoting pro-environmental behavior change has been to provide unordered, long lists of behaviors that do not emphasize the most effective actions and whose length can overwhelm people and lead to little or no action taken (Gardener and Stern 2008, 15). Therefore, providing clear, positively worded messages that include prioritized lists of desirable behaviors, framed with references to the adoption of those behaviors by one's peers, should be a highly effective strategy when designing a community-based behavior change intervention.

\section{Face-to-Face Communication}

Education campaigns rely on multiple channels to convey information to the intended audience. Printed materials continue to have a useful purpose, and websites have gained an increasingly prominent role in campaigns as well. But while mass media and information campaigns that rely on printed or broadcast messages are much easier to disseminate, there is ample evidence that the use of face-to-face communication is far more effective in influencing awareness and changing behaviors (Vedung 1999, 247). As 
McKenzie-Mohr asserted "Research on persuasion demonstrates that the major influence upon our attitudes and behavior is not the media, but rather our contact with other people" (McKenzie-Mohr 1999, 95). Cialdini and Goldstein noted in their research about compliance and conformity that people have a tendency to make decisions to comply with requests that come from people who are familiar to us because we have such strong desires to affiliate with others (Cialdini and Goldstein 2004, 598). They argued, "The more we like someone with whom we have an existing relationship, the greater should be our willingness to comply with [a] request" (Cialdini and Goldstein 2004, 598). This tendency also extends to strangers and is even more likely to occur during face-to-face encounters that involve complicated and unexpected requests. Therefore, in a community setting where a sense of affiliation is likely to be pronounced, a person's willingness to accept a request to join an activity made by another person in the community, whether they are well known to that person or not, is likely to be more readily complied with because, in part, they want to be liked by that person (Cialdini and Goldstein 2004, 598). Burn demonstrated how using block leaders to deliver persuasive appeals asking homeowners for a commitment to increase their recycling efforts were more than twice as effective than a second group who received only a written appeal, and a third group that was used as a control group (Burn 1991, 616-620). In addition to the impact of using a face-to-face communication style, the block leader was able to provide evidence of the social norms at work in the community and assisted in educating the community about the importance of recycling. Therefore, an intervention that can take advantage of existing patterns of socializing among community members that brings them into regular 
face-to-face contact, such as you would find in a religious organization, workplace, or parent body of a school, has an advantage over an intervention that has to work with a group of disassociated individuals. Further, it seems likely that using a face-to-face communication strategy to supplement the printed, web-based, or broadcast messages of a more traditional information campaign may increase how influential the information presented is compared to using either approach alone.

\section{Feedback}

Once an intervention designed to promote ERBs has captured the participation of a group of individuals, it is critical to find a way to help them maintain momentum and focus to continue to do the work of changing their behaviors. Feedback is a valuable tool for behavior change that scientists should consider when designing an intervention that would fulfill this purpose. McKenzie-Mohr asserted that feedback is valuable because providing "information about the impact of newly adopted activities" (McKenzie-Mohr $1999,100)$ is critical to producing effective information promoting behavior change. Vedung proposed that "instead of telling people what to do to save energy, they should get high-quality information about how much they are already using” (Vedung 1999, 250). Numerous researchers have produced empirical evidence that providing feedback about a person's behavior influences their future behaviors (Vedung 1999; Syme et al. 2000; Kantola, Syme, and Campbell 1984). McKenzie-Mohr cited several examples of how providing feedback can positively impact the adoption and maintenance of sustainable behavior, including the following: daily feedback about household electricity 
consumption lowered energy use by $11 \%$ compared to a physically identical control group, and weekly group feedback combined with public commitments lead to a $40 \%$ increase in the amount of paper households recycle (McKenzie-Mohr 1999, 100).

Another type of feedback, comparative feedback, is believed to be effective because by making people aware of the existence of another group, it makes their identification with their own group more salient and inspires "competitive feelings and striving for better performance" (Siero et al. 1996, 236). The use of comparative feedback was found to be highly successful in reducing energy-wasting behaviors of employees in a transport organization, where researchers compared personal feedback and comparative feedback to see which was more effective in promoting behavior change around energy use (Siero et al. 1996, 238-245). Their results clearly showed that employees in the comparative feedback condition, who received information about other peer units' conservation behavior, saved significantly more energy than employees who only received information about their own performance, even half a year after the intervention. It is worth noting that this study found that feedback about one's individual performance produced a sizeable amount of energy savings, as well. Therefore, designing an intervention that uses feedback, whether personal or comparative, can be an effective strategy for influencing behavior change, especially if combined with the use of a commitment strategy. 


\section{Targeting Household Behaviors}

Designers of effective educational interventions not only have to include strategies that motivate behaviors, but have to carefully select the scope and type of behaviors on which to focus their efforts. Examining how to motivate sustainable lifestyles that encompass a multitude of behaviors, as opposed to a few individual behaviors at a time, holds great promise of lasting and impactful change for a variety of reasons. O'Riordan noted that as the notion of sustainability has begun to penetrate the consciousness of society, "the very ethos of livelihood and lifestyle enters the frame of enquiry" (O’Riordan 2001, 154). Yet time and again in the academic literature, intervention studies "target only one or a few behaviors ... thus have limited scope," and result only in short-term changes (Staats, Harlan and Wilke 2004, 342). This shortcoming has been noted by other social scientists as well who are interested in finding practical and effective solutions to the multitude of environmental problems that household behaviors contribute to climate change (Gardener and Stern 2008, 14). Dietz et al. believed that as a society we may have no choice but to focus on lifestyles, that "lifestyle changes may become necessary ... under constrained energy supply or economic growth scenarios, and they may become more attractive as a result of changes in social attitudes or national or community priorities" (Dietz et al. 2009, 18455)

Vining and Embro asserted that the limited scope of behaviors examined in many studies is due to the fact that research findings are often inconsistent or ambiguous about both how to measure different types of ecological behavior and how to know what to attribute them to when behavior changes occur (Vining and Embro 2002, 27). This 
makes it difficult to determine whether a behavior change is the result of an underlying predisposition toward pro-environmental behavior, was influenced by the prior adoption of specific types of behaviors, or something else. Kaiser, who also supported looking at a wide variety of behaviors instead of just a few, suggested an approach that avoids the problems other social scientists have had, such as those noted by Vining and Embro (Kaiser 1998, 412-415). She noted that "inconsistency of people in their ecological behavior ... is the basis of the controversy ... about how to measure ecological behavior." Through her research she determined that "if inconsistency is allowed in a certain probabilistic range, and if we consider behavior difficulty in our measurement approach" then it is possible to reliably measure a dimension she calls general ecological behavior that encompasses a wide range of behaviors or lifestyle. Despite Kaiser's promising measure, there remain few studies that tackle a multitude of environmental behaviors, or lifestyles, as this study aims to do. One of the few studies that did, conducted by Staats, Harlan and Wilke, effectively used the social interaction of a small group of people, information appeals, and personal and comparative feedback to influence participants to adopt 100 wide-ranging household behaviors (Staats, Harlan and Wilke 2004, 361).

For the purpose of this study, one's lifestyle is defined by the multiple household behaviors one practices on a regular basis. Spaargaren and Vliet argued that lifestyle consists of "a mixture of habits, conventional ways of doing things, and reasoned actions" (Spaargaren and Vliet 2000, 53) and underpinning them are beliefs, values, and norms that are a product of socialization. Therefore when designing an intervention that 
targets lifestyle behaviors, social norms are invoked that can powerfully influence individuals who seek to change their behaviors. There are other, complementary definitions of lifestyle to consider. Giddens asserted that a lifestyle is "a more or less integrated set of practices which an individual embraces, not only because such practices fulfill utilitarian needs, but because they give material form to a particular narrative of self-identify" (Giddens 1991, 81). Or, as Spaargarden and Vliet argued, a lifestyle is a construct that should be viewed as a "life story, in the sense that by creating a specific unity of practices the actor expresses who he or she is or wants to be" (Spaargarden and Vliet 2000, 55). Taken together, when designing behavior change interventions, therefore, it is clear that attempting to influence lifestyle behaviors over a select few behaviors is a valuable approach because it provides participants with an opportunity to identify themselves as pro-environmental and align with the social norms of their community, and in so doing possibly provides greater motivation to change their behaviors and maintain them post intervention. Focusing on a wide range of lifestyle behaviors also provides a greater opportunity for participants to explore their deeper attitudes toward consumerism and environmentalism than would occur if they focused on only a limited number of behaviors.

The type of behaviors included in a behavior change intervention that seeks to reduce energy consumption is another important issue for intervention designers to consider. Dietz et al. identified 17 categories of household actions that prior research shows can be effectively used in interventions to motivate changes to energy use behavior, and argued that targeting U.S. household energy use that will help reduce 
national carbon emission levels because households are a "major emitter and because there is a significant body of knowledge about the potential to achieve near-term reductions in that sector" (Dietz et al. 2009, 18452-18454). They developed a unique categorization method for household actions that correlates specific intervention techniques with each type of action, making it easier for policymakers and scholars to design effective interventions. Household actions are divided into the following five categories: W for "home weatherization and upgrades of heating and cooling equipment," E for "more efficient vehicles and nonheating and cooling home equipment," $\mathrm{M}$ for “equipment maintenance," A for "equipment adjustments," and D for "daily use behaviors." The $\mathrm{W}$ and $\mathrm{E}$ actions involve one-time investments to improve energy-savings when items reach the end of their useful life. For W actions, a combination of financial incentives, convenience, quality assurance (certified inspectors, for example), and strong social marketing were effective intervention approaches. For E actions, financial incentives, improved rating/labeling systems, and strong social marketing were found to be most effective. The M, D, and A actions are performed either infrequently or daily, and are thereby sensitive to efforts that stimulate habit formation. According to the researchers, interventions that combine "mass-media messages, household- and behavior-specific information, and communication through individuals" social networks and communities," and "energy use feedback" are the most effective for motivating changes to habit-forming actions. These behavior categories provide intervention designers with an invaluable system to organize and track large 
numbers of behaviors presented to target households, and afford an easier way to communicate about the behaviors as well.

One hypothesis underlying the design of this intervention model is that participants will respond to their community's adoption of a collective carbon reducing identity and be motivated to work harder at the individual level in support of the greater good. Biel and Thøgersen reviewed the literature for evidence of how social norms can be used to promote cooperation in social dilemmas and recommended "issue entrepreneurs" to "communicate to the general public about existing environmental problems, how they relate to everyday behavior, and what the individual can do to help solve the problem(s)" (Biel and Thøgersen 2006, 107). Abrahamse et al. reviewed 38 intervention studies aimed at household energy conservation and identified a number of methodological criteria that helped assess effectiveness of the interventions, including: monitoring of behavior change and energy use, use of a control group not exposed to the intervention to better gauge the effectiveness of the intervention, measuring changes in underlying behavioral determinants to compare to actual behavior changes (and also gauge the intervention's effectiveness), and long-term monitoring to assess the persistence of the behavior changes that occur (Abrahamse et al. 2005, 275). Because the intervention included such a wide variety of strategies considered to be effective in influencing social change in general and behavior change in particular, and because this study incorporated all of the criteria recommended by the studies described above, it is reasonable to assume that this research will provide a reliable measure of the intervention's effectiveness in motivating changes to household energy use behaviors. 


\section{GAPS IN THE RESEARCH}

\section{Long Term Effectiveness of Behavior Change Interventions}

A review of the literature reveals limited evidence of interventions that have effectively established durable voluntary behavior change, or change that has lasted beyond the duration of the intervention. Many researchers have noted that not only has there been a surprising lack of follow-up to determine the long term effectiveness of interventions, but that behavior change has proven difficult to influence and maintain for even one year following an intervention (Staats, Harland and Wilke 2004, 361; Verhage 1978; and Agras, Jacob, and Lebedeck 1980, as cited by Syme 2000, 550). In their literature review of intervention techniques to increase pro-environmental behaviors, Staats, Harlan and Wilke noted that "in the relatively few cases that behavioral maintenance was investigated, persistence of voluntary pro-environmental behavior change was rare" (Staats, Harlan and Wilke 2004, 342-355). One intervention that did succeed was the EcoTeam approach, a program that followed groups of 6-10 individuals for eight months as they focused on six different categories of over 100 behaviors, meeting regularly to discuss their efforts. Results showed that participants not only were motivated by the program to change their behaviors, but that they maintained them for up to two years post-intervention. In order to encourage more rapid movement away from the heavy fossil-fuel use that defines our society currently, it is important that additional models be developed that also demonstrate durable, effective ways to motivate people to behave more responsibly toward the environment. 


\section{Examples of a Community-based Intervention}

My research efforts uncovered a wealth of information about educational interventions that sought to influence behaviors, but despite numerous attempts over long periods of time, I was mostly unsuccessful in finding examples of community-based interventions to guide my work. Staats, Harland and Wilke's analysis of the EcoTeam approach was helpful but relied on small groups of dedicated people instead of a community holding disparate interests toward the environment (Staats, Harland and Wilke 2004). McKenzie Moore's CBSM approach laid out the value of community-lead efforts generally, but contact with the author asking for examples of programs using this approach lead me back to the EcoTeam study. Internet research using "community-based education programs" and "community-based environmental programs" turned up numerous grassroots efforts attempting to affect legislation at the state level, and a handful of community initiatives to clean up streams or install compact fluorescent light bulbs (CFLs) in households, but detailed descriptions weren’t provided, making these efforts difficult to replicate. I hope to address this gap in the academic literature by providing this community-based intervention approach to assist other researchers interested in harnessing the power of community to improve energy use specifically or to effect social change in general. 


\section{PROBLEM STATEMENT}

As our planet continues to warm and cause extreme climate events that further harm the environment, our health and our ways of life, the race to develop an educational intervention model that can motivate consumers to reduce activities that generate greenhouse gases into the atmosphere takes on increasing urgency. The objective of this study is to establish whether a community-based environmental education program successfully motivated two communities to reduce their home energy use, compared to a control group observed during the same period, and whether the intervention had a lasting impact on participants' behaviors. This study also examined whether the community setting that was central to the design of the intervention contributed to the participants' motivation to reduce their energy use. This study addressed the following research questions:

1. Did the intervention influence individuals to reduce their home energy use?

a) Did intervention participants adopt new energy-use behaviors at a significantly higher rate than the control?

b) What were the adoption rates and trends for different types of proposed behaviors that involve high financial cost, time, and energy commitments versus low investment, high repeating behaviors?

2. Were the energy-reducing habits adopted by intervention participants long lasting?

a) Were the adopted behaviors maintained or were new behaviors adopted in the seven-month period following the intervention? 
3. Does the community-based nature of the campaign contribute to its effectiveness in getting individuals to adopt energy-saving behaviors?

a) Were there higher rates of participation in the intervention, as well as in monthly survey participation, for the intervention group compared to the control?

b) Did the intervention participants rate various community-based features of the intervention as having a motivational impact on their adoption of new energy use behaviors? 


\section{METHODS}

\section{STUDY DESIGN}

I developed the intervention program model used for this study in 2006 and, with the support of a local environmental organization, ran the program until 2009 and oversaw its adoption in a range of communities around the San Francisco Bay Area, primarily in faith-based organizations, elementary schools, and workplaces. The basic structure of the intervention, commonly referred to as a campaign among participants, follows.

\section{Description of the Intervention}

This description applies to both the intervention used in this research and to pilot studies referenced to validate the results of this study.

\section{Green Team}

Campaigns were lead by a Green Team, a previously self-selected group of volunteers whose primary purpose was to introduce environmentally responsible practices to their community or organization. I trained each Green Team how to run their community's campaign while they determined which members would be responsible for different roles and responsibilities, which included managing the campaign's messages and activities, selecting a launch date for either fall or late winter and planning a launch event, planning monthly outreach events, and tailoring a website template I provided 
which they could dedicate to their community and unveil on launch day. Sometimes one member took a primary leadership role if the other team members agreed to the idea. Typically this occurred with people who accepted the job of managing the communications effort and/or had experience interacting with the community for prior events. Green Team members had varying skills and were empowered to take leadership roles in their skill areas and to be proactive in developing meaningful activities that served the goal of motivating participants or improving the campaign experience. They referenced a communications strategy I created that (1) outlined how and when to use the available communication channels to get messages out about the campaign in a timely manner; (2) described how to tailor specific types of messages - keep them brief, simple, clear and positive and reference their personal experiences learning to conserve energy where they could - and (3) encouraged them to take turns authoring messages to keep the community from growing tired of any one voice or writing style. They were also encouraged to be as inclusive as possible, both in welcoming potential new team members who wanted to help the campaign and in being encouraging of and listening to community members who approached them to discuss the campaign generally. Since the campaign was meant for the entire community, it was important to acknowledge that the experience was as likely to engage active, outgoing personalities as it was to draw out those who did not typically engage with others but who wanted to respond to the social opportunity the campaign provided to add their voice and ideas. Ultimately, the Green Team consisted of familiar faces that helped unite the community and served as invaluable mentors and supportive peers to participants. 


\section{Launch and Pledge Gesture}

Campaign were launched with a formal announcement made by the Green Team during a regular Sunday service inviting all community members to join together to help fight climate change. They introduced themselves and their roles in the effort and provided a description of the campaign, outlining its five-month length, monthly surveys, and the various outreach events they had planned. The invitation was coupled with a request for a public pledge gesture, such as placing a rock in an oversize clear jar which was then kept on display in a common area at the church, to signal their commitment to the campaign's goals to help reduce their community's collective energy use (also known as their carbon footprint). As participants joined the campaign, the aggregation of pledge gestures made on launch day and throughout the rest of the first month was used as a visual centerpiece in their congregation. The high visibility of the pledge display served as a symbol of the community's overall commitment to the campaign, a form of comparative feedback.

\section{Email Group, Website, and Behavior Challenges}

Participants were invited to join an email group on launch day, a form of social support that encouraged a commitment norm, that the Green Team used to email information about the first month's energy-reducing behaviors (Appendix A), known as "monthly challenges." The email group, a column in the printed weekly or monthly

newsletter, and a campaign website were used by the Green Team to educate participants 
about the status of the intervention; promote monthly challenges, outreach events, and survey participation; and to discuss survey results. Participants were encouraged to visit the website to explore which behaviors they wanted to attempt to adopt, focusing only on the current month's promoted behaviors. The website (Figure 1) provided detailed information about each challenge, from statistics about the amount of carbon dioxide emissions (one of the primary greenhouse gases) that could be reduced by the adoption of that behavior, to positively framed, practical advice about how to incorporate it into everyday life. To establish credibility the campaign relied on information that could be considered reliable and trustworthy, and each behavior challenge webpage identified the government and environmental agencies used as sources for the recommended behaviors, plus any scientific or statistical data that helped to explain them.

Each month's set of challenges comprised a mix of low- and high-cost behaviors (such as replacing an incandescent light bulb with a compact fluorescent or installing an energy-efficient water heater) and behaviors that required varying degrees of effort and repetition to adopt (such as taking shorter showers or line-drying clothing instead of using the dryer) but also saved varying amounts of energy, with the most costly behaviors often being the ones that achieved the highest energy savings. Challenges were organized around the five following themes: winter heat, things you plug in, your consumer footprint, hot water, and transportation. 


\section{Going Green Gang (G3)}

Challenge: Take Shorter Showers

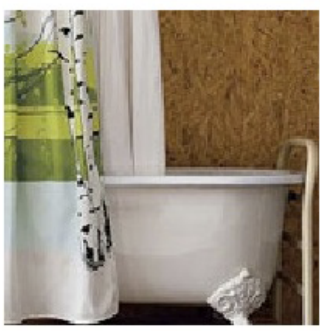

Who doesn't love taking a long, hot luxurious showe sometimes--or maybe most of the time? But did you know that your shower is the biggest user of hot water in the entire house? A typical shower uses up a whopping $37 \%$ of a household's hot-water usage and contributing mightily to your energy costs. If you're interested in reducing your energy use and costs, shortening the time you spend showering is a great way to start.

What You Should Know

V Solely at the sink and in the shower, the average person uses 50 gallons of hot water a day

Making simple modifications to your family's showering, bathing, teeth-brushing and shaving habits can lead to big savings.

Easy Things You Can Do

Take shorter showers. Have you ever timed yourself in the shower? An 8-minute shower is normal, but considering most older showerheads use 4 to 6 gallons of water per minute, you'll still be using up 32 to 48 gallons of water. Anything above 10 minutes wastes a lot of hot water. An 8-minute shower compared with

a lons

At the beginning of each month after the campaign launch, the Green Team

introduced a new theme in the community newsletter, and the corresponding behavior challenges were unveiled and explained in detail on the community web site. They also sent emails to reinforce the importance of the campaign's goals and remind participants to work on any of the current month's challenges that they found acceptable to their lifestyles and needs.

\section{Monthly Surveys}

At the end of the first, and all subsequent months of the campaign, the Green

Team issued an online survey (Appendix B) soliciting anonymous feedback about the 
specific behavior challenges each household had been encouraged to adopt that month. A reminder email was sent one week later to encourage survey participation. In addition, at the end of the first month's survey, questions seeking demographic information about the participating households were asked as well.

\section{Monthly Survey Results Graphs}

The surveys captured data about which behaviors were being adopted ("Did it because of the [intervention]" or "New or stronger habit because of [the intervention]), had been adopted previously ("Already doing this before the [intervention]"), had "Not yet" been adopted, or were "Not applicable." Survey results for all participants were aggregated and combined onto a bar graph (Appendix B), that was promoted within the community via the web site, newsletter, and emails and in some cases via large printed signs displayed in common areas, such as church entryways or meeting rooms. The monthly survey results served as a form of comparative feedback. The Green Team used the community results graphs to highlight the effectiveness of the campaign, encourage continued participation, and celebrate successful adoption of new habits that supported the overarching goal of fighting climate change.

\section{Green Team Outreach Events}

In addition to the launch, the challenges, the surveys, and the results graphs, the Green Team organized various outreach events promoting environmental behaviors that took place throughout the campaigns to provide opportunities for hands-on learning to 
supplement the information provided on the campaign website. Such activities included offering demonstrations of solar ovens, managing a lending library of tools to assist households in measuring the electricity used by their appliances and electronic devices, and offering table displays where participants could ask questions about energy or water use. They also offered "coffee hours" so that they could provide face-to-face opportunities to discuss the behavior challenges and generally provide social support and encouragement to participants. Other outreach efforts included screening environmentally themed films, handing out free compact fluorescent light bulbs to encourage their use, and organizing a community tree-planting event on their church grounds. After the fifth survey was administered the Green Team organized a final outreach effort, a "wrap event," to thank participants for their efforts and summarize the results of the campaign.

\section{The Follow Up Survey}

Seven months after the campaign's wrap event, the Green Team issued a "Follow Up Survey" (Appendix D) to solicit feedback about maintained or adopted post-campaign behaviors. The results of this survey helped establish whether the intervention had any lasting effects on participants' energy-use behaviors and identified which motivating factors the participants attributed those changes to. 
Demographic Surveys, Intervention Communities and Permissions

The two communities used as case studies for this research were selected to participate simply because they signed up for the program at around the same time, and were of similar sizes and type of organization. I worked with one Green Team member from each community to deliver the intervention's content, and I informed them of my intention to use their community as part of my research prior to the start of the intervention and asked them to keep this information confidential. Survey questions that sought demographic information about each participant's household, which was appended to the first monthly survey, and the Follow Up Survey were the only elements of the intervention designed specifically to facilitate this study. All other components of the intervention were programmatically identical to other campaigns run by me pre- and post-study.

Monthly surveys served as the major data collection method for this study, but because survey participation was anonymous and voluntary, participants in the intervention were required to provide only informed consent for me to use their survey responses for this research in order for this procedure to receive IRB approval. To acquire informed consent, the intervention community participants were made aware of the study when they encountered the last page of the first month's survey, which thanked them for taking the survey, informed them that their responses were a part of a research study seeking to better understand the most effective ways to motivate behavior change relating to home energy use, and that by clicking "Submit" they were giving their consent to participate. When they took the final Follow Up Survey seven-months post 
intervention, they were further informed that if they were interested in receiving a copy of the research upon publication, to provide their email address.

\section{Description of the Control}

I selected the control group community because it was a faith-based organization like the intervention communities, because it shared its location in Palo Alto with Intervention Group 1, and because a member of that community was willing to assist me in recruiting participants for my study by introducing me to the community. In addition, the community's Green Team had inquired about launching a campaign the previous year and decided it was not a fit for their interests due to a lack of volunteer capacity. To disguise the true intention of this study, my contact invited his community to participate in a "How Green Is Your Life" study at the end of a Sunday worship service by announcing "You are invited to participate in the How Green Is Your Life project, done by Ellen Wilkinson for her master's thesis in Environmental Studies. By answering a few survey questions each month for five months, you'll promote sustainability and learn more about what your household can do to help." The person who delivered the announcement was not a part of that organization's Green Team, nor did the organization's Green Team have any involvement with the study. Neither I, nor my contact, or anyone else further advertised or promoted the study or encouraged participation in it.

Each month for five months I sent individual email messages to each control group participant with a link to that month's online survey, which I created with identical 
questions to those sent to intervention groups. Because questions addressed to intervention groups sometimes referenced their campaigns, for example "Did it (because of the [intervention])" or "Already doing this (before the [intervention]," the response choices provided for control group surveys were simplified to "Did it (within the last month)," and "Already doing this (before this study began)." The control group received no additional encouragements, incentives, or reminders to participate. Seven months after the fifth survey was released, I also sent an email with a link to a modified version of the Follow Up Survey, in which questions about the intervention were removed. The release of the surveys coincided exactly with those provided to Intervention Group 1 and overlapped the release of surveys to Intervention Group 2 by three months.

In addition to the two case studies and control group used for this study, I have pre-experiment, pilot study data about participation rates and monthly survey results for three additional communities that I used for comparison and validation of some of my case study results. These communities, a workplace and two K-8 schools, were selected for this purpose among the many communities I worked with prior to this study because they received essentially the same intervention as the one presented here, and because I believe it is worthwhile to validate that the results found in this study were not unique to religious organizations or groups of an older median age, two characteristics shared by both intervention and control participants. In addition, I have pilot study data of a fourth community, a residential neighborhood in Sunnyvale that I approached to be a second control group for this study but whose data was not robust enough to include, other than to illustrate and lend support to my discussion of participation rates. 


\section{DATA COLLECTION}

Over the three years I spent running this program, I did very little marketing, as I found that communities that already had an active Green Team in place, and whose members had heard of my program via word of mouth, tended to seek my program out on their own initiative. The two communities selected for observation for this study were chosen because their Green Teams signed up for the program within a few months of one another and, when taken together, constituted a stronger population to observe than one small sized community or communities that did not overlap the same time period at all. Coincidentally they were both faith-based organizations. I selected a third community, also a faith-based organization, to serve as the control group to test my central hypothesis that participating in the intervention significantly influences home energy-reducing behavior change. My observation of these three communities occurred from October, 2008 to November, 2009. The three communities were located in the Palo Alto and Willow Glen areas of the greater San Francisco Bay Area.

The intervention lasted for five months and was lead by a Green Team from each intervention group with my guidance. The intervention taught 86 behaviors (Appendix A), including the most commonly recommended and effective behaviors that can reduce residential energy use, distilled from a variety of local and national energy experts and resources (Javna 2006; Rocky Mountain Institute 2008; and Gardener and Stern 2008). 


\section{Who Participated}

Intervention Group $1(\mathrm{~N}=80)$ was a Presbyterian church in Palo Alto that signed on to launch the intervention in October 2008. This community was comprised of approximately 150 households in Palo Alto and neighboring towns, and received the full intervention, outlined below, and a "Follow Up Survey" (Appendix D).

Intervention Group $2(\mathrm{~N}=84)$ was a Presbyterian church in Willow Glen that consisted of approximately 260 households from Willow Glen and around the greater San Jose area, including Almaden, Campbell, Los Gatos, other areas within Santa Clara county such as Cupertino and Sunnyvale and as far away as Morgan Hill and Milpitas (Jennifer Scott-Brand, interview by author, April 11, 2011). This community signed on to launch the intervention in January of 2009. This community also received the full intervention but did not participate in the Follow Up Survey.

A Quaker congregation, also located in Palo Alto, served as the control group $(\mathrm{N}=17)$. This congregation was comprised of 75 households, and shared a similar demographic makeup with both of the intervention communities. This community signed on to participate in the study in October 2008. Participants in the control group were invited to participate in a series of monthly surveys about sustainability and home energy use. They received no other information about the purpose of the surveys or feedback about their fellow community members' participation. While this group does belong to a community with a shared interest and sense of fellowship, and one that has a "Green Team," they were approached by a fellow congregation member to participate in the study as individuals, not as part of a community-based, collective effort. The results of 
all six of the control group's surveys were used as a baseline of behavior change, attitudes about environmental issues, and lasting effects against which I compared the intervention group's results.

\section{Demographic Information}

Overall, the results of the demographic survey (Appendix B) conducted early in the interventions showed that the three communities were strikingly similar to one another (table 1); they were fairly affluent, well educated, and older. The median age range for residents in their households was 50-64 years, they primarily owned their own homes, and the median level of education attained was a masters degree, or in the case of Intervention Group 2, mid-way between a 4-year college and a masters degree. While $25 \%$ to $36 \%$ of respondents across all three groups skipped the question about their household income, for those that did answer this question from the two intervention groups, they had a median income level of $\$ 80,000-\$ 99,000$, while the control group had a lower median income of $\$ 40,000-\$ 59,000$.

I did not collect demographic data from participants of the three other nearby communities whose monthly survey results are also reported in this study; two grade schools located in Menlo Park, and a workplace located in neighboring Palo Alto. According to City-data.com, an online resource that compiles census and other community profile data, the populations of these communities was likely to have been very similar to the case studies and control group at the heart of this study in terms of home ownership, education, and household income. But in regard to the median age of 
these communities, they were likely closer to the 30-45 year age range, younger than the case studies and control communities whose median age was 50-64, and thereby providing a generational counterpoint to those groups in terms of their responsiveness to the intervention.

Table 2. Demographic data of three case study communities

\begin{tabular}{|c|c|c|c|}
\hline & Int Group 1 & Int Group 2 & Control \\
\hline Total Households & $N=150$ & $N=260$ & $N=75$ \\
\hline Study Participants & $n=80(53 \%)$ & $n=84(32 \%)$ & $n=17(23 \%)$ \\
\hline Demographic Respondents & $n=38(48 \%)$ & $n=17(20 \%)$ & $n=2(16 \%)$ \\
\hline Own & $76 \%$ & $65 \%$ & $67 \%$ \\
\hline Rent & $16 \%$ & $29 \%$ & $33 \%$ \\
\hline \multicolumn{4}{|l|}{ By education } \\
\hline Some college & $5 \%$ & $18 \%$ & $8 \%$ \\
\hline 4-year college & $19 \%$ & $29 \%$ & $25 \%$ \\
\hline Masters & Median 43\% & Median 29\% & Median 33\% \\
\hline Doctoral & $16 \%$ & $6 \%$ & $17 \%$ \\
\hline Professional & $14 \%$ & $12 \%$ & $17 \%$ \\
\hline Skipped Q & $3 \%$ & $0 \%$ & $0 \%$ \\
\hline \multicolumn{4}{|l|}{ By income } \\
\hline$<\$ 19 \mathrm{~K}:$ & $0 \%$ & $0 \%$ & $8 \%$ \\
\hline$\$ 20$ to $\$ 39 \mathrm{~K}:$ & $3 \%$ & $6 \%$ & $25 \%$ \\
\hline$\$ 40$ to $\$ 59 \mathrm{~K}:$ & $11 \%$ & $6 \%$ & Median 33\% \\
\hline$\$ 60$ to $\$ 79 \mathrm{~K}:$ & $8 \%$ & $18 \%$ & $0 \%$ \\
\hline$\$ 80$ to $\$ 99 \mathrm{~K}:$ & Median 16\% & Median $24 \%$ & $0 \%$ \\
\hline$\$ 100$ to $\$ 149 \mathrm{~K}:$ & $8 \%$ & $41 \%$ & $25 \%$ \\
\hline Over $\$ 150 \mathrm{~K}$ : & $24 \%$ & $0 \%$ & $0 \%$ \\
\hline Skipped Q: & $30 \%$ & $36 \%$ & $25 \%$ \\
\hline \multicolumn{4}{|l|}{ By age } \\
\hline Under 18 & $22 \%$ & $18 \%$ & $8 \%$ \\
\hline $18-29$ & $8 \%$ & $6 \%$ & $17 \%$ \\
\hline $30-39$ & $3 \%$ & $12 \%$ & $8 \%$ \\
\hline $40-49$ & $19 \%$ & $6 \%$ & $8 \%$ \\
\hline $50-64$ & Median 35\% & Median 24\% & Median $42 \%$ \\
\hline Over 65 & $41 \%$ & $59 \%$ & $67 \%$ \\
\hline Skipped Qs & $0 \%$ & $0 \%$ & $0 \%$ \\
\hline
\end{tabular}




\section{Environmental Attitudes}

In addition to demographic questions, I asked respondents to rate on a five-point Likert scale (1=Disagree, 5=Agree) three questions about their attitudes toward the environment. Overall the respondents for both the intervention and control groups were aligned in their concerns about the environment. An independent t-test indicated that there was no significant difference (table 2) between the two groups in regard to the question "climate change (aka global warming) is one of the most important issues facing the world right now," "in terms of energy use, my household is at least as 'green' as most other households," or "I often think about how I can reduce my impact on the planet (energy use, resource use, or other)." As a result, the combined intervention groups (hereafter called the intervention group) and the control group were considered to have been similarly aware of and concerned about environmental issues at the outset of this study.

Table 3. Comparison of environmental attitudes

\begin{tabular}{|c|c|c|c|}
\hline \multirow[b]{2}{*}{ Question } & \multicolumn{2}{|c|}{ Mean and standard deviation } & \multirow[b]{2}{*}{$\begin{array}{l}\text { Independent t-test } \\
\text { for equality of means }\end{array}$} \\
\hline & $\begin{array}{l}\text { Intervention groups } \\
\qquad n=55\end{array}$ & $\begin{array}{c}\text { Control group } \\
\quad n=12 \\
\end{array}$ & \\
\hline $\begin{array}{l}\text { "Climate change (aka global } \\
\text { warming) is one of the most } \\
\text { important issues facing the world } \\
\text { right now." }\end{array}$ & $M=4.77, S D=.75$ & $M=4.83, S D=.38$ & $t(63)=-.26, n s$ \\
\hline $\begin{array}{l}\text { "In terms of energy use, my } \\
\text { household is at least as 'green' as } \\
\text { most other households." }\end{array}$ & $M=4.25, S D=.76$ & $M=4.25, S D=.75$ & $t(63)=-.20, n s$ \\
\hline $\begin{array}{l}\text { "I often think about how I can } \\
\text { reduce my impact on the planet } \\
\text { (energy use, resource use, or } \\
\text { other)." }\end{array}$ & $M=4.58, S D=.60$ & $M=4.75, S D=.45$ & $t(63)=-.89, n s$ \\
\hline
\end{tabular}




\section{Impact of the Intervention}

The impact of the intervention on behaviors was measured using five selfadministered monthly surveys covering five different topics (table 3 ) and 86 behaviors altogether (Appendix A). Participants were instructed to complete one survey per household, and survey responses were anonymous to encourage greater honesty in selfreports of behavior. For questions about one-time actions (e.g. replaced dishwasher with an energy efficient model) the following answer choices were provided: "Already did this (before the [intervention])," "Did it (because of the [intervention])," "Not yet," and "Not applicable." For repeating behaviors (e.g. line-drying clothes instead of using a clothes dryer), respondents could select "Already doing this (before the [intervention])," "New or stronger habit (because of [intervention])," "Not yet," and "Not applicable." The final question of each survey invited open-ended comments or suggestions to provide qualitative feedback about the intervention. I used an online survey software tool to standardize questionnaires for all three communities, capturing responses that could later be used with spreadsheet and statistics software to conduct data analysis on the results.

Table 4. Monthly survey topics

\begin{tabular}{lcc}
\hline Monthly survey topic & No. of questions & Focus of questions \\
\hline Things You Plug In (TPI) & 19 & Appliances, electronics use \\
Consumer Footprint (CF) & 24 & Consumer habits, from shopping to recycling \\
Winter Heat (WH) & 12 & Heating and insulation \\
Hot Water $(\mathrm{HW})$ & 12 & Hot water use \\
Transportation $(\mathrm{T})$ & 19 & Transportation issues \\
\hline
\end{tabular}

For each survey, I calculated each question's average percentage of endorsement from all respondents by response type by first adding up the number of responses by type 
("Not yet," "Did it" / "New or stronger habit," "Already doing" and "Not applicable") and dividing that number by the total number of respondents to that question. I then found the mean endorsement rate for each of the four response types per survey by adding up the total number of responses by type across the survey and dividing by the total number of possible behaviors. I created a score for each response type to evaluate the statistical differences between the intervention and control groups' "Did it" and "Already" responses for each survey, which was critical to my ability to establish whether the intervention effectively motivated behavior change or not. I then compared the two groups" "Already" scores using an independent t-test to determine whether there was a statistically significant difference between them. I also conducted an independent t-test to evaluate the difference between the two groups" "Did it" responses, which indicated behaviors that were newly adopted because of the intervention.

\section{Long Lasting Effects}

The Follow Up Survey was administered to gauge the long-lasting effects of the intervention and was comprised of questions about whether the participant had maintained any of a subset of 23 of the behaviors they had adopted as a result of the intervention (or for the control group, during the course of the study), or had newly adopted them in the interceding seven months since the fifth survey. The list of questions was shortened from 86 to 23 to minimize the possibility of questionnaire fatigue from negatively impacting participation, found in other studies of household energy use (Staats, et al. 2004, 350). The questions were made up of predominantly LR behaviors 
and two HI behaviors (Appendix A) in an effort to include actions that were the most likely to have been adopted during the intervention and therefore good candidates for the Follow Up Survey. At least three questions were selected from each survey and all questions were chosen for the degree of popularity they enjoyed with participants that I had observed while running the program, and that were also commonly included in the many web-based national campaigns presented by the EPA, the NRDC, and other prominent organizations I had studied. Due to programmatic challenges outside of the scope of this study, the Follow Up Survey was conducted only for Intervention Group 1 and the control group.

\section{Community Influence}

I gauged the community influence on participants' behaviors using the five following measures: their rate of participation in the intervention itself, their monthly survey participation, their self-reports of the motivating value of the intervention when framed in various ways as a "community-based" effort, their self-reports of the motivating value of the intervention's component features, and qualitative data offered in the open comments portion of the monthly surveys.

\section{Intervention Participation Rates}

The distinguishing feature of the intervention to potential participants is that it was conducted in full view of the community. The intervention was introduced by Green Team peers from within the community, launched by an event targeted to community 
members, and addressed to the community as a whole throughout its five-month duration. The pledge gesture was the centerpiece of the launch event, and was the Green Team's way to ask each household to make a commitment gesture in full view of the rest of the community to signal their interest in participating in the campaign and reducing their energy use. In Intervention Group 1, writing the family name on a paper footprint and adding it to an oversize "pathway" mural (signifying "Put your best footprint forward") (see fig. 2) during the launch event was their pledge gesture. The pledge was each household's commitment to save energy made public both to other community members in attendance and, to a lesser degree, to any members viewing the display in the four to six weeks following the launch event that the display was preserved for the community. For Intervention Group 2, the act of placing a rock in the pledge jar in view of their community served as the commitment gesture of each household's intention to participate in the campaign. While some rocks were written on to capture the family names of participating households, this identifying information was not easily visible in the six weeks following the launch that the display was maintained for public view, so the commitment was not as strongly reinforced as it was for Intervention Group 1. 

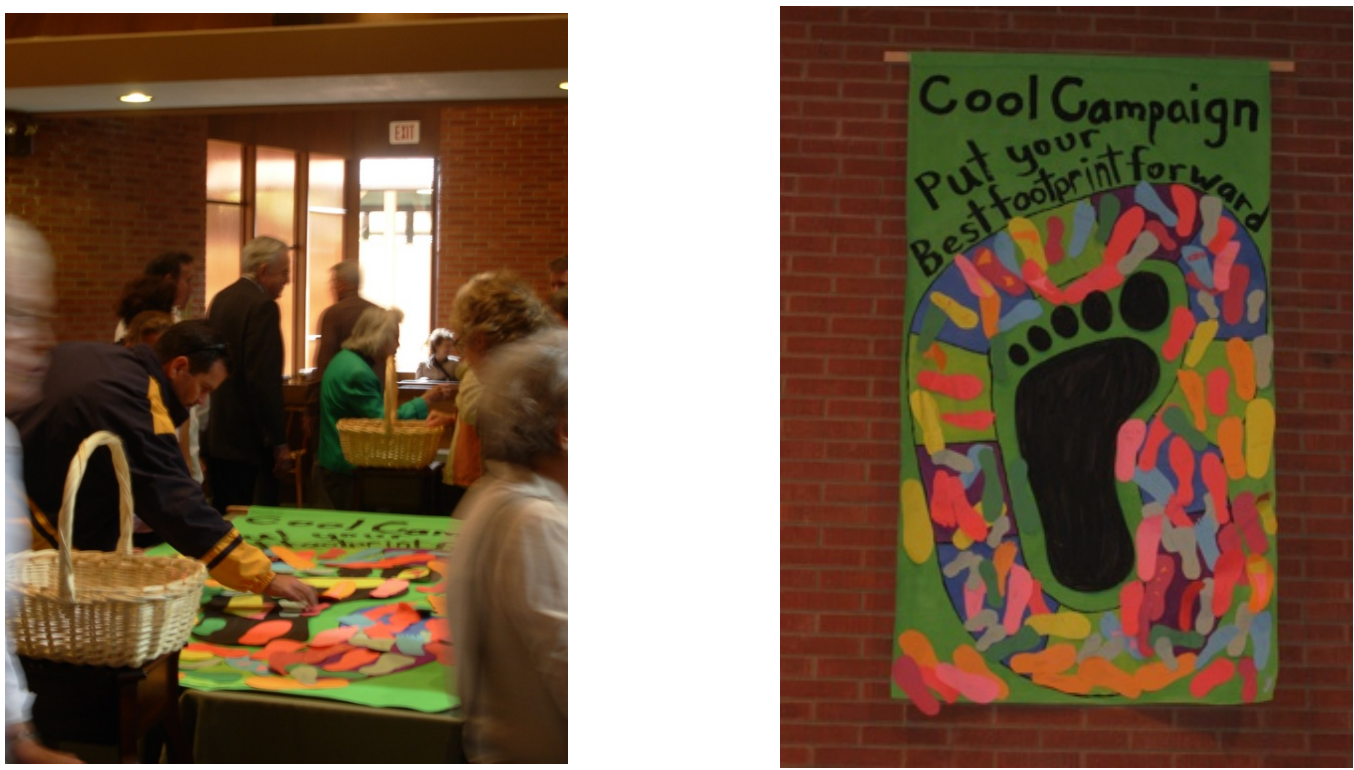

Figure 2. Left: Intervention Group 1's launch day; right, Their community pledge display.

Participation in the pledge gesture was voluntary, and for both communities most households that joined the campaign did so during the launch event, or in the immediate weeks following, with a few joining after the first month of the campaign. Neither community had a mechanism to track households that dropped out of the campaigns, since participation beyond the pledge gesture was anonymous and voluntary. I calculated the intervention participation rate by dividing the total number of pledges made for both intervention communities against the total number of households in both communities, and compared that rate to the control group's participation rate in the first survey, which served as a proxy for a pledge gesture. 


\section{Survey Participation Rates}

The community-focused nature of the intervention post-launch was primarily used to exert social pressure to encourage changes in energy-use behavior at home. Since the campaigns lasted for over five months and were reliant on self-reports to gauge whether new habits were being adopted, Green Teams were directed to remind and encourage community members through group emails, outreach efforts, and other communications to take each survey. So, while survey-taking was done in the privacy of one's home using the Internet, the social pressure to take them each month was applied at the community level through the various channels the Green Teams used to communicate with participants collectively. These communication channels included group email messages, posted signage, newsletter messages, and face-to-face interactions. Therefore, studying the rate of survey participation provided another measure of the effectiveness of community social pressure when compared to the control group.

\section{Attribution of Motivation to Change Behavior}

In addition to assessing the lasting effects of the intervention, the Follow Up survey asked intervention and control group respondents to rank how motivating various features of the intervention/study were on their energy-use behaviors, using a 5-point Likert scale $(1=$ not at all effective to $5=$ extremely effective), from which I derived average response values. Specifically they were asked, "How much did [your community's campaign/your participation in the study] motivate you to change your habits to reduce your home energy use?" to measure their awareness of the effect their 
participation in the community-based intervention (or study, for the control group) had on their behavior. To gauge whether participants perceived that social pressure had an effect on their energy use behavior, they were also asked "How much did the knowledge that [your community]/[friends and/or family members] have begun reducing their energy use, if they have, motivate you to change your energy habits?" and "How much did knowledge that reducing energy use has been gaining popularity around the country motivate you to change your energy use habits?" (Appendix D). Respondents were also given an opportunity to provide open-ended comments about their experience with the intervention. Lastly, since the intervention was comprised of so many features that brought social pressure to bear on participants' interest in adopting new energy use behaviors, I examined which ones were rated most motivating, as well. Respondents were asked "To the best of your memory, how much did each of the following motivate you to adopt energy reducing behaviors during the Campaign? $(1=$ not at all motivated by this, $2,3,4,5=$ extremely motivated by this)" about the following campaign features:

- campaign launch in your community

- pledge display/gesture

- knowing how many other households in your community had pledged to join the campaign

- campaign website

- green team communications about the campaign

- green team outreach events

- taking the monthly surveys 
- reviewing monthly survey results showing how many households changed their habits

- campaign wrap event

- discussions with other community members about the campaign generally or specific challenges

- firsthand knowledge of the efforts of other campaign households to reduce their energy use

\section{Open-ended Comments About the Intervention}

Each monthly survey and the Follow Up Survey provided an open-ended comment option for participants to share their feedback about any aspect of the intervention they wanted to discuss. Since comments were unprompted and made anonymously, they offered a rich source of useful information about the intervention's effectiveness from a participant's perspective. Because participants expressed their ideas and opinions freely and in their own words, there is no other way to evaluate them than to report the comments I believe demonstrate the most useful insights about what did and did not work about the intervention, or that help to further illustrate my interpretation of the results of the surveys and participation rates. 


\section{DATA ANALYSIS}

The communities that participated in this study were self-selected by their Green Teams, and then again through their pledge gestures, and therefore the populations were not randomly selected. The primary data that I collected and analyzed, primarily participation rates and responses to survey questions, allowed mostly for simple descriptive statistics such as means, medians, standard deviation, and standard error, as well as limited use of inferential statistics such as t-tests for independent samples, due to small sample sizes. All percentages were rounded up to the nearest whole number.

Because I measured the impact of the intervention by looking at survey results, the responses for both Intervention Group 1 and Intervention Group 2 were collapsed into one group, called simply the intervention group, and compared to the control. This was done in order to enlarge and strengthen the data set for the intervention communities and provide greater reliability and confidence in the numbers. That the two groups were demographically similar contributed to my confidence that combining them was a reasonable approach to take. However, the intervention was not administered to the two communities simultaneously, but over five-month periods that overlapped one another by three months (Intervention Group 1's campaign ran from October to March, and Intervention Group 2's campaign ran from January to June). While there was no a priori reason to believe that time shifting the presentation of surveys by a few months made a difference, I conducted a side-by-side comparison of percentage endorsement rates by response type, including standard error, for each survey (table 5) to be sure there were no signs that historical efforts had impacted results. I decided to collapse the two 
intervention communities into one group after I determined that the differences between the mean response rates appear to have no bias with respect to time. The intervention seemed to exert a similar influence on both communities, regardless of external factors that may have occurred in the different months the surveys were administered.

Table 5. Comparison of average percent of endorsement by response type per survey for two intervention groups that took the surveys from one to seven months apart in time.

\begin{tabular}{lcccccc}
\hline & & & \multicolumn{3}{c}{$\begin{array}{c}\text { Mean response rate (standard error) } \\
\text { by response type }\end{array}$} \\
\cline { 4 - 7 } Survey & Group & Month & Not yet & Did it & Already & NA \\
\hline Things You Plug In & One $(n=38)$ & Oct & $23( \pm 6)$ & $8( \pm 4)$ & $42( \pm 8)$ & $19( \pm 6)$ \\
& Two $(n=18)$ & May & $18( \pm 9)$ & $20( \pm 9)$ & $31( \pm 10)$ & $17( \pm 8)$ \\
Consumer Footprint & One $(n=28)$ & Nov & $17( \pm 7)$ & $19( \pm 7)$ & $65( \pm 9)$ & $\ldots$ \\
& Two $(n=12)$ & Jun & $11( \pm 9)$ & $34( \pm 13)$ & $53( \pm 14)$ & $\ldots$ \\
Winter Heat & One $(n=18)$ & Jan & $25( \pm 10)$ & $11( \pm 7)$ & $42( \pm 11)$ & $22( \pm 9)$ \\
& Two $(n=48)$ & Feb & $20( \pm 5)$ & $12( \pm 4)$ & $44( \pm 7)$ & $20( \pm 5)$ \\
Hot Water & One $(n=16)$ & Feb & $23( \pm 10)$ & $14( \pm 8)$ & $38( \pm 12)$ & $22( \pm 10)$ \\
& Two $(n=30)$ & Mar & $25( \pm 7)$ & $14( \pm 6)$ & $36( \pm 8)$ & $16( \pm 6)$ \\
Transportation & One $(n=24)$ & Mar & $14( \pm 7)$ & $10( \pm 6)$ & $40( \pm 10)$ & $8( \pm 5)$ \\
& Two $(n=17)$ & Apr & $12( \pm 7)$ & $23( \pm 10)$ & $29( \pm 11)$ & $12( \pm 7)$ \\
\hline
\end{tabular}

Note: The Consumer Footprint Survey did not include a "NA" response type.

\section{Impact of the Intervention}

Monthly survey results provided an indication of whether and how many participants actually changed behavior as a result of the intervention ("Did it (because of the [intervention])" / "New or Stronger Habit (because of the [intervention])") and were willing to report it, and served as the primary measure of the campaign's overall effectiveness. However the "Did it" responses do not tell the whole story. Where a community reported that they were "Already" performing behaviors presented in the surveys prior to the intervention, there was less capacity to motivate additional changes to 
their behavior, which limited their overall number of "Did it" responses. The "Not applicable" responses reflected the group's inability to adopt new behaviors for some reason. The "Not yet" responses indicated a lack of readiness to adopt a new behavior and were an indicator of the additional capacity within that group to adopt new behaviors that were not swayed by the intervention.

To simplify the response patterns for each community and find appropriate values to compare given the relatively few number of survey respondents in the control group compared to the intervention, I calculated the average percentage of endorsement for each response type ("Not yet," "Did it" / "New or stronger habit," "Already doing" and "Not applicable") per question in the following manner: I summed the frequency for each response type across each question, then divided that value by the number of respondents who took that survey and multiplied it by 100 . To find the average percentage of endorsement for each of the four response types per survey I added up the total number of responses by response type across the survey and divided those figures by the total number of possible behaviors. To identify trends, I compared these mean values, by response type, of the intervention and control groups for each survey. Where a higher percentage of "Did it"/“New or stronger habit" responses appeared in the intervention communities compared to the control group, those results helped to confirm the effectiveness of the intervention in changing energy use behaviors. This was especially true when the "Already doing" (hereafter referred to as "Already") and "Not yet" responses indicated whether there was capacity for new behavior adoption in both groups. 
To statistically establish whether significant differences existed in the rate of "Did it" and "Already" responses between the intervention and control groups, I created a score for each response type using the following method: I assigned a point to each behavior a participant was already doing, then added all points for all participants together for each survey to obtain a score representing the behaviors adopted prior to the intervention that I then compared to the control group's similarly obtained score using an independent $\mathrm{t}$-test. I used this same approach to calculate a score and conduct an independent t-test for behaviors that were newly adopted because of the intervention.

To identify trends in the types of behavior adopted by communities in this study, I created behavior categories to help simplify the analysis (Appendix A). For the purposes of this study, the W and E actions identified by Dietz et al. as being for "home weatherization and upgrades of heating and cooling equipment" and "more efficient vehicles and nonheating and cooling home equipment," (Dietz et al. 2009, 18453), respectively, were combined into "High Investment" (HI category) since these actions involve relatively high degrees of financial investment, time, and energy to adopt. Note that actions such as "keep your car tuned" and "install faucet aerators" are also included in this category despite being moderate or even relatively low-cost behaviors because they require more time and energy to complete than typical daily behaviors. The M, A, and D actions identified by Dietz for "equipment maintenance," "equipment adjustments," and "daily use behaviors," (Dietz et al. 2009, 18453) respectively, were combined into a single category "Low investment, high Repeating" (LR category) since these actions require low financial investment but a high degree of dedication to both 
adopt/maintain and repeat behaviors that improve energy use. To help identify patterns and trends in how green the communities were prior to the intervention, I first graphed the behaviors that had been previously adopted ("Already") and presented them in descending order. I graphed adopted behaviors ("Did it" and "New or Stronger Habit") in the same manner in order to get a complete picture of the behavior practices that resulted from the intervention.

\section{Long Lasting Effects}

To examine whether the intervention had long lasting effects on energy use behavior I calculated the percentage of respondents who had adopted any of 23 behaviors during the intervention and had "continued" or "later adopted" them during the seven months post-intervention, compared to the control group. To obtain an accurate percentage of maintained behaviors post-intervention and -study, I calculated the total number of behaviors that the number of respondents to the survey had capacity for, and divided that by the actual number of reported continued or later adopted behaviors. Overall, a higher rate of behavior maintenance ("continued") among the intervention community participants compared to the control group indicated the existence and strength of long lasting effects of the intervention on behavior. Behaviors that were adopted post-intervention and post-study also provided insight into the motivational impact of the intervention and study on respondents' behaviors. I then conducted a difference of proportions test using an online calculator to determine the probability that the two percentages were statistically different. 


\title{
Community Influence
}

\author{
Intervention Participation Rates
}

To measure the impact of the community-based nature of the intervention I looked at the primary focus of the Green Teams' first communications to its community members: taking a pledge to join the community in reducing home energy use. I calculated the initial participation rates of the intervention communities by counting the total number of household pledges made within the first month of the campaign and dividing it by the total number of households in the community, and compared this to the number of participants in the control group who took the first monthly survey, which served as a proxy for a pledge gesture, divided by the total number of households in that community. I also tested the difference of proportion to determine whether there was a significant difference between rates.

\section{Monthly Survey Participation Rates}

Survey participation was another measure of the community-based influence on participant behavior. For intervention communities, the total number of survey respondents each month was tallied and divided by the total number of pledges (participants) for that community to gauge that survey's participation rate. For the control group, I divided the total number of survey respondents for each month's survey by the total number of households in that community to gauge that survey's participation rate. These rates were compared to see whether the intervention communities had a 
higher rate of participation than the control on a month-to-month basis. Because intervention participants received frequent social marketing messages about participating, including email, newsletter, and face-to-face reminders, a higher rate of participation among intervention community members provided another indication of the effectiveness of the community-based nature of the campaign. I also tested the difference of proportion to determine whether the difference between rates was significant.

\section{Attribution of Motivations to Change Behavior}

To gain insight into whether community-based social pressure motivated participants' willingness to adopt energy reducing behaviors, I compared ranked responses and conducted independent t-tests on the following three questions: the motivating influence of participating in the intervention/study, the motivating influence of knowledge that your community (intervention)/friends and family (control) were reducing their energy use, and the knowledge that energy reduction has gained popularity across the country. Lastly, I examined how intervention participants ranked the numerous community-based features of the intervention for their motivational force in order to provide further insights into whether there is value in using social pressure to influence behavior change and to identify which types of intervention features were considered the most effective.

\section{Open-ended Comments}

I reviewed only comments made by intervention participants and grouped them by survey. Negative and positive comments were included but given the number of 
comments made, I selected only those that were clearly worded, offered useful insights into the intervention's effectiveness, or represented ideas or opinions repeated by more than one participant. 


\section{RESULTS}

\section{BEHAVIOR ADOPTION RATES AND TRENDS}

To determine whether the intervention was responsible for the adoption of new behaviors, I first looked at the entire range of responses, as defined by the average response rates calculated across all questions about the behaviors presented in each survey, to establish how much opportunity for behavior change was possible. Since the intervention and control group participants identified themselves as being fairly proenvironmental in their attitudes, a high rate of "Already" responses was expected and was, in fact, observed for each survey, although at differing rates. The "Did it" responses provide the clearest measure of the intervention's impact on behavior, but only when looked at in comparison to the other responses, particularly to the "Already" responses. To establish whether behavior adoption occurred at a higher rate in the intervention group compared to the control group, I generated a score for the total "Already" behaviors for both groups, and a score for the total "Did It" behaviors then conducted independent t-tests to evaluate whether differences in the responses between the two groups were significant. Please note that when looking at responses across a survey, results do not necessarily add up to $100 \%$ because participants could choose different responses to each question. 


\section{Things You Plug In Survey}

The Things You Plug In (TPI) Survey comprised 19 questions about home appliances and electronics use. Fourteen questions focused on low-investment, high repeating (LR) behaviors, and five focused on high investment (HI) actions related to replacing appliances with more efficient models. I compared the average response rates by type (see fig. 3 ) and found that the intervention group $(M=7.16, S D=3.1,38 \%$ of TPI behaviors previously adopted) did not have a higher rate of "Already" adopted behaviors compared to the control group $(M=5.75, S D=2.09,30 \%$ of TPI behaviors previously adopted), $t(66)=1.49, n s$, meaning that the two groups shared a baseline level of previously adopted behavior.

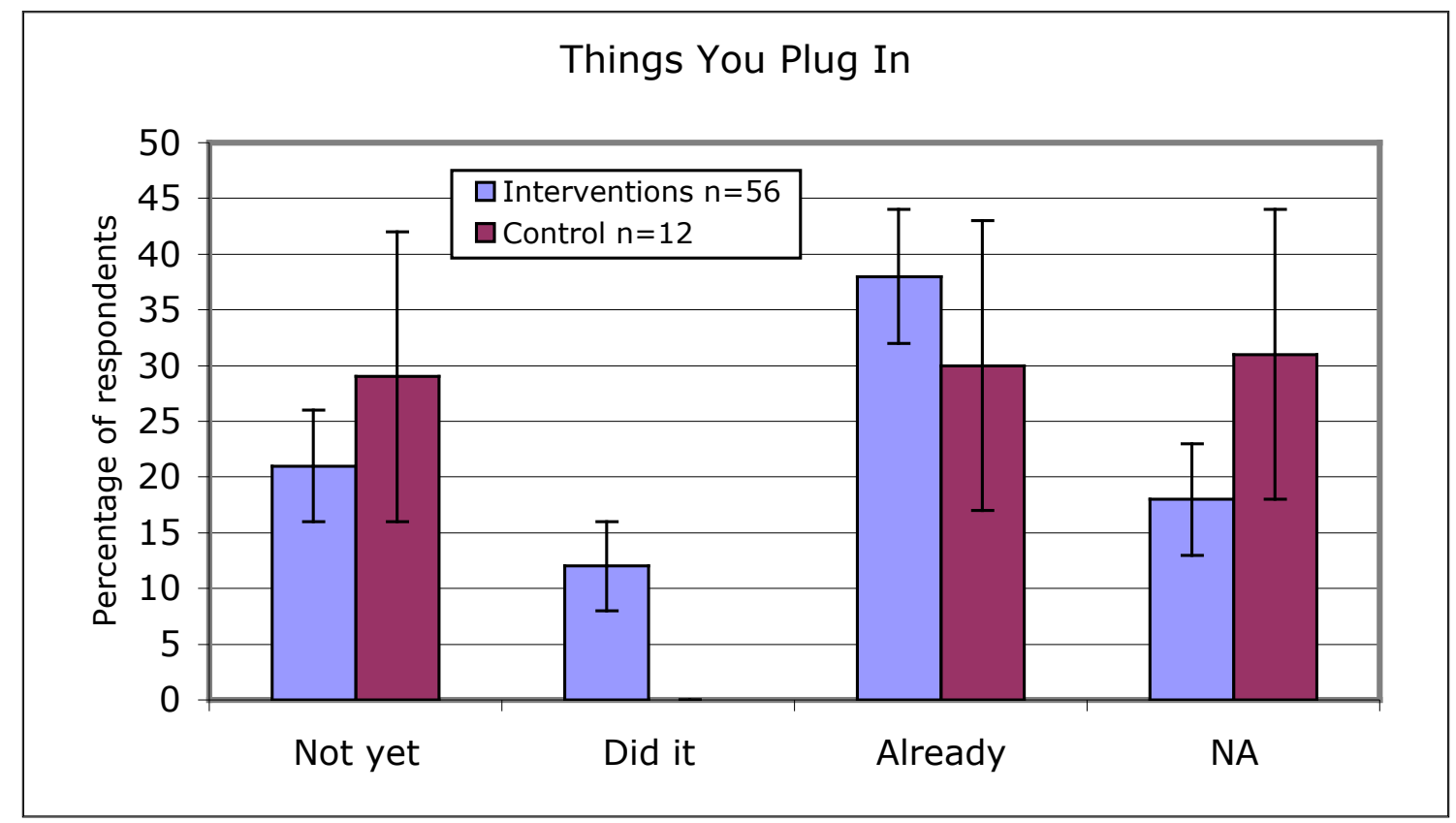

Figure 3. Comparison of Things You Plug In Survey responses. Error bars indicate standard error of proportion. 
The intervention group $(M=2.19, S D=2.29,12 \%$ of TPI behaviors newly adopted $)$ reported adopting significantly more of the TPI behaviors than the control group $(M=$ $.08, S D=.28,0 \%$ of TPI behaviors newly adopted), $t(66)=3.17, p<.05$. The intervention group indicated that $18 \%$ of the behaviors did not apply to them and $21 \%$ of them they were "Not yet" ready to adopt, in addition to the many they were already practicing. The control group indicated that a third of the TPI behaviors were "Not applicable" (31\%) to them and the remaining third they were "Not yet" ready to adopt $(29 \%)$.

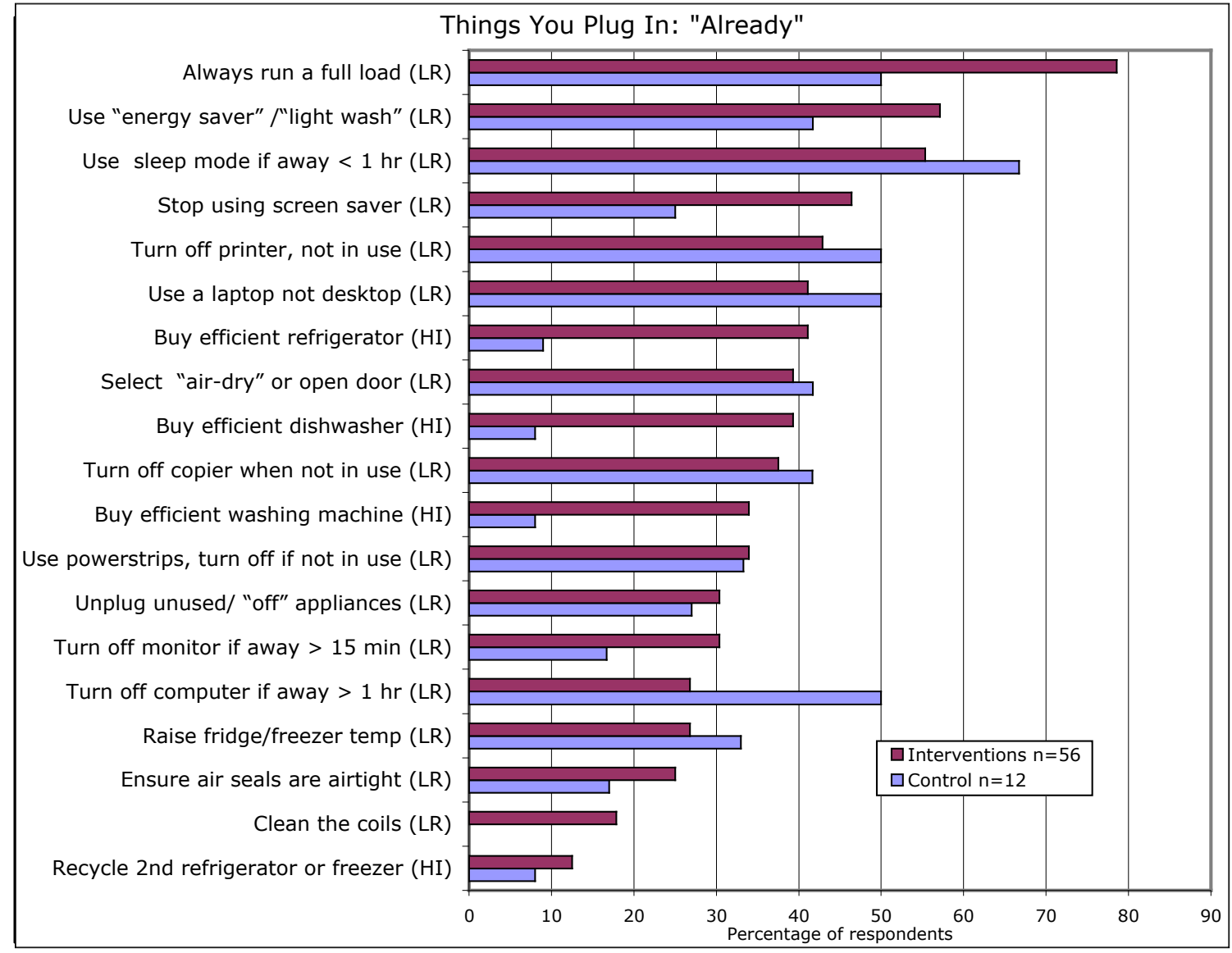

Figure 4. Comparison of previously adopted behaviors reported in the Things You Plug In Survey. 
A closer look at the "Already" responses to the questions on this survey (see fig. 4) reveals that the intervention group was primarily already performing the low investment, high repeating behaviors (LR) such as always running a full load of dishes, using the "energy saver" setting when using the dishwasher, putting the computer to sleep, and avoiding using the screen saver. Slightly more of the control group than the intervention had already been in the habit of using their computers' sleep mode, turning off the printer when not in use, using a laptop, and turning off their computer when away for over an hour. But among the high-cost, high-effort (HI) behaviors, between 34\% and $41 \%$ of intervention respondents had already purchased energy-efficient appliances for their homes, compared to the control group (between $8 \%$ and $9 \%$ ).

Despite the fact that the intervention group and control groups did not differ statistically on the number of TPI behaviors they had previously adopted, the intervention group still managed to adopt behaviors ("Did it") at a higher rate than the control group (see fig. 5), primarily the LR behaviors. Unplugging unused or "off" appliances, raising the refrigerator and freezer temperatures, and turning off the computer if away more than an hour were the actions adopted by the highest percentage of respondents of the intervention communities, followed by making their refrigerators more energy efficient by ensuring that the coils were cleaned and air seals were airtight, and turning off the printer when not in use. However, of the HI behaviors, 7\% (four households) recycled their second refrigerators and $2 \%$ (one household) replaced their refrigerator with a more energy efficient model "because of the [intervention]." During this same time period, 8\% (one household) of the control started using their computer's sleep mode. 


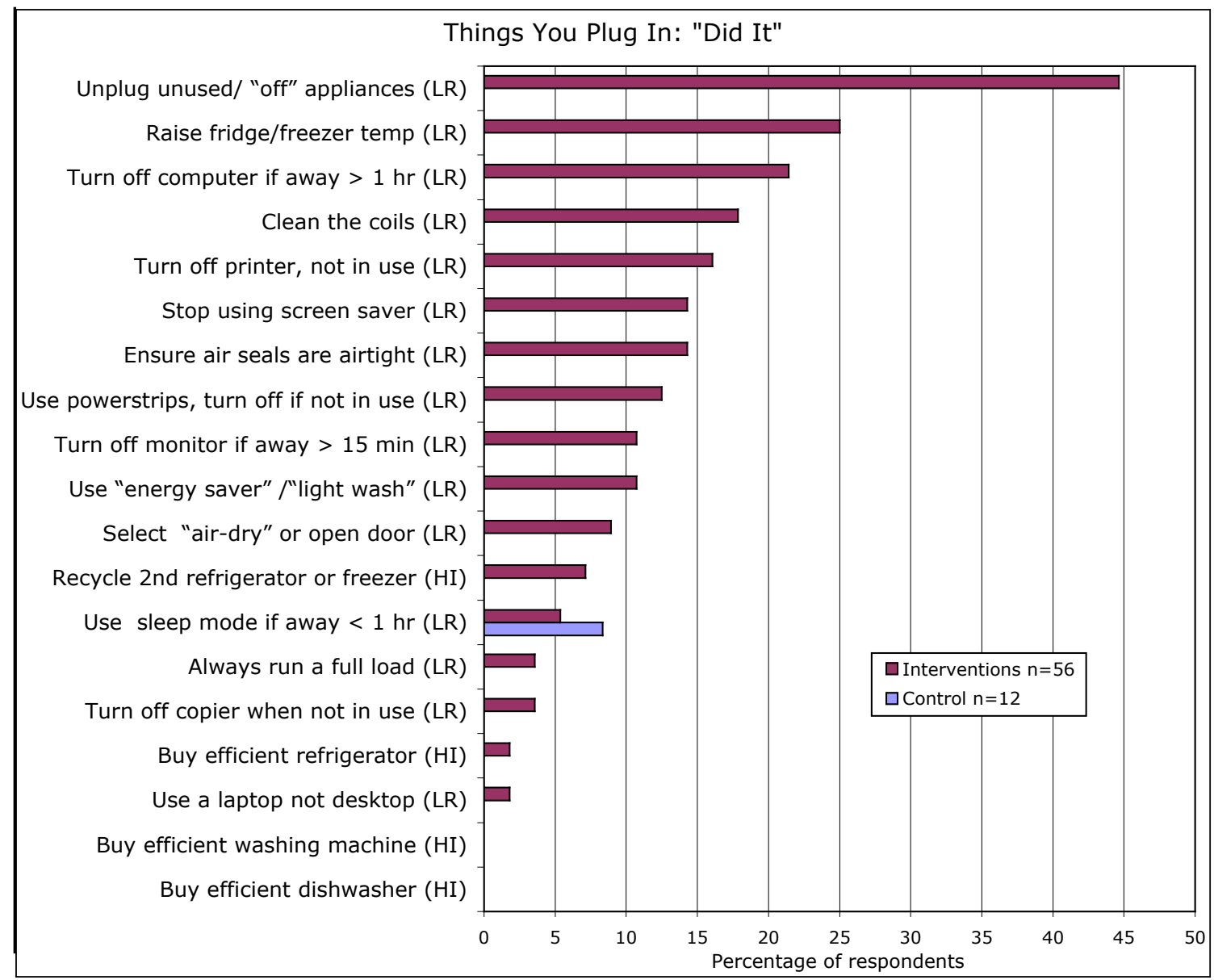

Figure 5. Comparison of the most adopted behaviors reported in the Things You Plug In Survey.

Overall, results show that while both groups had previously adopted many of the TPI behaviors previously, including many of HI behaviors presented, there was no difference in the amount of previously adopted behaviors between the two groups. The intervention group, however, did adopt significantly more new behaviors than the control, predominantly LR behaviors. The control group's behavior adoption rate was $0 \%$, the lowest adoption rate for any of the five surveys for either group. 


\section{Consumer Footprint Survey}

The Consumer Footprint (CF) Survey offered 25 questions about behaviors ranging from general consumer purchasing habits to waste and recycling practices. All of the behaviors presented were low investment, high-repeating behaviors (LR). This survey did not offer a "Not applicable" option (see fig. 6).

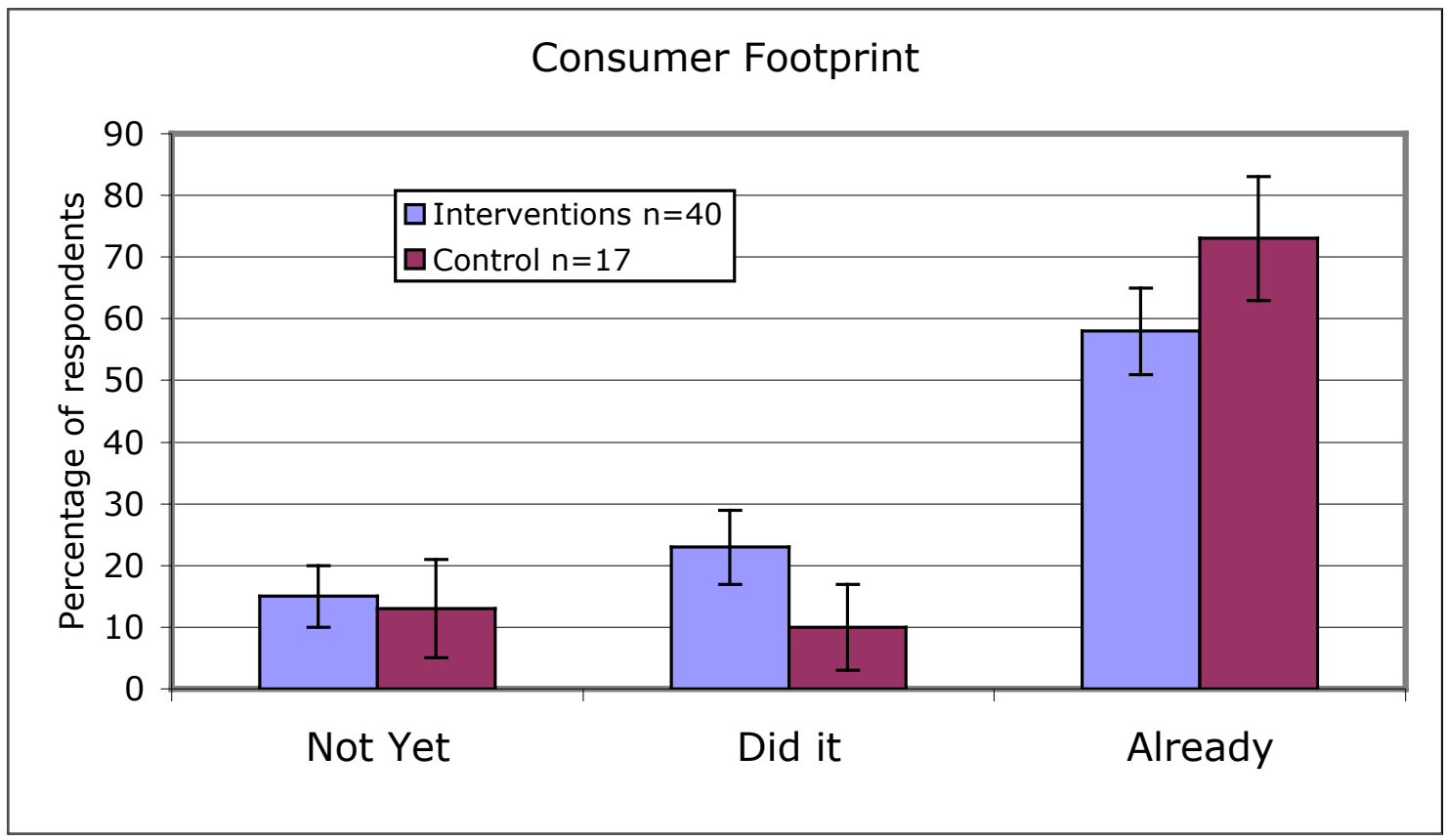

Figure 6. Comparison of Consumer Footprint Survey responses. Error bars indicate standard error of proportion.

Overall, the control group $(M=17.47, S D=3.69,73 \%$ of CF behaviors previously adopted) reported a $15 \%$ higher rate of behaviors that they were "Already" performing compared to the intervention group $(M=14.02, S D=5.13,58 \%$ of CF behaviors previously adopted), which was a significant difference, $t(55)=-2.50, p<.05$. Conversely, the intervention respondents $(M=5.40, S D=4.30,23 \%$ of CF behaviors newly adopted) reported adopting new behaviors ("Did it") at a rate that was $13 \%$ higher than that of the 
control group ( $M=2.35, S D=1.86,10 \%$ of $\mathrm{CF}$ behaviors newly adopted), which was also a significant difference, $t(55)=2.79, p<.05$. The intervention and control communities were fairly evenly matched (15\% and $13 \%$ respectively) in the proportion of behaviors that they were "Not yet" ready to adopt.

While the Consumer Footprint Survey is made up entirely of LR behaviors, the high rates of behaviors that had been previously adopted by both groups still tell an interesting story (see fig. 7). Namely, the pro-environmental attitudes observed in both groups were most clearly visible in regard to their households' consumption of the earth's resources. Recycling behaviors, long the behavioral focus of the environmental movement, were among the top behaviors already being practiced, followed by behaviors that avoided unnecessary consumption such as "use up your food," "use a personal waterbottle," "use less paper," and "precycling" (buy products with the least packaging). While the control group had a higher rate of respondents already buying in bulk, fixing broken items and shrinking their garbage, overall almost $50 \%$ or more of both groups reported that they had previously adopted 19 of the 23 behaviors presented on this survey. 


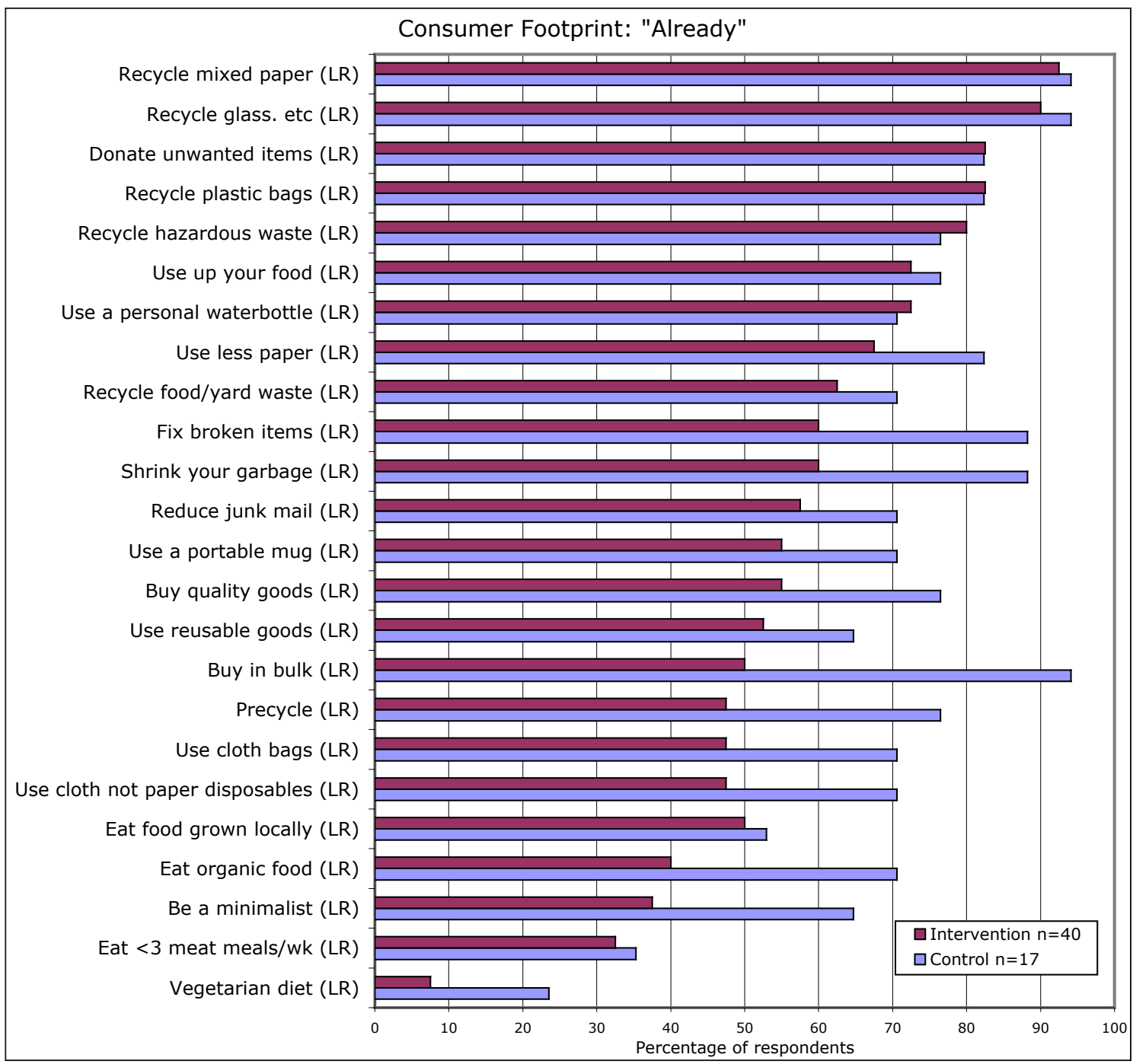

Figure 7. Comparison of previously adopted behaviors reported in the Consumer Footprint Survey.

\section{Since so many of the respondents had already adopted a majority of the $\mathrm{CF}$}

behaviors, the capacity to adopt new ones was relatively low (see fig. 8) for both groups, yet almost one quarter of the intervention households still managed to adopt some new behaviors compared to $10 \%$ of the control group. The top rated behavior "be a minimalist, buy only what you need" refers to a general commitment to reduce overall consumption. The next nine behaviors were more specific and were adopted by $30 \%$ or 
more of the intervention group, including using cloth bags instead of paper or plastic ones, buying quality goods that last, precycling, eating organic and locally produced foods, using cloth not paper disposables, and switching to reusable goods. The behaviors adopted most frequently by the control group were similar, though adopted at far lower rates, with the exception of eating locally produced food, which was adopted by $35 \%$ of this group.

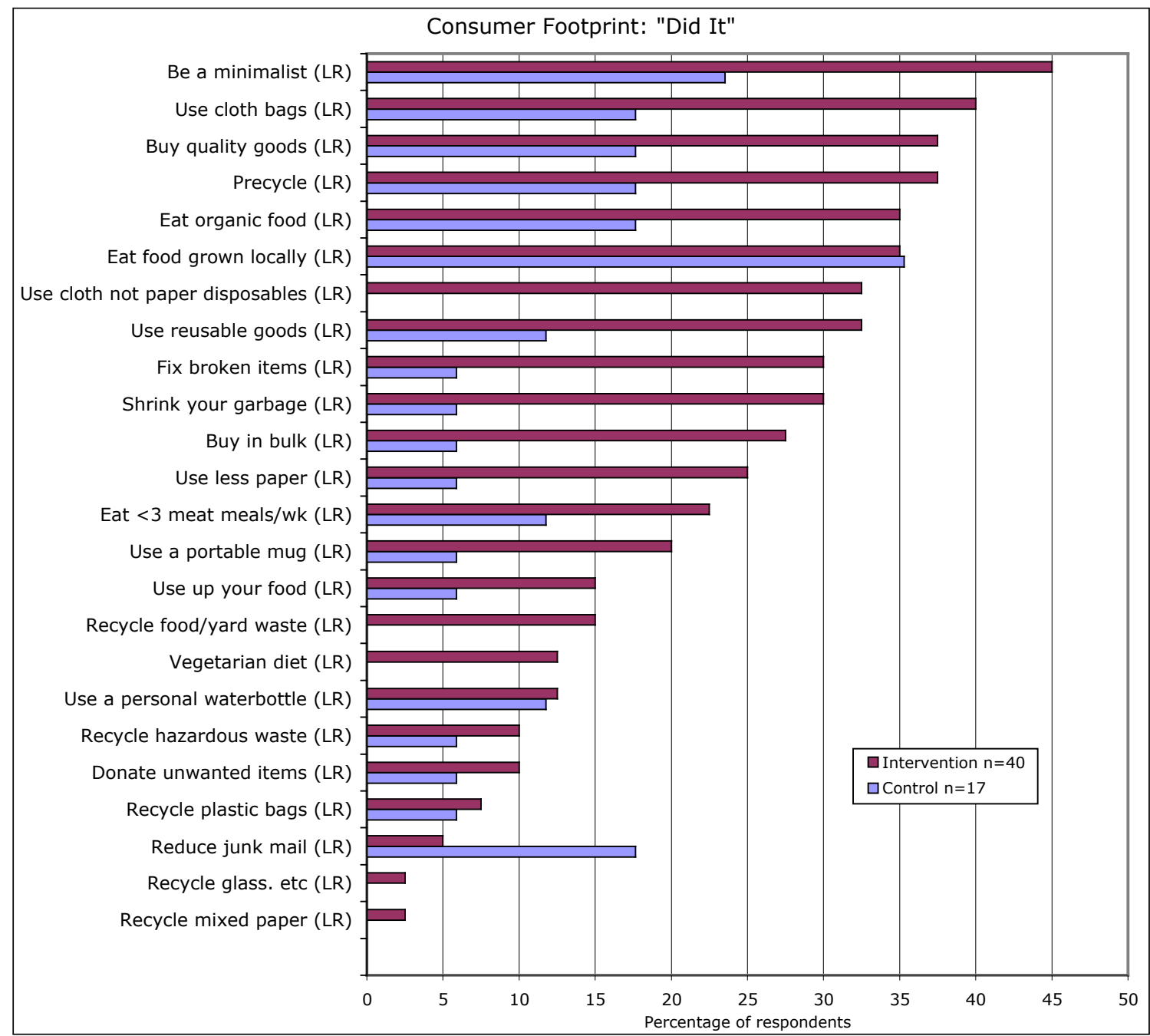

Figure 8. Comparison of the most adopted behaviors reported in the Consumer Footprint Survey. 
Overall, both groups reported not only the highest rate of newly adopted behaviors (intervention $23 \%$ and control $10 \%$ ), but the highest rate of previously adopted behaviors (intervention $58 \%$ and control $73 \%$ ) out of all five surveys, as well. Results showed that while the control group had previously adopted a higher number of CF behaviors, the intervention group adopted a higher number of behaviors as a result of the intervention.

\section{Winter Heat Survey}

The Winter Heat (WH) Survey was issued to communities at the height of winter weather to encourage the adoption of up to twelve behaviors, eight of which were HI behaviors, when participants were naturally more sensitive to the need to retain heat to stay warm and do so efficiently to keep costs low. As was seen in other surveys, there was no statistical difference between the intervention group's ( $M=5.01, S D=2.17,53 \%$ of WH behaviors previously adopted) reported rate of "Already" adopted behaviors compared to the control group's ( $M=6.30, S D=2.62,44 \%$ of WH behaviors previously adopted), $t(76)=-1.69, n s$, which means the two groups shared a baseline level of previously adopted behaviors (see fig. 9). But while the intervention group $(M=1.35$, $S D=1.42$ ) reported adopting $12 \%$ of the behaviors presented in this survey and the control group $(M=.5, S D=.85)$ reported adopting only $4 \%$ in the same time period, the difference between the rates of adoption of new behaviors was also not significant, $t(76)=1.84, n s$. It is noteworthy that the two groups' capacity for new behaviors was roughly matched at $20 \%$ ("Not yet"). 


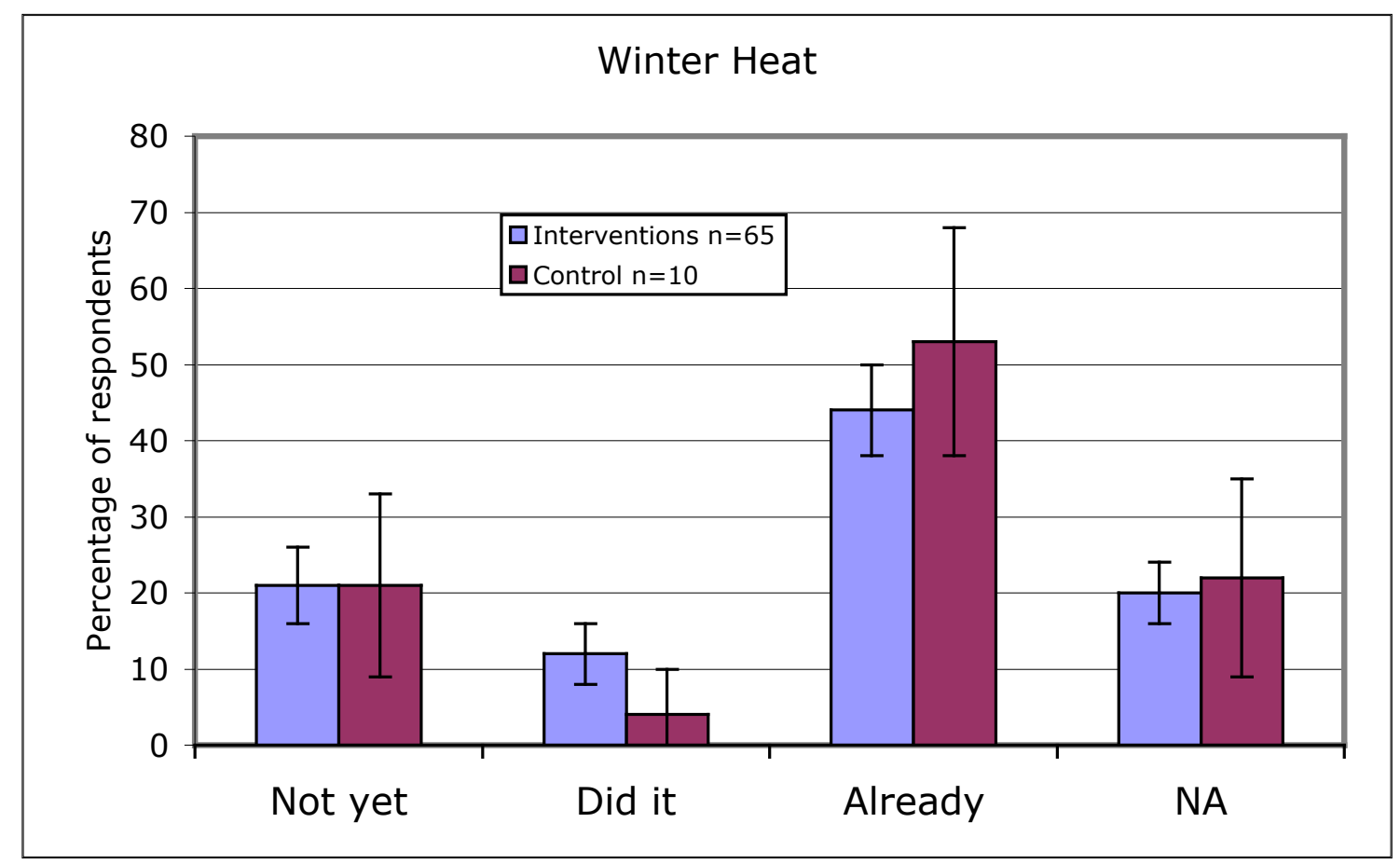

Figure 9. Comparison of Winter Heat Survey responses. Error bars indicate standard error of proportion.

The winter heat behaviors previously adopted by both groups (see fig. 10) were a mix of LR and HI behaviors. Of the eight HI behaviors introduced in this survey, $30 \%$ or more of respondents from both groups had previously done five of them. They had switched to CFLs (the top previously adopted behavior of the intervention respondents), installed a programmable thermostat, double pane windows, insulation and skylights, and caulked and weather stripped around windows and doorways to block air leaks. Of the LR behaviors, turning off the lights (the top previously adopted behavior of the control group), turning down the thermostat when away and using curtains to trap warm air indoors were previously adopted by roughly $50 \%$ or more of respondents from both groups. 


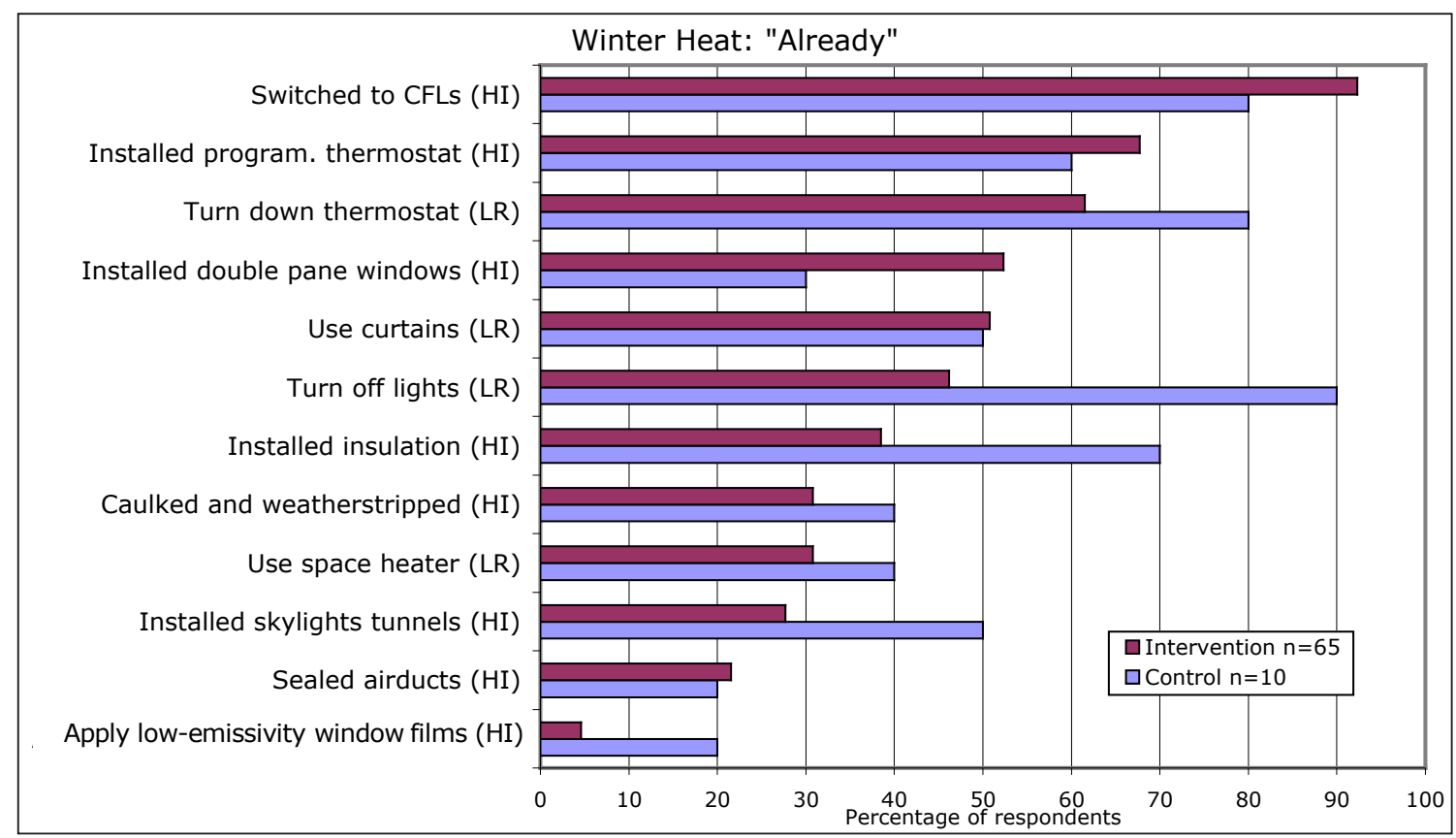

Figure 10. Comparison of the previously adopted behaviors reported in the Winter Heat Survey

Considering how many of the WH behaviors were already being practiced by both of these pro-environmental communities, as well as the relatively high number of HI behaviors there were to choose from, it's less surprising that the new behaviors most favored for adoption by the intervention group (see fig. 11) were LR behaviors that required the formation (or reinforcement) of daily habits instead of a financial investment. These included turning off lights, turning down the thermostat, using curtains to trap in winter heat, and using a space heater instead of turning up the thermostat. Despite the lack of statistical significance between the higher rate of adopted behaviors reported by the intervention than the control group, it should be noted that only one respondent (10\%) was responsible for adopting each of five of these same LR behaviors in this same time period. 


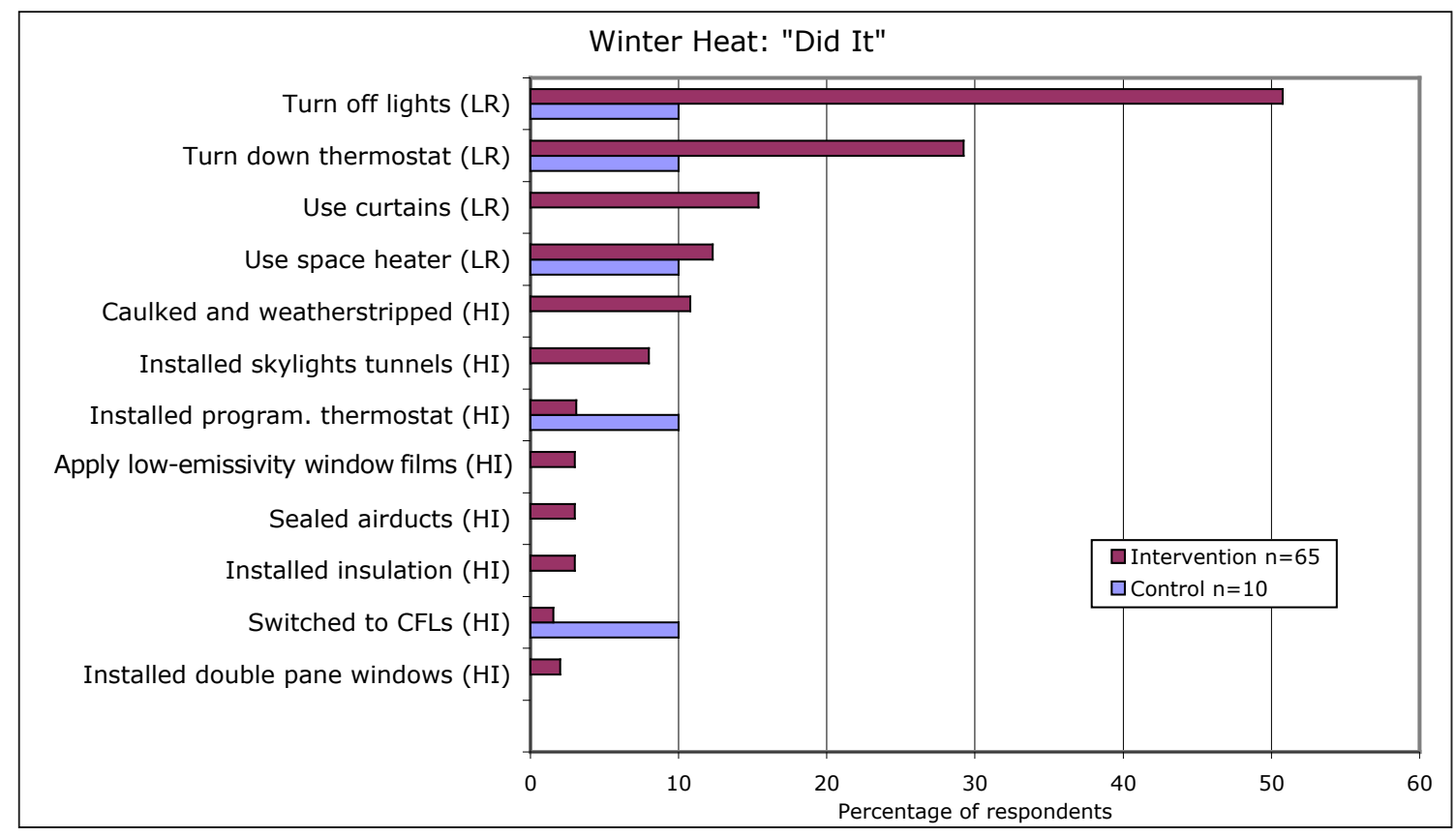

Figure 11. Comparison of the most adopted behaviors reported in the Winter Heat Survey.

Overall, the Winter Heat Survey results mimicked those seen in the other surveys. The pro-environmental attitudes of both the intervention and control groups was evident in the finding that they had "Already" adopted a similar amount (53\% and 44\% respectively) of winter heat behaviors, mostly comprised of the HI behaviors that dominated this survey. Perhaps as a result of the relatively high prior adoption rate, the Winter Heat Survey had one of the lowest rates of new behavior adoption for the intervention group among the five surveys, and indeed results showed that the intervention did not motivate a significantly higher number of adopted behaviors in the intervention group compared to the control, although the behaviors that they did adopt were primarily LR behaviors. 


\section{Hot Water Survey}

Similar to the Winter Heat Survey, the Hot Water (HW) Survey presented more HI than LR behaviors (see fig. 12) and each group reported that they had "Already" adopted roughly the same number of them. Neither the intervention $(M=4.34, S D=$ $1.81,35 \%$ of HW behaviors previously adopted $)$ nor the control group $(M=3.87, S D=$ $2.64,37 \%$ of HW behaviors previously adopted) reported a statistically different rate of prior behavior adoption compared to the other group, $t(52)=.63, n s$. However, the intervention group ( $M=1.69, S D=1.47,14 \%$ of $\mathrm{HW}$ behaviors newly adopted $)$ did adopt a significantly higher rate of behaviors than the control group $(M=.37, S D=.51$, $4 \%$ of HW behaviors newly adopted), $t(52)=2.49, p<.05$, reported during the same time period. This survey had the largest disparity in "Not applicable" responses, the control group reported that $35 \%$ of behaviors didn't apply to them compared to $20 \%$ reported by the intervention, and each community was "Not yet" ready to change about a quarter of the suggested hot water use behaviors at all.

Looking at the previously adopted HW behaviors (see fig. 13), I noted that, once again, the top behaviors were comprised of a mix of LR and HI behaviors. Both groups had upgraded their faucets and showerheads with aerators or low-flow adaptors, installed energy efficient water heaters or insulated their older one, set a lower water heater temperature and were in the habit of washing full loads of their clothes (the top action for the control group) in cold water. 


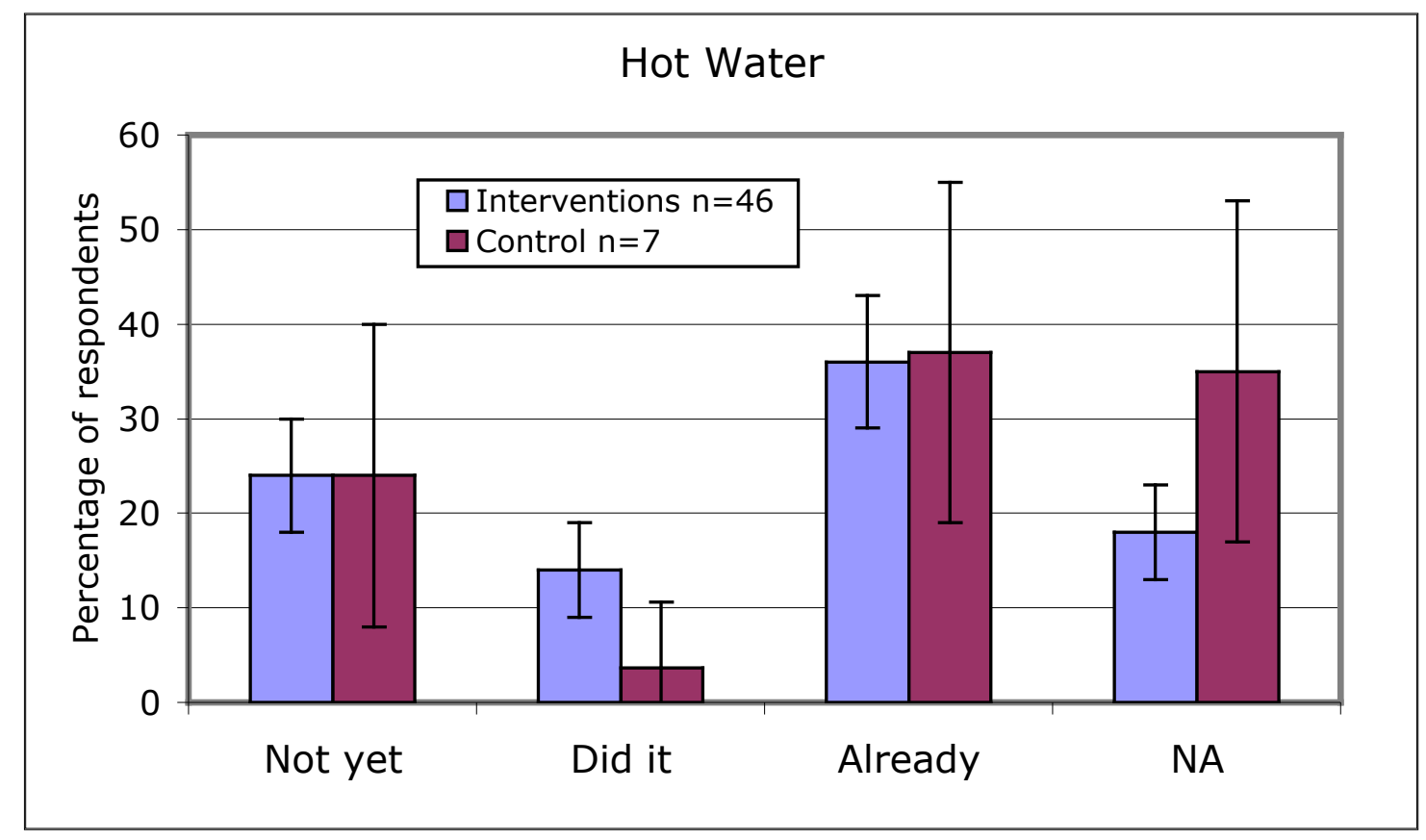

Figure 12. Comparison of Hot Water Survey responses. Error bars indicate standard error of proportion.

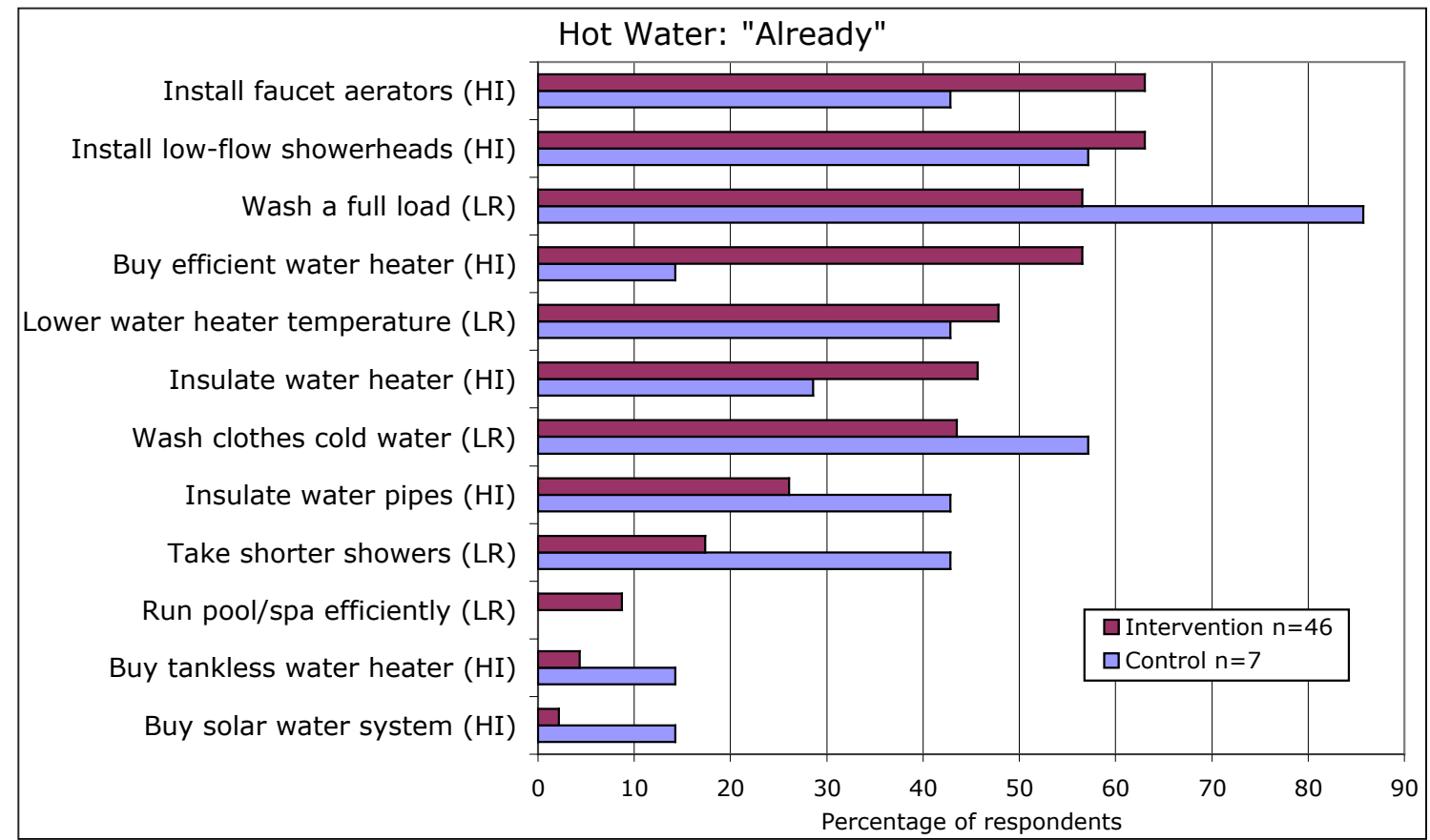

Figure 13. Comparison of previously adopted behaviors reported in the Hot Water Survey. 
The most heavily adopted new HW behaviors (see fig. 14) among the intervention respondents were taking shorter showers to cut down on hot water, followed by washing only full loads of laundry in cold water, and lowering their water heater temperature; all low investment, high repeating behaviors. However, in addition, (four intervention households) (8\%) went to the high expense of installing an energy efficient water heater, tankless water heater, or solar hot water system because of the intervention. For the control group one respondent (14\%) was responsible for the adoption of the following three behaviors in the same time period: lowering their water heater temperature, taking shorter showers, and purchasing a solar hot water system.

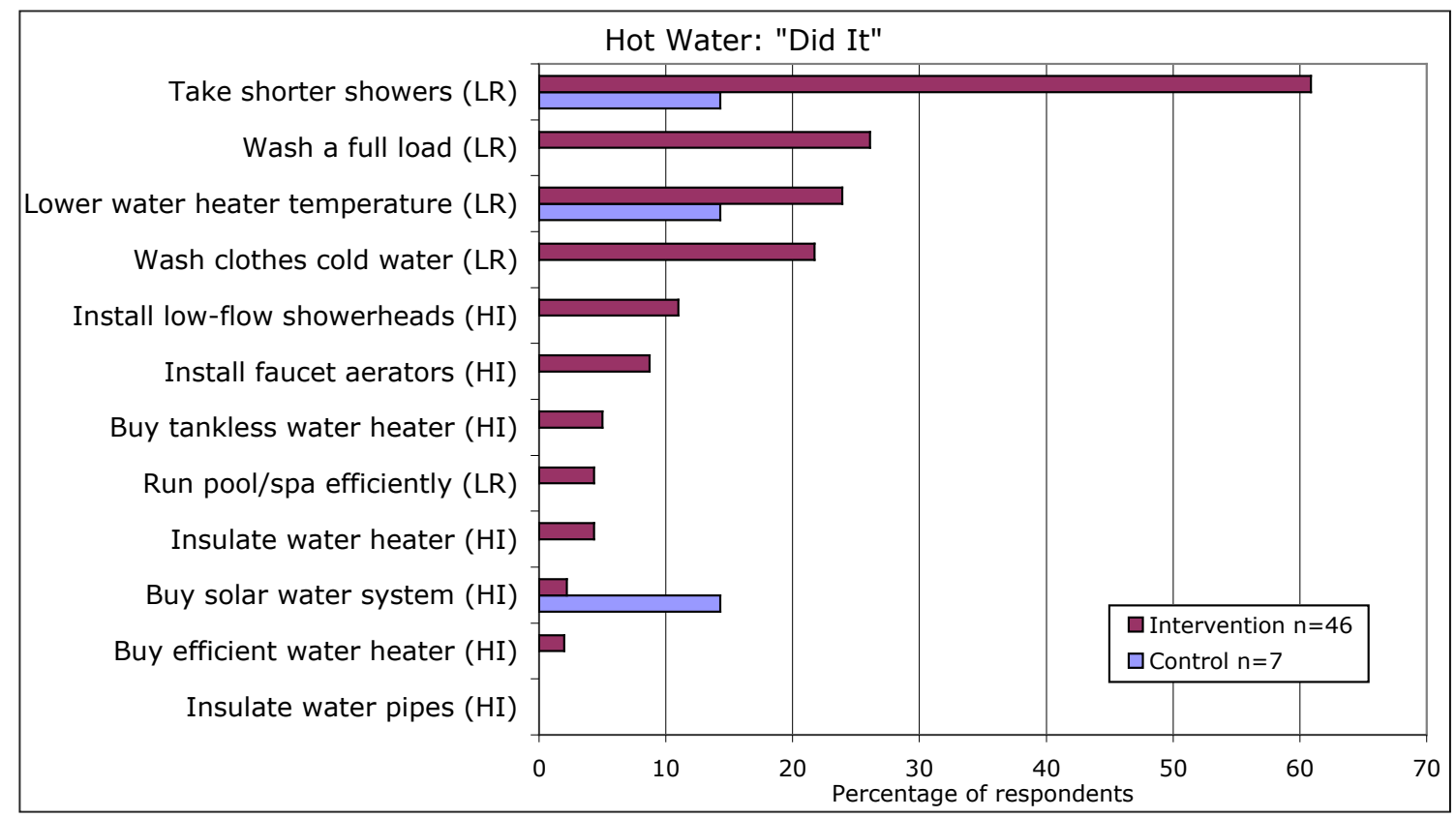

Figure 14. Comparison of the most adopted behaviors reported in the Hot Water Survey.

Overall, the results of the Hot Water Survey provided another example where the intervention and control groups shared a baseline of previously adopted behavior, yet the intervention group adopted a significantly higher number of new behaviors, indicating that 
the intervention was influential in this important regard. Four out of the seven HI behaviors presented in the Hot Water Survey had been previously adopted by both groups, which may have contributed to the very low rates of adoption of those same behaviors. As was seen in other survey results, the LR behaviors constituted the most popular adopted behaviors on this survey.

\section{Transportation Survey}

The Transportation (T) Survey addresses 19 of the most fossil-fuel intensive behaviors included in the intervention, and provides an interesting snapshot into the lengths that pro-environmental communities, such as those at the heart of this study, will go to avoid adding more $\mathrm{CO} 2$ emissions into the atmosphere. However, this survey also saw the smallest number of control group participants of all the surveys: only 3 people. A little over a third of respondents (see fig. 15) from the intervention $(M=6.70, S D=3.30,35 \%$ of T behaviors previously adopted $)$ and the control $(M=6.66, S D=1.15,38 \%$ of $\mathrm{T}$ behaviors previously adopted) were already practicing some of these behaviors, a difference in rates that was not significant, $t(42)=.02, n s$. However, unlike the results of three of the other surveys, the rate of newly adopted behaviors reported by the intervention $(M=2.80, S D=$ $3.01,15 \%$ of $\mathrm{T}$ behaviors newly adopted) was not significant in comparison to those reported by the control $(M=1.66, S D=2.08,5 \%$ of $\mathrm{T}$ behaviors newly adopted $)$ in the same time period, $t(42)=.63, n s$. Thirteen percent of the intervention and $17 \%$ of the control group remained "Not yet" willing to pursue new transportation behaviors. 


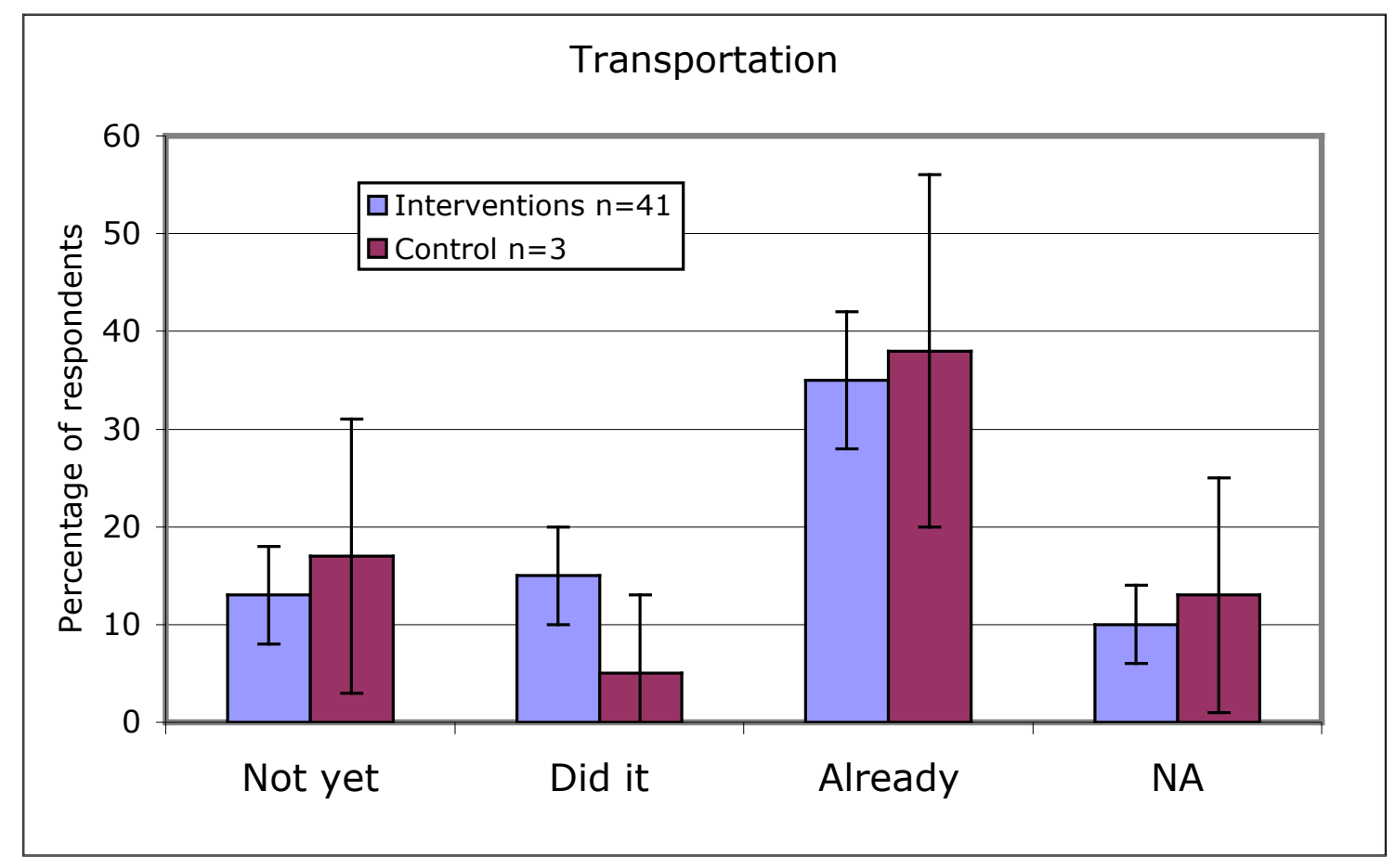

Figure 15. Comparison of Transportation Survey responses. Error bars indicate standard error or proportion.

The majority of the T behaviors presented in this survey were LR behaviors. However, out of three HI behaviors presented on this survey, keeping your car tuned had the highest rate of previously adopted behaviors for both groups (see fig. 16), while no one from either group reported having previously adopted either of the other two HI behaviors presented. The other top behaviors that had been previously adopted were frequenting nearby businesses and combining errands, avoiding idling their car, driving the household's most fuel-efficient car, keeping vehicle tires properly inflated to improve gas mileage, and conducting bank business on-line to avoid driving. In addition, the control group was already practicing shopping online and choosing slow-shipping to reduce fuel use. 


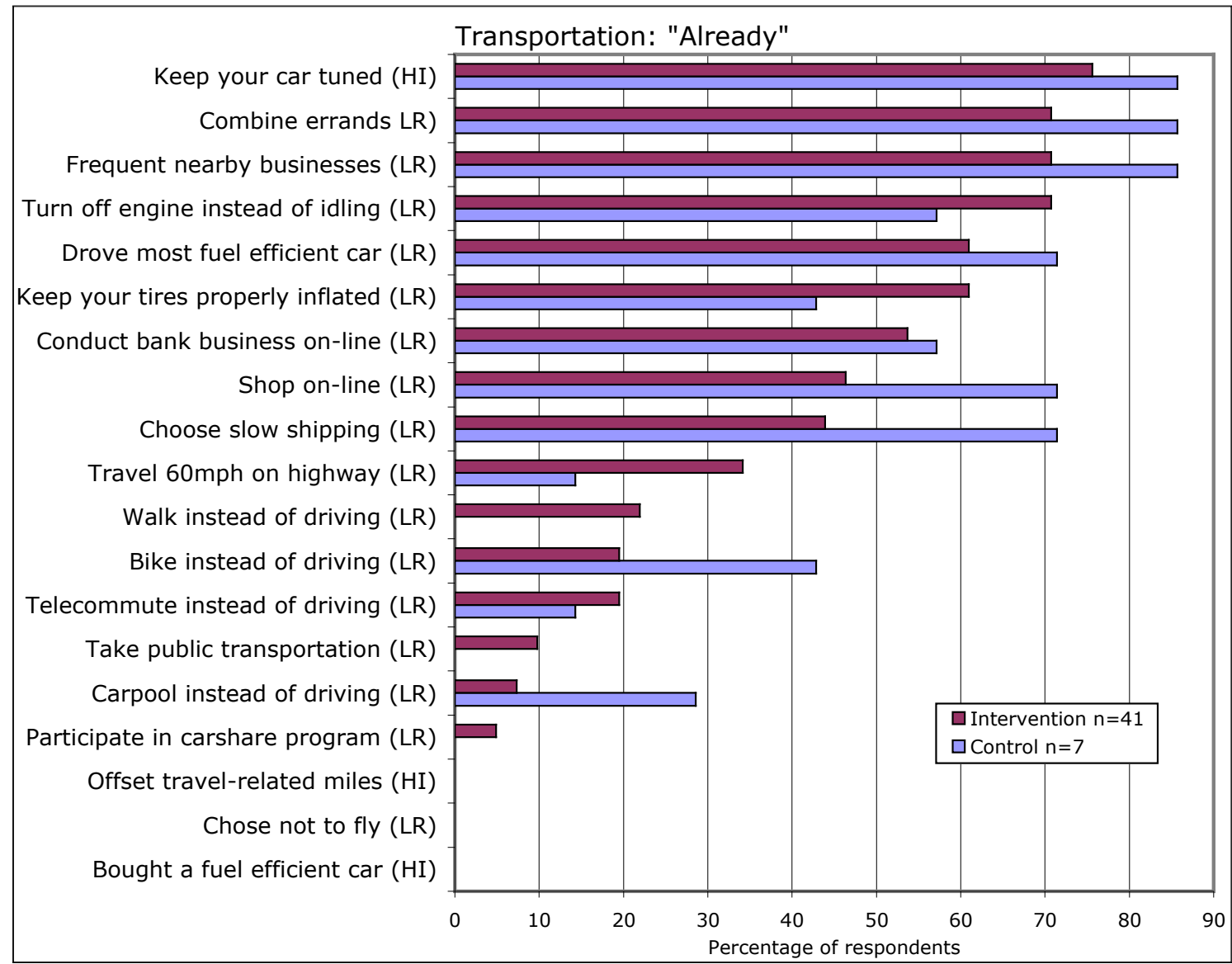

Figure 16. Comparison of previously adopted behaviors reported in the Transportation Survey.

Given the urgency of finding alternative forms of fossil fuel and the high visibility and high cost of fuel consumption, it is perhaps not surprising that the Transportation Survey saw the second highest percentage of behavior adoption of the five surveys for both groups. Low investment, high repeating behaviors such as keeping tires properly inflated, choosing slow shipping, banking online, combining errands, and frequenting nearby businesses and restaurants to reduce driving were the most popular new behaviors to adopt (see fig. 17). 


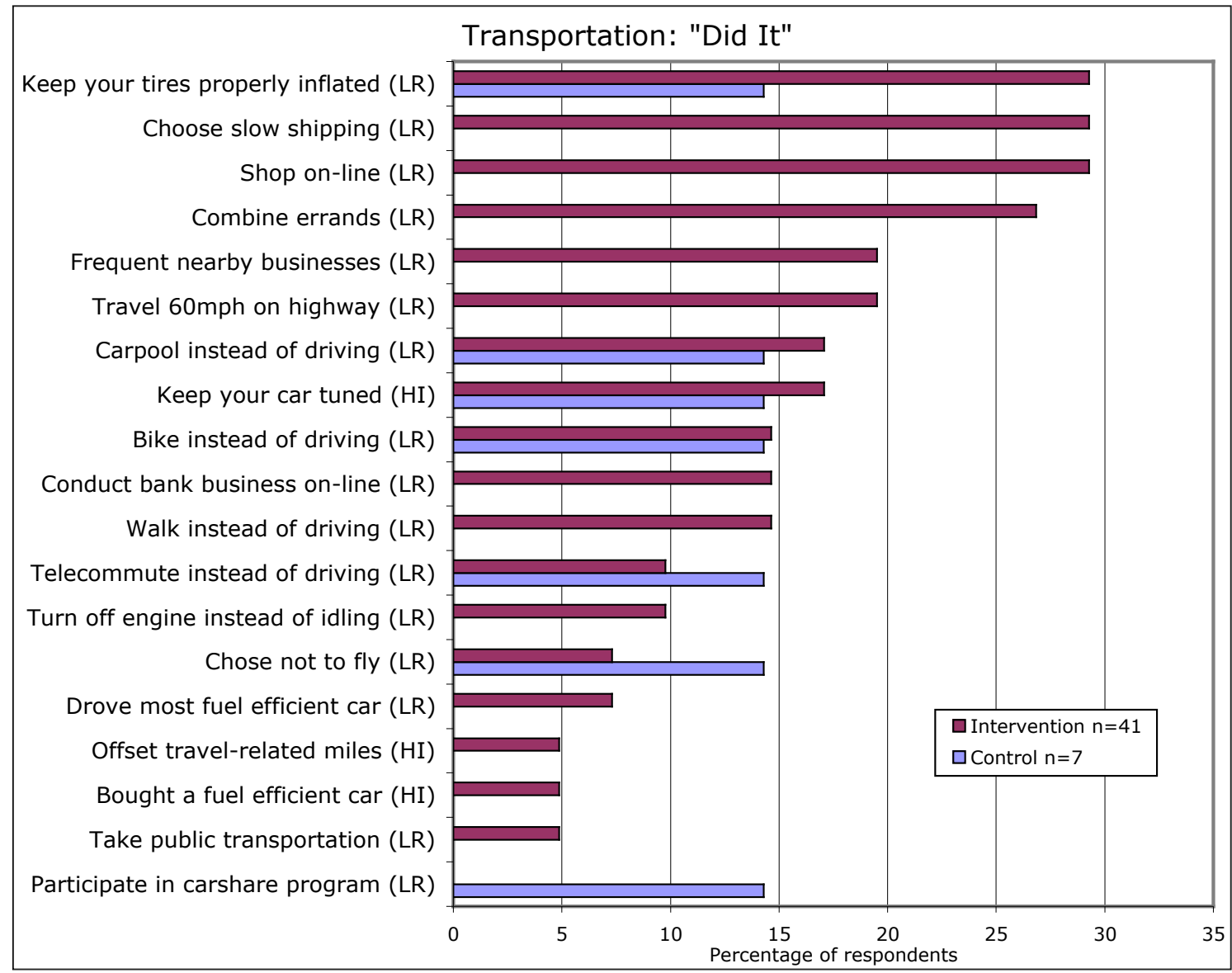

Figure 17. Comparison of the most adopted behaviors reported in the Transportation Survey.

The intervention also succeeded in motivating roughly $15 \%$ of survey respondents to carpool, bike, and walk instead of drive, whereas the control group had a single respondent adopt some of these behaviors in the same time period. However, where the Transportation Survey results were most surprising were the following three high investment behaviors that the intervention group adopted as a result of the intervention: three households $(7 \%)$ altered their travel plans to avoid flying, two households $(5 \%)$ chose to purchase carbon offsets for their travel-related miles and most impressive of all, two households (5\%) purchased new fuel efficient cars (hybrids in both cases). 
Overall, the Transportation Survey results showed that there was no statistical difference in either the rate of previously adopted behaviors or newly adopted behaviors, indicating that the intervention did not effectively motivate participants to adopt new behaviors more than they perhaps would have without the intervention, although the ability to detect significance may have been hindered by the very small sample size of the control group. The notable exception to the finding of no significant difference in adopted behaviors is that two households purchased energy-efficient vehicles as a result of the intervention. Considering the high cost and effort required to purchase a new vehicle, the significance of motivating two households to adopt this behavior should not be understated, despite the overall lack of significance in the higher rate of adopted behaviors for this survey. The type of new behaviors adopted most frequently were LR behaviors, a trend supported by the results of the other surveys.

Altogether, intervention respondents reported that they had previously adopted $43 \%$ of all behaviors presented in the five surveys, and managed to adopt $15 \%$ of the new behaviors because of the intervention. In contrast, control respondents reported having previously adopted $53 \%$ of the behaviors presented in the five surveys, but only adopted $6 \%$ of the new behaviors during the same time period.

In the two-year period prior to this study, the three pilot study communities participated in campaigns identical to the intervention described in this study. Their combined response rates to the five surveys were strikingly similar to those found in the intervention group (table 6). Differences occurred in three surveys where the intervention group reported a higher rate of behaviors that were "Not applicable" than the 
three pilot study communities, and for all surveys the pilot study communities reported a higher rate of behaviors they were "Not yet" willing to adopt. But the most important comparison is of the "Already" and "Did it" response rates for both groups, which for all but three surveys, were within three percent of each other.

Table 6. Comparison of average percent of endorsement, by response type, for the intervention group and 3 pilot study communities who also underwent the intervention.

\begin{tabular}{|c|c|c|c|c|c|}
\hline \multirow[b]{2}{*}{ Survey } & \multirow[b]{2}{*}{ Group (n) } & \multicolumn{4}{|c|}{$\begin{array}{l}\text { Average } \% \text { of endorsement } \\
\text { by response type (standard error) }\end{array}$} \\
\hline & & Not yet & Did it & Already & NA \\
\hline \multirow[t]{2}{*}{ Things You Plug In } & Intervention $(n=56)$ & $21( \pm 5)$ & $12( \pm 4)$ & $38( \pm 6)$ & $18( \pm 5)$ \\
\hline & 3 Pilot Groups $(n=117)$ & $29( \pm 4)$ & $14( \pm 3)$ & $37( \pm 4)$ & $9( \pm 2)$ \\
\hline \multirow[t]{2}{*}{ Consumer Footprint } & Intervention $(n=40)$ & $15( \pm 5)$ & $23( \pm 6)$ & $58( \pm 7)$ & $\ldots$ \\
\hline & 3 Pilot Groups $(n=39)$ & $18( \pm 6)$ & $20( \pm 6)$ & $57( \pm 7)$ & $\ldots$ \\
\hline \multirow[t]{2}{*}{ Winter Heat } & Intervention $(n=65)$ & $21( \pm 5)$ & $12( \pm 4)$ & $44( \pm 6)$ & $20( \pm 4)$ \\
\hline & 3 Pilot Groups $(n=156)$ & $29( \pm 3)$ & $10( \pm 2)$ & $46( \pm 3)$ & $6( \pm 1)$ \\
\hline \multirow[t]{2}{*}{ Hot Water } & Intervention $(n=46)$ & $24( \pm 6)$ & $14( \pm 5)$ & $36( \pm 7)$ & $18( \pm 5)$ \\
\hline & 3 Pilot Groups $(n=96)$ & $35( \pm 4)$ & $9( \pm 2)$ & $33( \pm 4)$ & $12( \pm 3)$ \\
\hline \multirow[t]{2}{*}{ Transportation } & Intervention $(n=41)$ & $13( \pm 5)$ & $15( \pm 5)$ & $35( \pm 7)$ & $10( \pm 4)$ \\
\hline & 2 Pilot Groups ${ }^{\mathrm{a}}(n=28)$ & $14( \pm 6)$ & $11( \pm 5)$ & $45( \pm 9)$ & $15( \pm 6)$ \\
\hline
\end{tabular}

Note: The Consumer Footprint Survey did not offer the "Not applicable" response option.

${ }^{a}$ The Transportation Survey was not administered to the Workplace Pilot Group.

\section{Behavior Trends Across Surveys}

Looking across all five surveys at behavior adoption trends, the top 25 behaviors adopted because of the intervention by at least $10 \%$ of households (see fig. 18) were lowinvestment, high repeating behaviors. This was primarily explained by the fact that most HI behaviors had been previously adopted by a large portion of the respondents. As a result, when there was capacity in some households to adopt HI behaviors, only a few households in the intervention group needed to do so (17\% kept their car tuned, $11 \%$ caulked and weather stripped and installed low-flow showerheads). However, buying 
major appliances $(5 \%)$ or a new automobile $(5 \%)$, while adopted at low rates overall, were high impact actions because they helped those households achieve significant energy savings compared to most other behaviors.

Looking at the top 25 adopted behaviors by the three pilot study communities (see fig. 19) all but two of them were LR behaviors ("switched to CFLs" [19\%] and "offset travel-related miles" [10\%, not displayed]), similar to the trend seen in the intervention group. The behaviors adopted at a $30 \%$ or higher rate by both communities were "be a minimalist," "turn off lights when away," "eat food grown locally," and "unplug unused or off appliances." The remaining behaviors that rounded out this category for both groups differed. The intervention's top behavior was "take shorter showers," and the other behaviors that were adopted at a rate of $30 \%$ or higher were "use cloth bags," "buy quality goods," "precycle," "buy organic food," "use cloth, not paper disposables," and "use reusable goods," all of which fell lower on the list of behaviors adopted by the three pilot study communities. For that group "use less paper," "combine errands," "use up your food," and "reduce junk mail" were adopted at 30\% or higher rates than in the intervention group. 


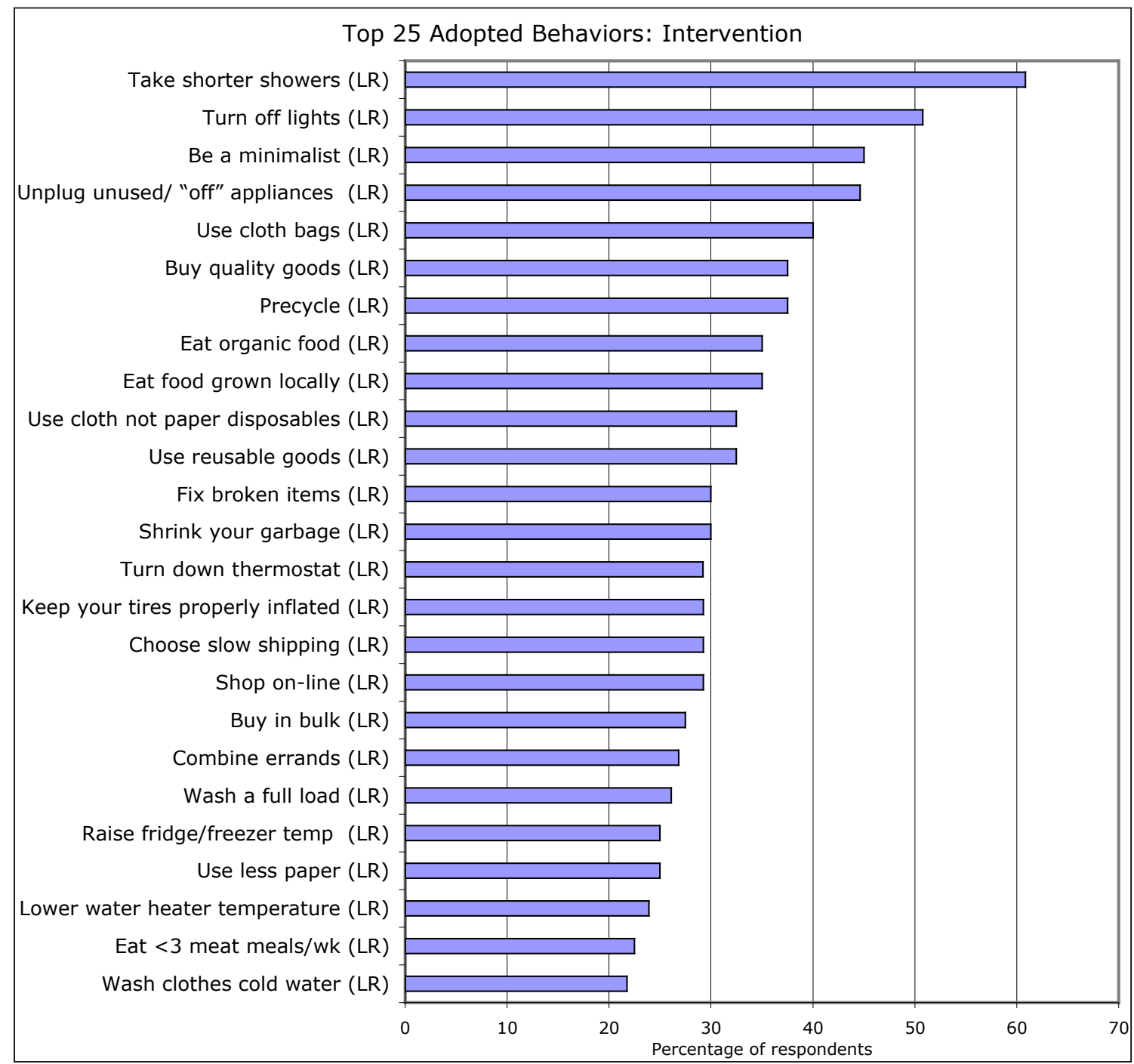

Figure 18. Top 25 newly adopted behaviors by the intervention group, by percentage of respondents. 


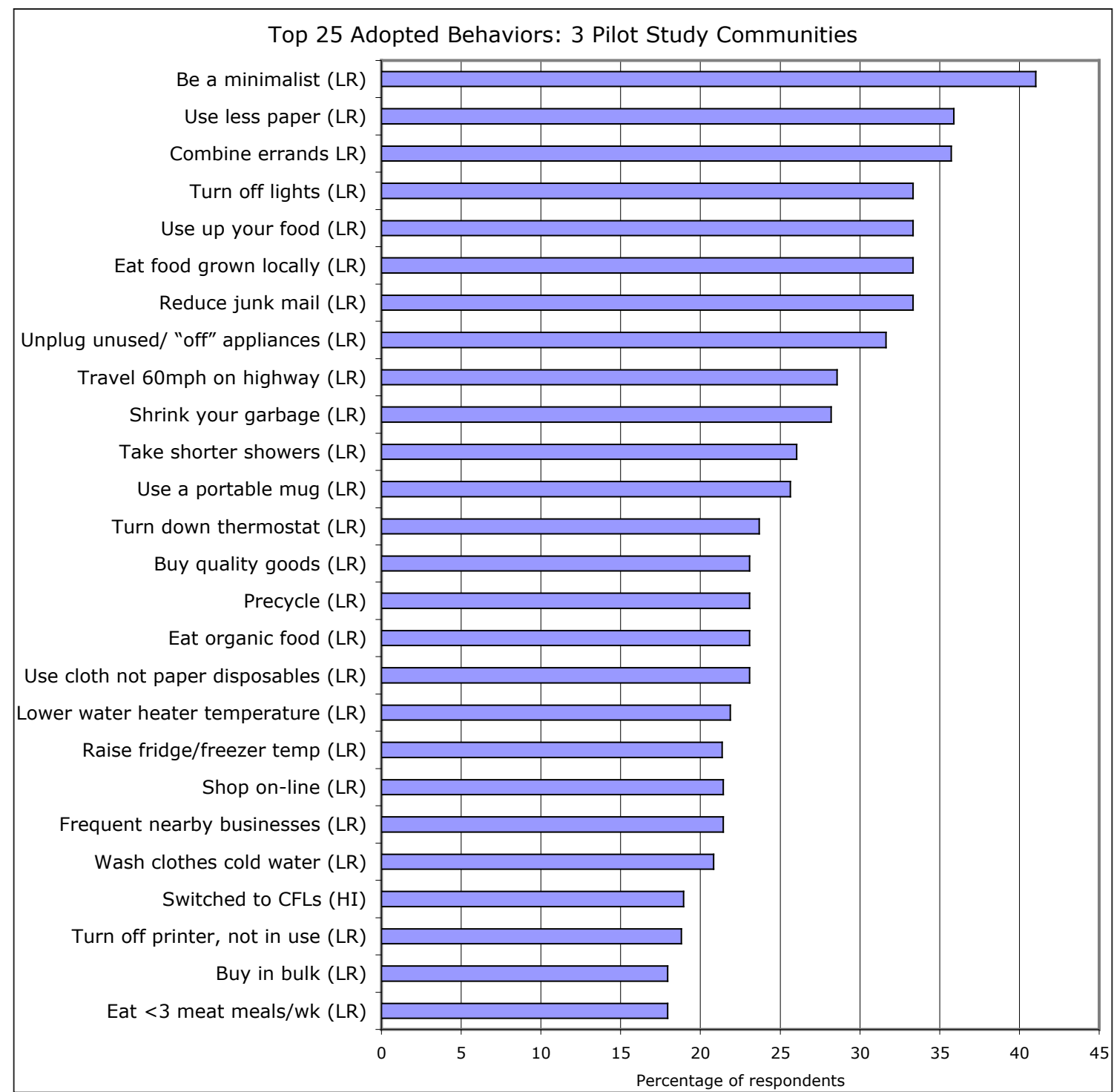

Figure 19. Top 25 newly adopted behaviors because of the intervention by 3 pilot study communities.

As far as the three HI behaviors on the intervention group's adopted behaviors list, "keeping your car tuned," "installed low-flow showerheads," and "caulked and weather stripped," were each adopted at rates too low to be included on the top thirty list for the three pilot study communities. Conversely, the three pilot study communities had a higher rate of switching to CFLs and purchasing carbon offsets than was seen for the 
intervention. As was true for the intervention group, the campaign did influence one household in one of the school communities to purchase two fuel-efficient vehicles for one household, a significant impact. Overall, while the behaviors adopted by the three communities who participated in a campaign within the last two years occupied slightly different places when put in descending order of participation rates, they were mostly similar to the behaviors adopted by the intervention group.

\section{LASTING EFFECTS ON BEHAVIORS}

The Follow Up Survey was taken by a very small self-selected sample of intervention and control group participants, and therefore it is difficult to do more than speculate whether responses from the eleven intervention respondents and seven control respondents may or may not have been representative of their groups' responses. While it is therefore not possible to make any conclusive statements about what the results showed, the survey responses did seem to indicate that the intervention had a lasting effect on behaviors adopted during the intervention (see fig. 20). The eleven intervention survey respondents $(M=13.45, S D=4.88)$ reported they had maintained $59 \%$ of 23 specific behaviors they had adopted during the intervention compared to $47 \%$ of the seven control group respondents $(M=9.5, S D=4.5)$, which was not, however, a significant difference, $t(17)=1.79, n s$. 

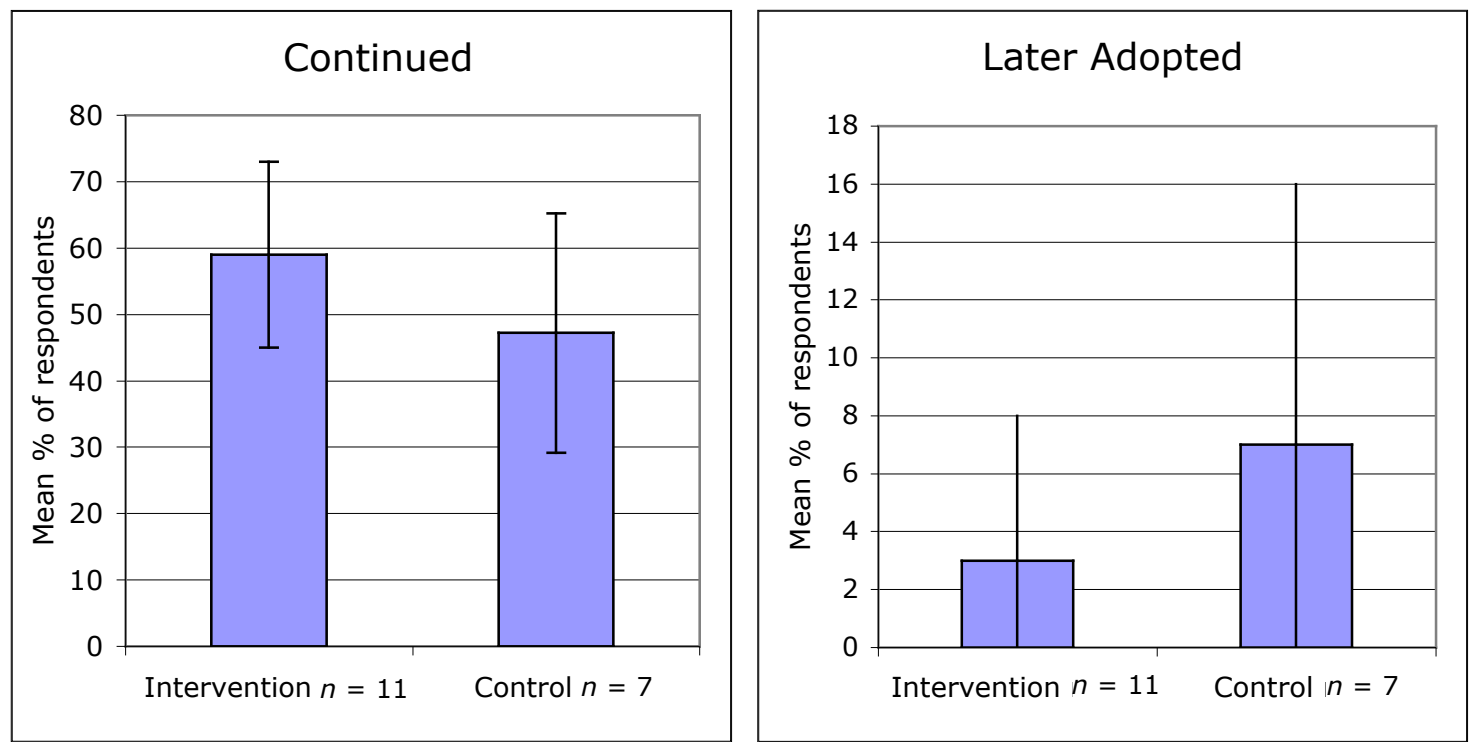

Figure 20. Left, Comparison of the mean rank of continued behaviors seven months post-intervention and post-study; right, Behaviors adopted seven months post-intervention/study. Error bars indicate standard error of proportion.

In terms of adopting new energy-reducing habits post-intervention and post-study, intervention survey respondents $(M=.72, S D=1.79)$ reported adopting only $3 \%$ of them compared to $7 \%$ of the control group $(M=1.5, S D=1.6)$, which is also not a significant difference, $t(17)=-.96, n s$. While the results do not show a significant difference in response rates for the two groups, the purpose of the survey was to establish whether intervention participants continued behaviors adopted during the intervention, and they did maintain a large proportion of them. It is interesting to find that the control group's behaviors had durability as well, and that, moreover, this group had a slightly higher rate of adoption of new behaviors post-study than did intervention participants, especially considering that they were operating as individuals, in isolation from one another. 


\section{COMMUNITY INFLUENCE}

\section{Participation Rates}

One of the important questions this study seeks to answer is whether uniting a community around climate change actually increased individual community members' interest in participating in the intervention. Results showed that $40 \%$ of intervention households (see fig. 21) pledged to participate in their community's campaign to reduce home energy use, compared to $16 \%$ of the control group households who took the first monthly survey, which served as a proxy for participating in the pledge. Due to the small sample size of the control group, a test of the difference of proportion reveals that the higher participation rate of the intervention group compared to the control approaches but is not significant, and therefore interpretation should be made with caution. These results seem to support that it was the community-lead nature of the intervention, specifically the launch and pledge opportunity that was responsible for the higher participation rate. 


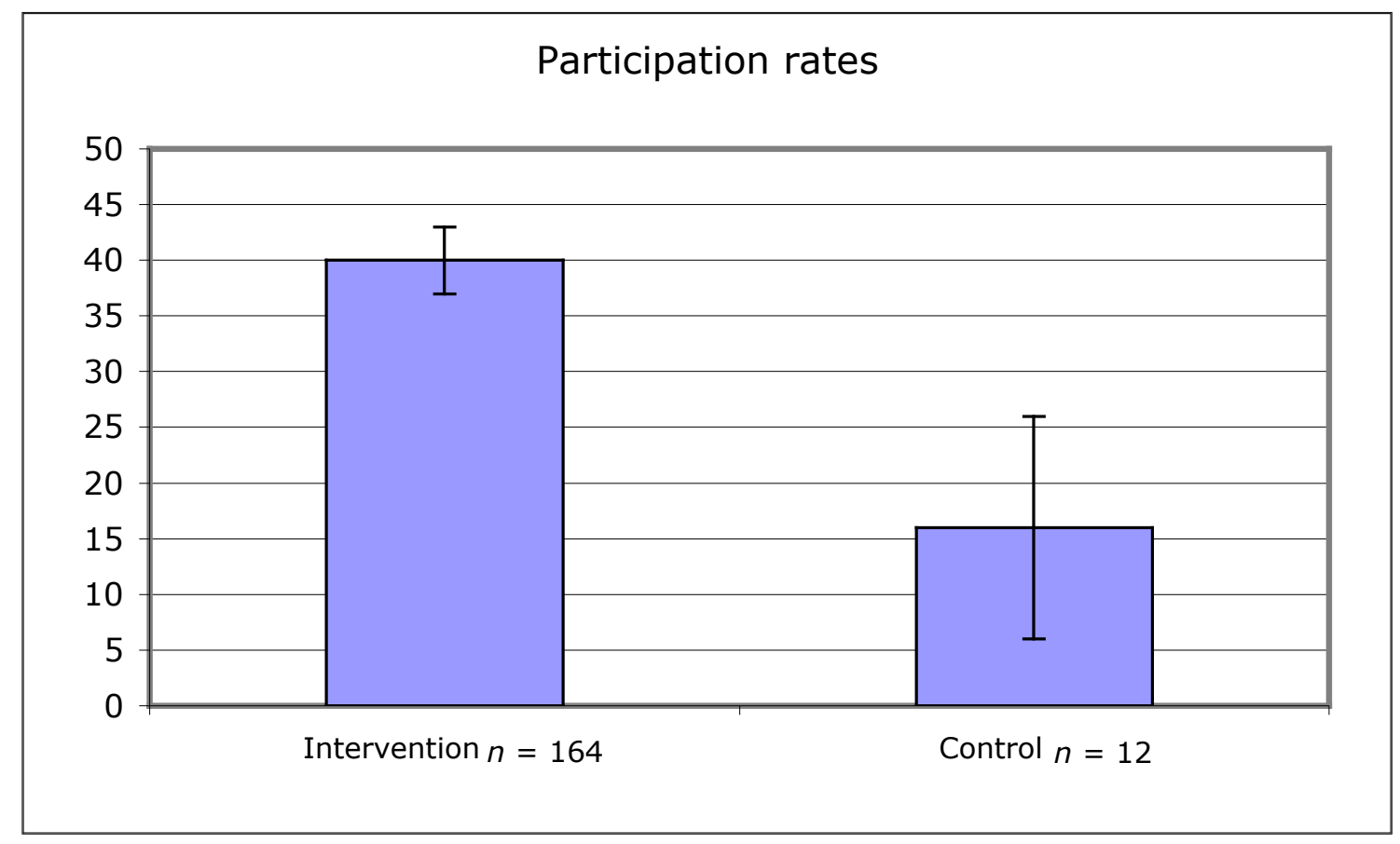

Figure 21. Comparison of pledge participation rates. Error bars indicate standard error of proportion.

The ability of the intervention communities to maintain participation in the program over its five-month period, as measured by their participation in the five monthly surveys, provided another measure of the important role that community support can play. It was expected that survey fatigue might impact the rate of survey participation over the duration of the intervention, and indeed the trend for both communities was a decline in participation rates overall (see fig. 22), with the following two exceptions: the participation rate for the intervention rebounded slightly for the final survey, and the control group's survey participation surged for the second survey before declining for the remaining surveys. While the intervention survey participation rates were consistently higher than the control group participation rates, a test of the difference of proportion for each survey determined that only the first survey had a significant 
difference in participation rates. The difference in rates for the remaining four surveys was not significant.

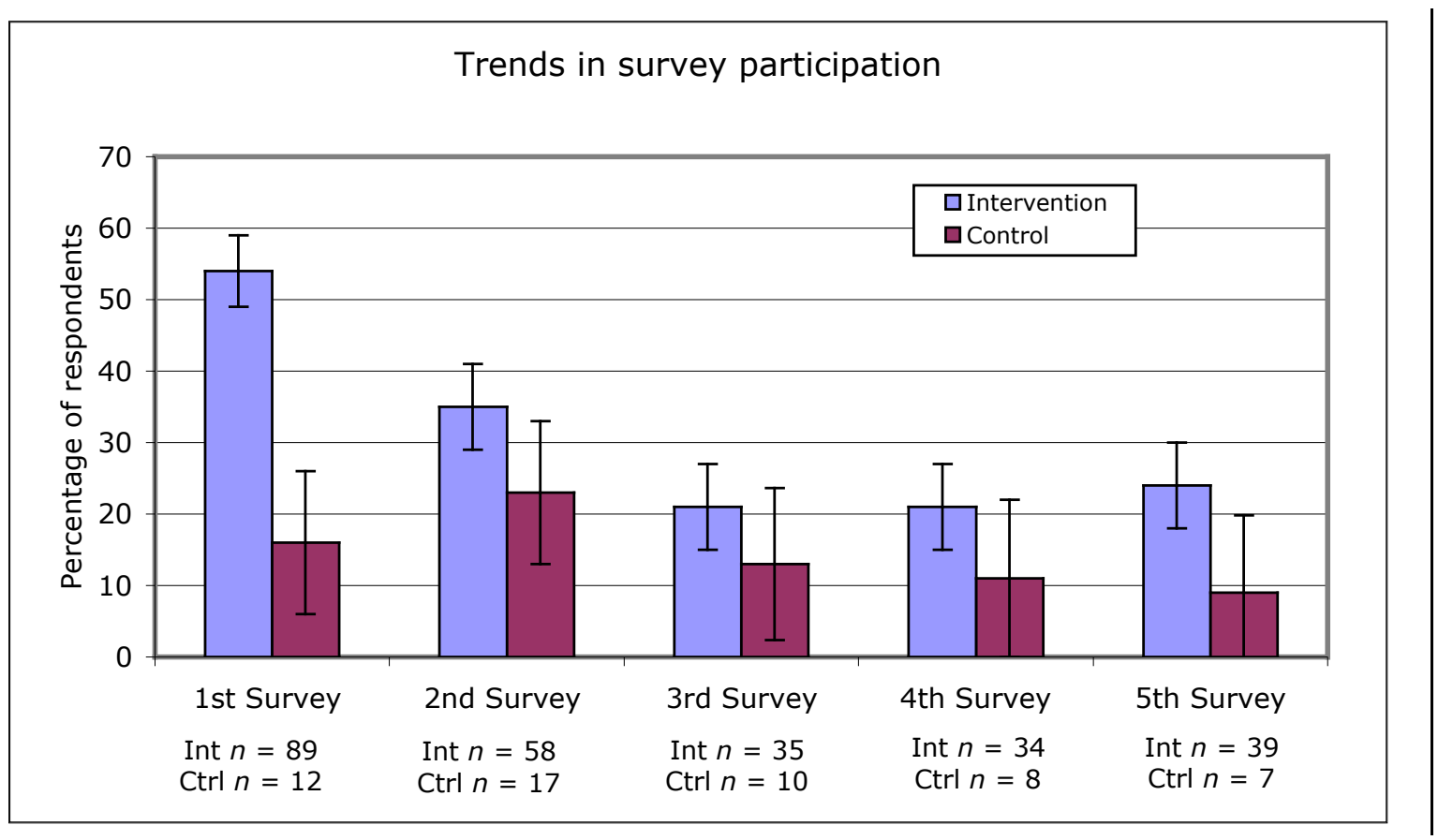

Figure 22. Comparison of survey response trends over five monthly surveys. The intervention survey participation rate was calculated using total number of pledged households. The control survey participation rate was calculated using total number of households that took the first month's survey. Error bars indicate standard error of proportion.

The participation rates and trends among the three other communities (table 7) who underwent the intervention prior to this study showed similar patterns. The mean pledge participation rate was $42 \%$, just slightly higher than the rate found for the intervention case studies. The mean survey participation rates for the three pilot study communities were $29 \%$, only slightly lower than that found for the intervention groups. The survey participation trends mirror the patterns of declining rates over time seen in the case studies, as well. 
Table 7. Participation rates for three pilot study intervention communities

\begin{tabular}{|c|c|c|c|c|c|c|c|}
\hline \multirow[b]{2}{*}{ Community } & \multirow[b]{2}{*}{$\begin{array}{l}\% \text { of pledge } \\
\text { participation }\end{array}$} & \multicolumn{5}{|c|}{ As $\%$ of survey participation } & \multirow[b]{2}{*}{$\begin{array}{c}\text { Mean } \% \text { of } \\
\text { participation in } \\
\text { the five surveys }\end{array}$} \\
\hline & & $\begin{array}{c}1^{\text {st }} \\
\text { survey }\end{array}$ & $\begin{array}{c}2^{\text {nd }} \\
\text { survey }\end{array}$ & $\begin{array}{c}3^{\text {rd }} \\
\text { survey }\end{array}$ & $\begin{array}{c}4^{\text {th }} \\
\text { survey }\end{array}$ & $\begin{array}{c}5^{\text {th }} \\
\text { survey }\end{array}$ & \\
\hline School 1 & 75 & 36 & 21 & 30 & 30 & 14 & 26 \\
\hline School 2 & 29 & 36 & 17 & 21 & 20 & 10 & 21 \\
\hline Workplace & 23 & 62 & 47 & 22 & $\ldots$ & 29 & 40 \\
\hline $\begin{array}{l}\text { Mean of Pilot } \\
\text { Study Groups }\end{array}$ & 42 & 45 & 28 & 24 & 25 & 18 & 29 \\
\hline Intervention & 40 & 54 & 35 & 21 & 21 & 24 & 31 \\
\hline
\end{tabular}

Note: The Workplace community did not participate in the 4th survey.

\section{Follow Up Survey}

To measure the motivational impact of the community-based nature of the campaign, I looked at the average rating on a 5-point Likert scale $(1=$ not at all motivated by this to $5=$ extremely motivated by this) that respondents gave for Follow Up Survey questions that explicitly asked about this issue. In response to the question "How much did your [community's campaign][participation in the study] motivate you to change your habits to reduce your home energy use?" $65 \%$ of intervention respondents reported being very or extremely motivated by this (see fig. 23) while the remaining $37 \%$ reported being neutral, pulling the average ranking down to 3.73 overall $(S D=.65)$. In comparison, the control group gave a $3.0(S D=1)$, or neutral, rating to the same question, mostly because there was an even split between those that felt the study was not very motivating and those who felt it was very motivating. The difference between the two responses was not significant $(t(16)=1.88, n s)$. Interestingly, when the previous question was rephrased as "How much did the knowledge that [your community was 
united in a campaign to reduce their energy use][friends and/or family members have begun reducing their energy use] motivate you to change your energy habits" (see fig. $24), 45 \%$ of intervention respondents rated this as very or extremely motivating, $36 \%$ were neutral, and $18 \%$ rated it as not very motivating. Altogether this produced a slightly less motivating average of $3.45 \%(S D=1.03)$. Yet this average rating was significantly higher than the average rating of $2.43(S D=.78)$ given by the control group respondents $(t(16)=2.23, p<.05)$.

The intervention respondents also gave "knowledge that reducing energy use has been gaining popularity around the country" an average rating of $3.45(S D=1.21)$ which was not significantly higher than the $2.86(S D=.69)$ average rating given by the control group $(t(16)=1.18, n s)$.

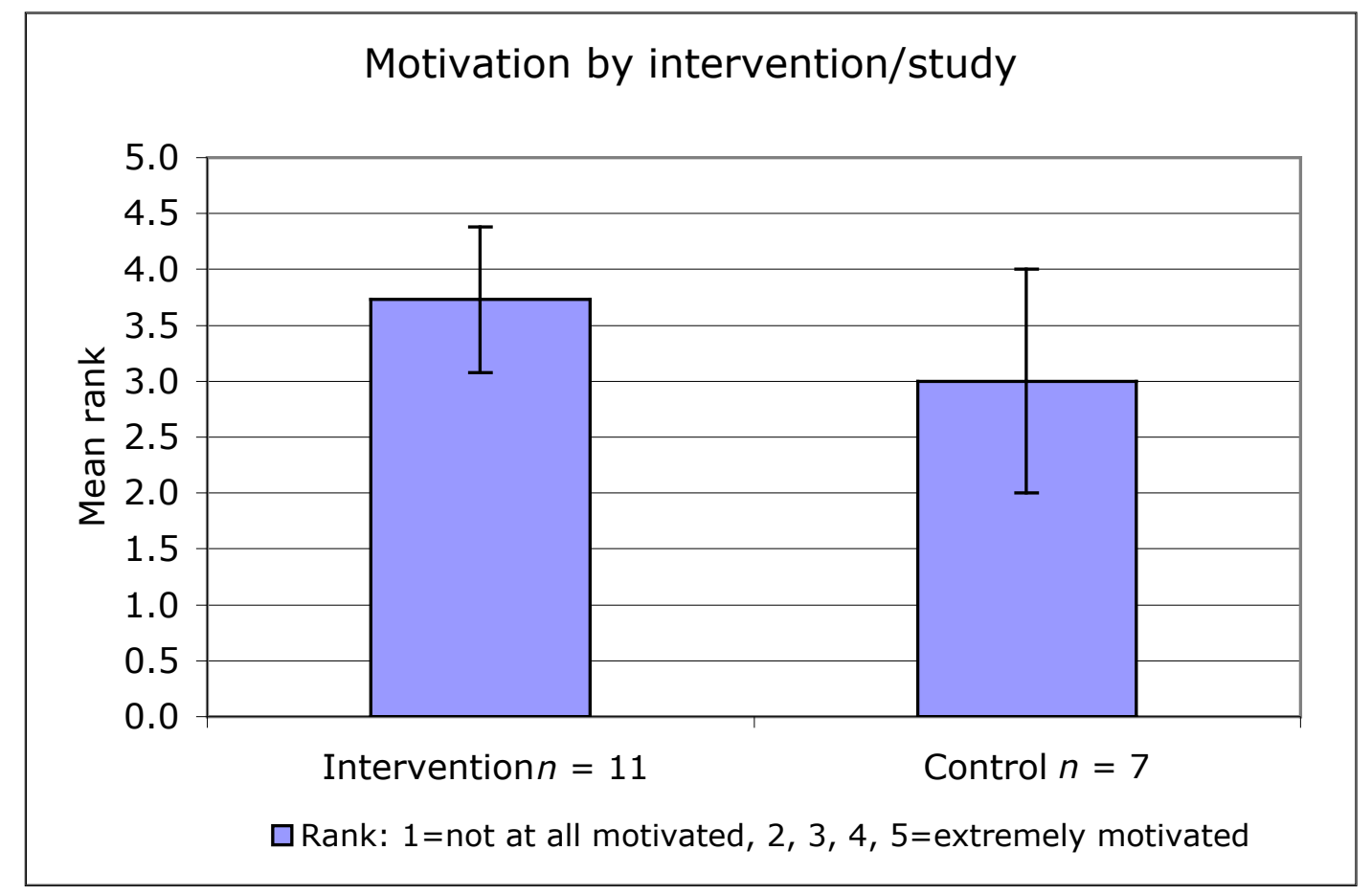

Figure 23. Average rank given for the question "How much did your [intervention][study] motivate you to change your habits to reduce your home energy use?" Error bars indicate standard error of proportion. 


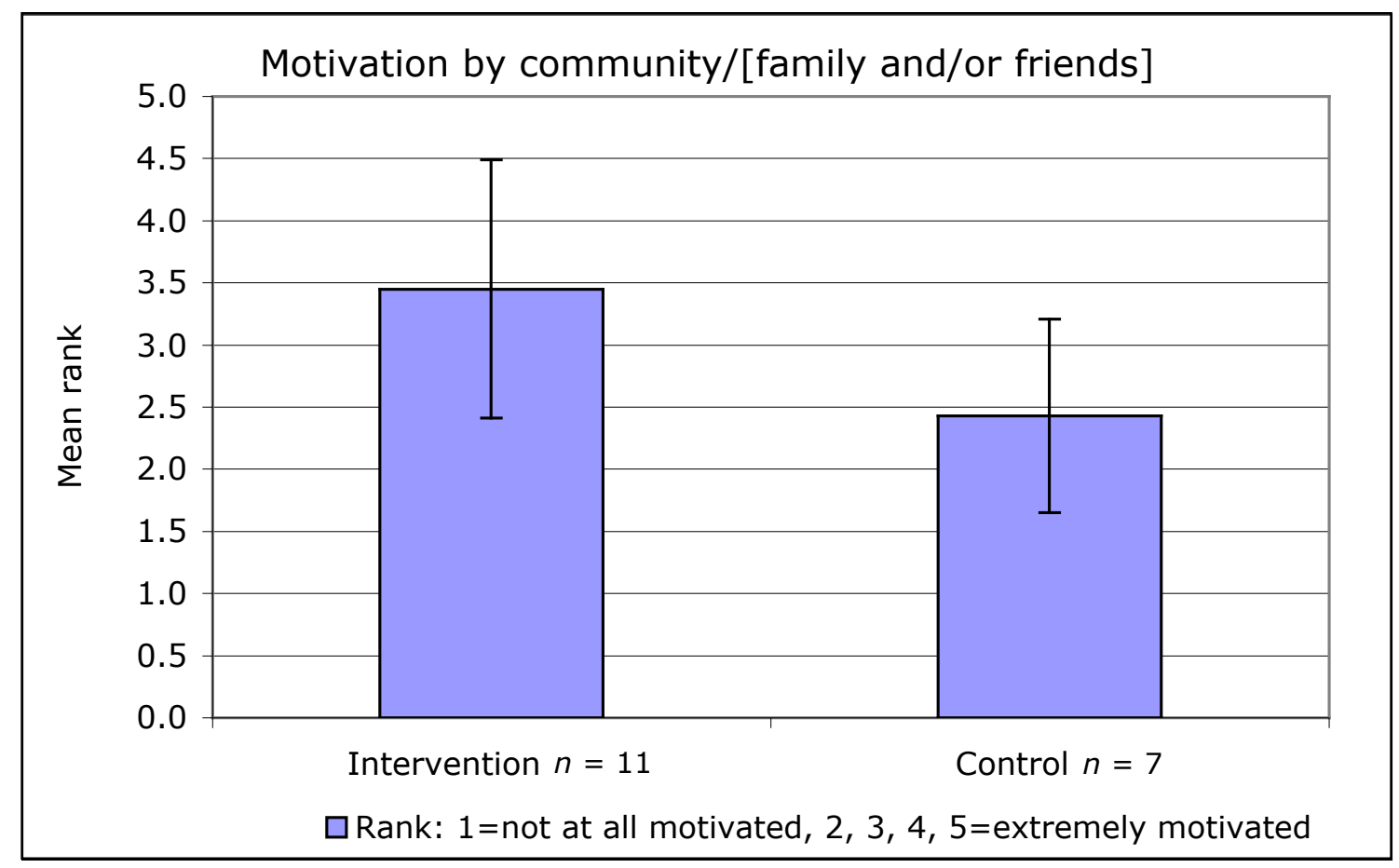

Figure 24. Average rank given for the question "How much did the knowledge that [your community was united in a campaign to reduce their energy use][friends and/or family members have begun reducing their energy use] motivate you to change your energy habits?" Error bars indicate standard error of proportion.

In regard to taking the monthly surveys, the sole feature that the intervention and study had in common, there was an interesting difference in results between the two groups. The control group gave the monthly survey taking activity, the only feature of the study they came into contact with and therefore the only one that they shared with intervention participants, an average rating of $3.14(S D=.89)$, which is leaning toward very motivated by this. The intervention group, who experienced monthly surveys alongside frequent Green Team emails, newsletter announcements and posted signs about the campaign, exposure to the website, regular invitations to outreach events, monthly survey results graphs, and casual social interactions with fellow community members about the campaign, rated it as having a value of $2.80(S D=1.61)$, which I interpreted as 
leaning toward not very motivated by this. The difference between these results was not significant, $t(15)=-.50, n s$.

To understand which features of the intervention were seen as being more motivational than others in getting participants to reduce their home energy use, I again looked at the average rating on a 5-point Likert scale $(1=$ not at all motivated by this to $5=$ extremely motivated by this) given by the intervention group for each feature. In regard to community-based features (see fig. 25), the "campaign launch in your community," "Green Team communications about the campaign," and "knowing how many other households in your community had pledged to join the campaign" received the top three rankings.

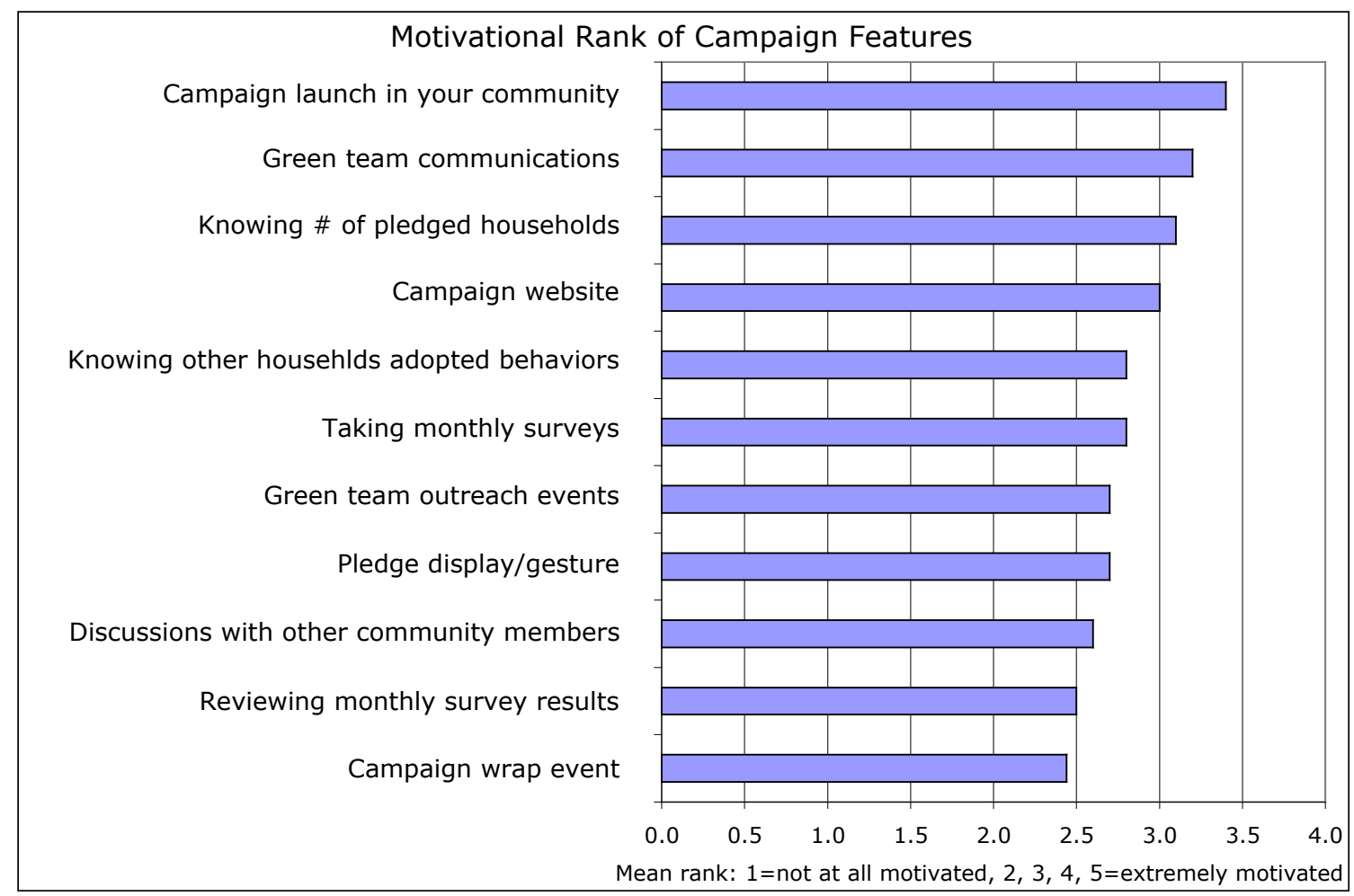

Figure 25. The average rank of community-based intervention features by respondents, using a 1-5 Likert scale, to the survey question "To the best of your memory, how much did each of the following motivate you to adopt energy reduction behaviors during the Campaign?" 
The remaining seven community-based features of the intervention were given an average rating of anywhere from 2.5 to 3.0 , which placed them at slightly less than neutral in motivational value.

\section{Open-ended Comments}

The open-ended comments (Appendix E) captured participants' opinions and suggestions at each monthly increment of the intervention. Organizing the comments by type (general, suggestions, reported new habits, complaints, thanks or praise) provided a helpful overview of what the intervention participants thought of the campaign overall. There were four suggestions on how to improve the program, and four complaints from renters who did not feel the surveys reflected their limited ability to adopt certain recommended behaviors unique to homeowners, and from one person who wanted less confusing questions on the Transportation Survey. Respondents reported 14 stories about their efforts to adopt new behaviors, such as "Because of your suggestions, I had SJ Water come out and do a water audit ... Thanks!" and "Have not used dishwasher this month - waiting for parts. Will shop for a more efficient one if parts do not show up." But the highest number (18) of comments were devoted to expressions of thanks or praise for the Green Team's efforts or for the program in general, such as "[G]reat, thanks for setting up the program. We got a lot from it and will continue the changes we made with the program," "Yes, let's keep the dialogue/info sharing ongoing," and "I think it's a great idea and like the fact that the church has taken an active part in this campaign. Thank you to those of you who have taken leadership in this project." The Winter Heat 
Survey received 17 comments altogether, primarily due to the fact that this survey had the highest number of total respondents and was one intervention community's first survey, so respondents were likely eager to share their first impressions of the campaign initiative. The Hot Water Survey received nine comments, most reporting what additional actions they had taken in their household to improve their energy savings. The Transportation Survey received only two comments, which was partly a reflection of the low number of participants who took that survey. Overall, the comments reveal a sense of engagement with the intervention's goals to promote energy conservation, and appreciation for the opportunity to work on their behaviors and of the Green Team's efforts to bring the intervention to the community. 


\section{DISCUSSION}

The primary purpose of this research was to determine whether a communitybased behavior change intervention was effective in motivating individuals to reduce their household energy use. The results indicated that the intervention achieved a statistically significant level of effectiveness in this regard in many of the areas measured. A greater number of people chose to participate in the intervention, maintained a higher rate of participation throughout the five-month duration of the intervention, and most important to the goal of reducing household energy use, reported statistically significant higher numbers of adopted behaviors that reduced energy use than did the people in the control group overall. These findings are important in that they lend support to a number of theories about how to design effective interventions, in particular those theories coming from social and community psychology that focus on ways to leverage social awareness and support to influence behavior.

Many features of the intervention served to establish or reinforce participant awareness of prevailing social norms around the community's interest in fighting climate change, which seemed to be the primary reason for its success. Participants were able to ascertain from the launch event and pledge gesture that not only did others approve of the community's collective commitment to take pro-environmental action, they were also provided regular proof that others were taking action to conserve energy through Green Team communications and monthly survey results. The importance of the launch and pledge gesture in motivating participant behaviors was evidenced by the Follow Up 
Survey results where these campaign features were rated highly for their motivating influence, and supports the social science literature that recommends feedback and commitment strategies be used to promote ERBs. Likewise, the same survey results showed that the community setting played an important role in the intervention's success in influencing behavior, which agrees with Maton's $(2007,14-16)$ assertion that the external impacts of empowering community settings can influence community betterment and social change. The community setting achieved this by providing a unifying framework of social support from which Green Team members could develop messages and activities to engage and inspire participants to take meaningful action, and participants could associate their individual efforts with the shared goal of fighting climate change because they knew they were working concurrently with their fellow community members to adopt the same behaviors.

The intervention depended on the existence of a Green Team to bring it to life, deliver it to the community and guide its progress. Since the intervention was an information campaign, the primary focus of the Green Teams' efforts was in conveying messages about the campaign that they had tailored to engage participants at each stage of the intervention. The launch invitation and reporting of pledge results built awareness about the enhanced sense of community participants created by joining the campaign, as demonstrated by one pilot study campaign's first email group message that read, "Great News! 159 [of our community] HOUSEHOLDS HAVE PLEDGED to fight global climate change! That's a LOT of households and great news for our environment, our children, and our planet." Once the intervention was underway, the Green Team worked 
on messages of encouragement to keep participants focused on adopting behaviors. To avoid overwhelming participants with expectations that were too high to be realistic, they instead tried to be persuasive by setting simple goals for each household, for example encouraging them to adopt at least one behavior per month and more only if they could. The ability to tailor messages that are simple, clear, and directive that also respond to participants' particular needs for practical advice are hallmarks of effective information campaigns that seek to influence ERBs.

Ultimately, providing a campaign where individuals could take action within the larger supportive social structure of their community helped strengthen their sense of purpose and attach meaning to each step they took toward adopting a new behavior. Knowing they had their community's support, as expressed through the Green Team's efforts, seemed to have been a helpful spur for individuals experiencing great concern about climate change who wanted to do something about it.

\section{ADOPTED BEHAVIORS}

As the pro-environmental attitudes discussed in the demographic survey foreshadowed, the high percentage of "Already" responses across the five surveys compared to the other response types showed not only how "green" these communities were to begin with, but that there was less room to motivate behavior change than perhaps would have been found in other communities. However, the "Did it" results showed that the intervention was able to motivate the adoption of new behaviors anyway, compared to the control. In fact, the intervention achieved a statistically significant level 
of effective behavior change in the three following surveys: Things You Plug In,

\section{Consumer Footprint and Hot Water (in table 8).}

Table 8. Summary of independent t-test results for "Did it" and "Already" responses for five surveys

\begin{tabular}{|c|c|c|c|c|c|}
\hline \multirow[b]{2}{*}{ Survey } & \multirow[b]{2}{*}{ Response } & \multicolumn{2}{|c|}{$\begin{array}{c}\text { Mean } \% \text { of responses, } \\
\text { mean and standard deviation } \\
\text { of scored response }\end{array}$} & \multirow[b]{2}{*}{ Significance } & \multirow[b]{2}{*}{ Conclusion } \\
\hline & & Intervention & Control & & \\
\hline \multirow{4}{*}{$\begin{array}{l}\text { Things You } \\
\text { Plug In }\end{array}$} & "Already" & $38 \%$ & $30 \%$ & $t(66)=1.49$ & No difference in \\
\hline & & $\begin{aligned} M & =7.16 \\
S D & =3.1\end{aligned}$ & $\begin{array}{l}M=5.75 \\
S D=2.09\end{array}$ & $n s$ & $\begin{array}{c}\text { previously adopted } \\
\text { behaviors }\end{array}$ \\
\hline & "Did It" & $12 \%$ & $0 \%$ & $t(66)=3.17$ & Intervention adopted \\
\hline & & $\begin{aligned} M & =2.19 \\
S D & =2.29\end{aligned}$ & $\begin{aligned} M & =.08 \\
S D & =.28\end{aligned}$ & $p<.05$ & $\begin{array}{c}\text { significantly more } \\
\text { behaviors }\end{array}$ \\
\hline \multirow{4}{*}{$\begin{array}{l}\text { Consumer } \\
\text { Footprint }\end{array}$} & "Already" & $58 \%$ & $73 \%$ & $t(55)=-2.50$ & Control previously \\
\hline & & $\begin{array}{c}M=14.02 \\
S D=5.13\end{array}$ & $\begin{array}{l}M=17.47 \\
S D=3.69\end{array}$ & $p<.05$ & $\begin{array}{c}\text { adopted significantly } \\
\text { more behaviors }\end{array}$ \\
\hline & "Did It" & $23 \%$ & $10 \%$ & $t(55)=2.79$ & Intervention adopted \\
\hline & & $\begin{aligned} M & =5.40 \\
S D & =4.30\end{aligned}$ & $\begin{aligned} M & =2.35 \\
S D & =1.86\end{aligned}$ & $p<.05$ & $\begin{array}{c}\text { significantly more } \\
\text { behaviors }\end{array}$ \\
\hline \multirow[t]{5}{*}{ Winter Heat } & "Already" & $53 \%$ & $44 \%$ & $t(76)=-1.69$ & No difference in \\
\hline & & $\begin{aligned} M & =5.01 \\
S D & =2.17\end{aligned}$ & $\begin{aligned} M & =6.30 \\
S D & =2.62\end{aligned}$ & $n s$ & $\begin{array}{c}\text { previously adopted } \\
\text { behaviors }\end{array}$ \\
\hline & "Did It" & $12 \%$ & $4 \%$ & $t(76)=1.84$ & No difference in \\
\hline & & $M=1.35$ & $M=10$ & $n s$ & adopted behaviors \\
\hline & & $S D=1.42$ & $S D=.50$ & & \\
\hline \multirow[t]{4}{*}{ Hot Water } & "Already" & $36 \%$ & $37 \%$ & $t(52)=.63$ & No difference in \\
\hline & & $\begin{aligned} M & =4.34 \\
S D & =1.81\end{aligned}$ & $\begin{array}{l}M=3.87 \\
S D=2.64\end{array}$ & $n s$ & $\begin{array}{c}\text { previously adopted } \\
\text { behaviors }\end{array}$ \\
\hline & "Did It" & $14 \%$ & $4 \%$ & $t(52)=2.49$ & Intervention adopted \\
\hline & & $\begin{aligned} M & =1.69 \\
S D & =1.47\end{aligned}$ & $\begin{aligned} M & =.37 \\
S D & =.51\end{aligned}$ & $p<.05$ & $\begin{array}{c}\text { significantly more } \\
\text { behaviors }\end{array}$ \\
\hline \multirow[t]{4}{*}{ Transportation } & "Already" & $35 \%$ & $38 \%$ & $t(42)=.02$ & No difference in \\
\hline & & $\begin{aligned} M & =6.70 \\
S D & =3.30\end{aligned}$ & $\begin{array}{l}M=6.66 \\
S D=1.15\end{array}$ & $n s$ & $\begin{array}{c}\text { previously adopted } \\
\text { behaviors }\end{array}$ \\
\hline & "Did It" & $15 \%$ & $5 \%$ & $t(42)=.63$ & No difference in \\
\hline & & $\begin{aligned} M & =2.80 \\
S D & =3.01\end{aligned}$ & $\begin{aligned} M & =1.66 \\
S D & =2.08\end{aligned}$ & & adopted behaviors \\
\hline
\end{tabular}

Note: Scored responses were calculated by assigning a point to each "Already" and "Did it" response for each question, aggregating all points for each response type across all questions in a survey, then running an independent t-test comparing the intervention and control groups' results for both response types. 
The low rate of adopted behaviors for the Winter Heat Survey seemed to stem from a high rate of previously adopted $\mathrm{HI}$ behaviors on the part of both groups. There simply was not sufficient capacity for new behaviors to be adopted. However, the extremely small number of control participants was responsible for the lack of significant results in the Transportation Survey. Moreover, the extremely high financial investment made by a few intervention households to purchase a new fuel efficient vehicle, as well as to buy carbon offsets which is a far lesser but still impressive financial investment, reveals that the intervention had an important effect on transportation behaviors regardless of the lack of statistical significance for this survey's results.

Overall, the interpretation for the success of the intervention in influencing behavior change extends to the three younger pilot study communities whose results from the same surveys showed a markedly similar pattern of response rates. This high degree of similarity between results for all five communities who received the intervention, at different time periods, provides additional validation that the intervention is effective at motivating communities to change their energy use behaviors. Further, it demonstrates that neither the religious background of the intervention communities, historical effects, nor the older median age of the intervention communities' participants were important factors in its effectiveness. Rather, that all three types of communities showed similar responses to the intervention communities indicates that it was not the type of community that played a role in the intervention outcomes, but the force of community itself. 
It is noteworthy that across all surveys, the control group had the same or higher rates of "Not yet" responses than the intervention group — an indication of their capacity to change their behaviors - yet they did not adopt a meaningful number of new behaviors compared to intervention communities. A respondent who is "Not yet" ready to adopt a behavior may select that answer choice because they may be unfamiliar with the behavior generally, unconvinced that the behavior is worth adopting, or may simply not be interested in that behavior despite understanding fully its value in reducing energy. What is clear is that the control group's rate of "Not yet" responses, and concurrent lower rate of "Did it" responses, is more likely due to not having received an intervention to educate and motivate them to try and adopt those behaviors. Demographically the control group was very similar to the intervention group in terms of age, level of affluence, education, attitudes about the environment and, it seems reasonable to suppose, access to local and national news and opinions in the mass media about climate change and energy use issues generally. It was the intervention that was the key difference separating these two groups. The intervention educated community members about behaviors, demonstrated the importance their community placed on adopting them, and motivated them through social pressure to follow through on their good intentions to save energy. Without an intervention of this type, for any group, regardless of their environmental leanings, the interest and effort needed to try to adopt new energy conservation behaviors will likely be similarly low.

In terms of the types of behaviors that were adopted more frequently than others, the low investment, high repeating (LR) behaviors were the most likely to be adopted 
overall. Partly, this was due to the lower number of high investment behaviors presented, but more importantly, this finding seemed to result from the fact that many of the participants had already adopted a large portion of the high investment behaviors previously. This trend was also observed for the three pilot study communities. Despite the overwhelming popularity of LR behaviors, there were a satisfying level of HI behaviors adopted across all surveys, such as buying refrigerators, solar water heaters, and especially hybrid vehicles, demonstrating that the intervention was capable of spurring serious motivation in improving household energy use.

Some of the open-ended comments made by participants from one intervention community's campaign demonstrate that the intervention created or reinforced an eagerness to pursue the more cost- and effort-intensive actions. For example, "I appreciate your doing this. I am still thinking about doing some of the things suggested for February ... like getting the air ducts checked for leaks ... and I'd love to get sun tunnels or sky lights, but that will require lots of convincing for my husband! But it's on my list to work on;" and "We hope, this year, to install a solar system for our home, and then, if possible, buy an electric car next time we need to change cars." Finally, a participant in a pilot study campaign wrote, "I thought [the campaign] was a great thing for the school community to rally behind. It helped bring the issues to fore not just with the adults but to really involve the kids. We've gone all-Prius-all-the-time. Picking up our second this week ... Your programs have shown the kids they have to take control of their planet ... in our case ride pleasantly in a much smaller vehicle. It worked. Keep it up." What these comments have in common is that they demonstrate that the 
intervention engaged not only individuals, but entire families in thinking about how to reduce their environmental impacts, sometimes spurring them to make significant adjustments to their lifestyles as a result. These unsolicited comments show that families were inspired to go beyond the intervention's recommended behaviors and adopt meaningful changes to their attitudes as well, in effect adopting anew or strengthening their commitment to protect the environment and, in so doing, offer additional validation that the intervention was effective.

The trend that showed that it was primarily LR behaviors that were adopted by the intervention was also observed for the three pilot study communities. The two groups' primarily had the same most-adopted behaviors in common, although there was some disparity in the rates of adoption between the two groups for many behaviors, as would be expected. In terms of HI behaviors, the intervention community had capacity and was motivated to adopt certain HI behaviors (keep their car tuned, install low-flow showerheads, and caulk and weather strip for air leaks) that the pilot study groups had previously adopted. Instead, for this younger group, installing CFLs and buying carbon offsets for travel mileage had a higher rate of new behavior adoption among the HI behaviors. I speculate that these two behaviors were popular for those communities primarily because they had high appeal during their campaigns. In particular, the explosion in media coverage that CFLs received for their cost- and energy-savings during those campaigns (2007-2008), and to a lesser extent for carbon offsets which were introduced at around this same time, likely explains this result. Otherwise, the difference in the types of behaviors previously and newly adopted by the two groups seemed similar 
enough to indicate that the intervention's ability to educate participants about the importance of adopting new behaviors generally was effective over time and consistent among different types of communities whose median ages were different as well.

It is important to acknowledge that I had to carefully examine the issues surrounding survey use to determine whether survey results could be relied on to draw conclusions about this study. While self-reports of environmental behaviors in answer to questionnaires are widely used in environmental psychology, there are well known concerns about their accuracy. For instance, Steg and Vleck in a review of the literature on measurements of behavior change, noted that while some scientists have found strong correlations between self-reports and actual behavior performed, others have found low correlations (Steg and Vleck 2008, 310). Vining and Embreo noted similar discrepancies in their review of various studies on the accuracy of self-reports, and also noted that overestimation is a problem for behaviors that have high social approval, such as those being examined in this intervention (Vining and Embreo 2002, 25). But looking more closely at anonymous online questionnaires conducted via the Internet, Johnson found evidence that anonymous self-reports lowered social desirability and social anxiety and increased self-focus, suggesting that when survey participants answered questions about their behaviors online, their anonymity may mitigate concerns about the social approval attached to behaviors and therefore may render moot the argument about overestimation of behavior (Johnson 1999, 437). In regard to this study, since self-reports were used for both the intervention communities and control group, the amount of overestimation of behavior change reported, if it existed, should have been consistent for both groups. 
Another issue that needs to be addressed relates to the timing of this study; the U.S. was undergoing the onset of the Great Recession when these interventions were launched, and concerns about financial wellbeing were widespread and may well have caused more people to join the campaigns and adopt more behaviors than they otherwise would have done in healthier economic times. Moreover, the behavior challenge descriptions presented the financial savings that can accompany the adoption of a behavior, and this information may have played to participants' financial concerns and helped deepen their motivations to follow through in adopting more behaviors in ways they may not have done otherwise. However, it is equally possible that job loss or financial stress in general may have so preoccupied some community members that they chose not to participate when they might have were the nation experiencing a more stable economy. While it is impossible to speculate how the results of this study would have been different if concerns about the recession were not in the news and on everyone's minds, it is clear that the impact was at least as much of an issue for the intervention communities as it was for the control group. In fact, considering that the median income of the control group was lower than that of the intervention, it would be reasonable to expect that the control group would have been more active in adopting behaviors that reduced their electricity bills, particularly $\mathrm{HI}$ behaviors that are known to save the most money, but the opposite was true. The intervention adopted more behaviors across all five surveys, including HI behaviors. I suspect the recession, at the time not clearly recognized to be as deep and lasting as it has become, was not yet an overwhelming concern for many, and speculate that the general affluence of the participating 
communities sufficiently protected a majority of households from having to pursue the adoption of energy conserving behaviors out of a need to save money. Overall I do not believe the recession played a significant role in the behavior adoption outcomes presented in this research.

Finally, it is important to acknowledge that because this study did not randomly assign participants to the intervention condition, interpretation of this study's results must be made carefully. The program this intervention was based on is predicated on the idea that participants are self-selected, that they join a campaign because they want to change their energy use behaviors. Therefore random assignment of participants was not an option for this study. So, while results indicate that the intervention caused behavior change, it is possible that part of the explanation for this is that participants adopted behaviors because they were more positively disposed toward the idea of taking action than randomly selected participants would perhaps have been. However, if this was the case, the intervention can still offer substantial value to the wider society because intervention communities by definition are trying to effect change for the greater good and are designed to have a wide reach. Once an intervention succeeds in uniting a subset of a community to fight climate change, and their energy conservation goals and behavior change outcomes are broadcast to the entire community, a new norm to support energy conservation takes hold and influences participants and non-participants alike. Moreover, the environmental knowledge introduced by the intervention will likely have its own ripple effect as well, further priming the rest of the community to be more open to ideas 
that tie human behavior to climate change, and influencing their thoughts about energy conservation over time, as well.

\section{LASTING EFFECTS}

The results of the Follow Up study demonstrated that the intervention had a lasting impact on intervention respondents' behavior: they reported that seven months later they had maintained $59 \%$ of the behaviors adopted during the intervention. While the control group reported that they maintained $42 \%$ of behaviors adopted during the course of the study as well, and the difference between the two rates of behavior maintenance was not found to be significant, these facts do not diminish the evidence that behaviors were maintained by the intervention group, the primary research question this survey was designed to answer. However, this survey had the lowest number of respondents of any survey, eleven respondents for the intervention group compared to seven for the control group, which was too low to not only find significance in the difference between rates but also requires that interpretation of the results be made cautiously. It is plausible that the self-selected few people who took this survey were more motivated to report their results because they had achieved more adopted behaviors than others in their respective groups and simply wanted to report that fact. If this was the case this means that the results were inflated, indicating that a greater proportion of respondents maintained behaviors than was actually the case. I believe, however, that the

results were at least somewhat representative of the wider community of participants, and that it was the intervention's repeated emphasis on the goal of reducing household energy 
use coupled with its long duration that influenced participants to maintain behaviors long after it ended. This reasoning would account for the higher rate of retained behaviors in that group compared to the control group, who had no such reminders. That the control group respondents were also able to retain behaviors over time is interesting for reasons separate from the research question. I speculate that control participants were able to maintain new behaviors simply because they were practiced at incorporating green behaviors into their lifestyles already. They also may have been inspired by their participation in the study to focus harder on the energy use behaviors presented in the surveys, which would also account for the slightly higher rate of behaviors adopted poststudy than the intervention group.

\section{COMMUNITY INFLUENCE}

The first measurable impact that an intervention has on a community's behavior is the number of pledges made by community members to demonstrate their commitment to reducing their household energy use. The results of the analysis of participation rates showed that there was a (trend toward) significant difference in the intervention group's pledge participation rates and survey participation compared to the control group's rates. This result was found despite the small control group sample size, which could not otherwise detect significance between the two groups for the other surveys. These participation results support my contention that the community-based nature of the intervention has an influence on behavior generally. 
While the small sample size of the control group hindered this study's ability to establish conclusively what some of the effects of this intervention were, I believe that the small control group sample size provided another measure of the intervention's success. Absent the social pressure the intervention community received to participate, the majority of the control group community lacked a motivating reason to join the study. Additional support for this comes from the fact that, originally, this study had a second control group consisting of 300 houses in a residential neighborhood in Sunnyvale. I approached this second group at the same time that I approached the control group used in this research. I left printed invitations to join the "How Green Is Your Life" study at the front door of each household, sometimes delivering them in person. However, despite the large number of invitations issued I only received three responses, so I chose not to include the second control group in this research. When taken together, I invited 375 households to participate in the study but only $20(5 \%)$ chose to participate. I contend that my failure to attract a sizeable control group when I approached people as individuals, compared to my success in attracting $40 \%$ of the 410 households in the intervention community, is precisely due to the fact that I was not using a community approach (or another strong incentive of some kind) to appeal to them. In other words, if an educational intervention does not offer a highly compelling reason for an individual to engage with it, the likelihood of attracting many participants is low. If, on the other hand, an educational intervention uses a community approach to inspire its individual members to participate, it is likely to attract meaningful numbers of participants, as this research showed. 
I looked more closely at the surge in participation for the fifth survey to try and determine what may have accounted for it and what implications there may be for the intervention's impact. The surge in survey participation witnessed for the intervention's fifth survey correlated to a successful push by the Green Teams to rally the community to register behavior changes before their campaigns wrapped up a few weeks later. The Green Team posted new signs promoting the wrap event and signaling the end of the campaign, replacing the "please remember to take this month's survey" messaging used the preceding four months that I believe was contributing to survey fatigue among participants. The new messages reminded participants of the community's potential environmental impact as it promoted the wrap event where final results were to be shared, reinforcing the social norm that everyone was working to save energy. That this effort reversed the downward trend in survey participation reinforces my contention that the intervention's success was dependent on the community-based approach, in particular the Green Team's ability to communicate effectively about survey responsibilities and provide motivational messages that their community would respond to.

Central to this study of the intervention's effectiveness is determining whether the community-based nature of the campaign played an important motivational role for participants trying to change their energy use behavior, and results showed that it did. A significantly higher number of intervention participants ranked their community's campaign as being very or extremely motivating to their adoption of new habit. When the question was restated, replacing "campaign" with "knowledge that your community was united in a campaign to reduce their energy use," which underscored the social 
influence of the intervention, intervention respondents rated it as a bit less significant on average. This slightly lower score may have been a result of the fact that, as Cialdini noted, people can be poor judges about how the things that others do motivates their own actions (Cialdini 2005, 158). Nevertheless, the statistically significant higher rating that this question was given by the intervention compared to the control group indicated that it was harder to find motivation to change behavior with an absence of visible social support.

Because the intervention is explicit about its community focus and was built around a high number of community-based interactions with participants, it is important to examine closely the three community-based elements of the intervention that participants rated as most effective at influencing their behaviors. The campaign launch was the most motivating aspect of the intervention. This is understandable because the launch served to create awareness of a shared concern for the environment, articulated a shared vision and goal to fight climate change, and in so doing established a social norm around taking action to reduce collective greenhouse gas emissions. Moreover, the launch was the single moment in the campaign when participants faced each other and witnessed one another's reaction to the pledge invitation, so social pressure would have been palpable. The third highest ranked motivator for behavior change was "knowing how many other households in your community had pledged to join the campaign," which is an explicit acknowledgement of the power that social norms wield when they are spelled out, as the Green Teams did in the first communications to the community that reported how many households had pledged to participate. As one participant 
commented "It's still early in the campaign, but we are interested to see what other members are doing that perhaps we are not," which illustrates just how compelling it can be to want to join with our peers in a collective effort, to participate in something that matters to society as a whole.

The second highest ranked motivator for behavior adoption was the Green Team communications. The Green Team's involvement was crucial, as their presence helped to establish a relational environment that reinforced the sense of community inherent to the effort and provided a clear structure of social support. But this survey result underscores that it was also the messages that they conveyed, carrying the force of social pressure, which made an important contribution to the campaign's effectiveness. It was the Green Team who made the intervention possible and created the launch event that introduced it to the community. And it was their verbal invitation in front of their congregation to join the campaign in order to protect the earth and all its creatures from the harm of climate change, and their call to take collective action to reduce harmful GHG emissions and serve as better environmental stewards for future generations, that sparked community interest to participate. They promoted the shared goals of the campaign and encouraged participation by presenting pledge gestures to each participant with an accompanying statement that read "Our family pledges to challenge ourselves each month to reduce the amount of carbon dioxide (CO2) we emit into the Earth's atmosphere, thereby protecting the climate for our children and future generations." The invitation and other early email communications about the campaign continued to build awareness and generate excitement about the community's efforts to support the environment, key features of 
effective information campaigns. The Green Teams also shared their personal interest in finding new ways to reduce their own energy use to serve as an example for others to follow, and by reporting on the total number of pledges the first few weeks of the campaign and sharing their excitement about it, they generated additional persuasive appeal that helped reinforce the resolve of participants to adhere to their pledge commitments.

Of the numerous messages the Green Team issued, it was the reminders to the community that they were united in an effort that was important and potentially improved the lives of everyone that may have been most compelling for participants. The following message, for example, accompanied the release of one community's first survey results graph: "WOW! Our team was inspired to see such positive numbers: they tell us that many of you are being conscientious and getting engaged in doing what you can to reduce your energy use ... Imagine how much $\mathrm{CO} 2$ we can save together if we all keep working on new monthly cooling challenges to reduce our energy use at home!" This type of support was invaluable for an intervention that asked participants to maintain their focus for such a long duration, and was demonstrated by the Green Teams' ability to tailor communication efforts to commiserate with participants and provide extra support when needed, as the following group email message, presented in the fourth month of a campaign, reveals:

AN IMPORTANT MESSAGE: SMALL CHANGES COUNT! If your family has managed only one or two challenges so far, and you're feeling overwhelmed or guilty about all the other challenges you just can't take on now, we want you to know its okay, and that you're not alone .... If you find yourself increasingly thoughtful about other ways you can save energy, and asking more questions about how you are living on the earth, congratulations, you're AWARE and 
SEEKING other ways to act. To [our] team, your participation on any level is a cause for celebration. Keep it up!

As the Final Survey results and open-ended comments indicated, the social support that the Green Team provided meant a great deal to participants. Their presence helped participants feel purposeful in their efforts and reinforced their intentions to change their behaviors. But it was their successful communications effort, one that relied on many of the information campaign and behavior-change strategies recommended in the literature, that provided the unifying force behind the community effort and made the intervention work.

The campaign website, which received a neutral average rating, was nevertheless the fourth most motivating feature of the intervention. Behavior change is complex and in order to change behavior it is important to have a way to convey information about why it matters both individually — to our self esteem, to reinforce our beliefs and morals that value supporting the environment, to our wallets if saving energy also saves money — and collectively as a society, something a website is uniquely capable of doing in our Internet-driven world. For an intervention to be effective, it is critical to have a website that is highly credible, that helps participants understand what performing a behavior entails and provides access to practical advice and suggestions for how to accomplish it. The campaign website not only delivered all of these features, it also provided a platform to display the monthly survey results which showed the collective behaviors adopted each month by fellow community members, an important form of comparative feedback. Overall, the campaign website was presented to the community 
by the Green Team, who tailored it to fit their community's identity, and it thereby served as not only an educational tool but another symbol of the community's commitment to reduce greenhouse gas emissions. After the campaigns ended, the websites remained as a document of the community's environmental efforts, their unity around taking action for the greater good of society, and as an important resource for new families to use who want to reduce their energy use.

Overall, the participation rates and Final Survey results demonstrated the important motivating role the community played in encouraging participants to change their behaviors in support of the environment, which agrees with the findings that an empowering community setting can be effective in helping a community effect social change. Moreover these results showed that the information campaign approach and many of the community-based features of the intervention that made use of feedback, face-to-face communications, and commitment strategies were as effective in motivating participants to change their energy use behaviors as social scientists maintained they would.

\section{VALUE OF A COMMUNITY-BASED INTERVENTION APPROACH}

This study seeks to find support for the use of an educational intervention model that uses a community-based approach to effect social change. It is important, therefore, to mention the strengths and weaknesses of using this type of model and make suggestions for those interested in trying the approach I have outlined here. The strengths of this model are that it takes advantage of existing social relationships within a 
community to form a Green Team and gain an audience for the intervention, but allows individuals to pursue conservation behaviors privately, at their own pace; it uses the Internet to share information, communicate with participants and measure behaviors; it is designed around suggested behaviors that are widely described and promoted on national websites; it defines a shared goal of supporting the environment that young and old can relate to; and, by framing it as an attempt to create social change, engages people around the opportunity to do something important that serves society as a whole. There are also many drawbacks to this type of approach. For instance, an intervention of this type requires at least two people who will voluntarily plan a launch and outreach events and share the responsibilities of providing leadership to the community; it requires all participants to maintain involvement for over a five month period; it requires that the lead team members have or can find additional volunteers who have technical and communication skills to create websites, design messages and manage email groups; it requires at least an elementary grasp of the various strategies presented in this study to identify ways to engage participants; and it requires the cooperation of the larger community to launch an effort of this type on its behalf. It is worth noting that Staats, Harland and Wilke demonstrated in their study of the Eco Team approach that it is possible to create an effective educational intervention to change household behaviors that works in a small group setting, relies on a monthly meeting to allow participants to work through a workbook and discuss suggested behaviors, and is guided by a single group leader (Staats, Harland and Wilke 2004, 341-367). While this type of intervention was effective, the Eco Team workbooks are proprietary, the program required that 
participants devote an hour or more each month to a group meeting, and the intervention was designed to last for eight months to work through all the behaviors presented.

Having worked with a dozen communities so far, I believe this intervention, as it has been defined in this study, has been refined to its most essential elements. But if I were to streamline it, I would strip out some of the LR behaviors from each survey and focus greater attention on the $\mathrm{HI}$ behaviors, particularly transportation behaviors, to achieve greater energy reductions more quickly. I would also expand the number of Green Team members in order to distribute responsibilities more widely and lighten the load on any one individual, and I would invite participants to draft messages and design outreach efforts to make the intervention more appealing to the widest variety of community members as possible.

Finally, the external validity of this research merits some attention. At issue is whether this study's results can be generalized to the wider society beyond the San Francisco Bay Area, where it took place. The San Francisco Bay Area has been at the forefront of the environment movement since the days of John Muir, and its citizens are considered generally to be more aware of environment concerns than the rest of the nation historically (Walker 2007, 13). However, I believe that the high degree of national awareness about climate change and its causes makes it likely that the pro-environmental attitudes of the intervention communities were more representative than not. Further, I contend that having a pro-environmental attitude is not a prerequisite for a person to be interested in taking action to support the environment, and in some ways may make an intervention of this sort less appealing if the subject of energy conservation-familiar to 
most environmentally-minded people - has been explored in great depth previously. In regard to people who do not align themselves with environmentalism, it is not difficult to conceive that they may still develop an interest in an intervention of this sort in order either to educate themselves about the environment and how to take action to support it, or to avoid being left behind while others in their community or in the wider society increasingly seek such knowledge. Moreover it is reasonable to assume that if an intervention were to be successfully introduced to a community where pre-existing levels of concern for the environment was low, it may influence even higher rates of behavior adoption than were seen here because there would be greater capacity to do so, assuming that such a community would not likely have adopted many energy behaviors previously. However, the ability to introduce the intervention and gain the interest of potential participants in such a community would be the critical challenge for the intervention to solve. Identifying volunteers and community leaders to participate in a Green Team and having them brainstorm ways to appeal to the wider community would likely be the most productive way to find a solution for this issue.

Participants in this study were also more highly educated and affluent than the average American. I contend that because higher income households tend to consume more energy — and generate more GHG emissions - than their lower income peers, the environment stands to benefit more from teaching these high consumers how to save energy than other populations, reinforcing the need for interventions of this type. This is not to say that lower income households are not deserving of attention in this area as well. Low-income households certainly have the capacity to improve their energy use 
even if their carbon footprint is smaller than their wealthier peers. And low-income communities that expand their collective knowledge of environmental issues stand to benefit in additional ways as well, such as being able to identify and perhaps find solutions for environmental and social justice issues that often plague their communities. Overall, I do not believe a participant's income level affects how responsive they may be to an intervention of this sort as much as their level of education does. A highly educated person may be able to more quickly grasp concepts that explain the link between GHG emissions and the adoption of certain behaviors, whereas a less educated person may require more time and educational support before they can make decisions about which behaviors to adopt. But this difference can be addressed by tailoring the educational approach to fit the needs of the community. Otherwise, I believe that people of lower income and educational backgrounds are likely to be as concerned about their impact on the environment, as eager to assert some control over their household's energy use, and as welcoming of a community effort to support the environment as any more educated and financially secure campaign participant who has participated in this intervention. 


\section{CONCLUSION}

In the face of a global crisis as daunting as the one we face with climate change, it is important to identify effective ways to motivate individuals to adopt as many energy conservation behaviors as possible at home to help reduce our collective energy use. Two important goals of this intervention model was to provide participants with a feeling of personal empowerment in working toward a solution for this environmental crisis, and to keep them engaged in the effort long term. By introducing a community-based approach, I hoped to establish that tying individuals' efforts to the efforts of the wider community increased their motivation to change their energy behaviors, compared to working on the same goal in isolation from others. Overall, the results of this study have much to offer designers of future educational interventions who are looking for a template to follow that will help ensure that their interventions will be effective in changing energy behavior.

The primary question of this study was whether or not the intervention influenced people to reduce their household energy use. In general, the answer was that the intervention had a significant impact on influencing numerous types of behavior change around home energy use for the communities studied and that it had a lasting impact as well. Working with communities that were already "green" in their attitudes was challenging because they had previously adopted many of the behaviors presented in the study. However, the intervention proved its worth by finding plenty of capacity for the adoption of new behaviors despite this fact. Moreover, this result implies that working 
with communities that are not as environmentally friendly and who therefore have less knowledge of, or experience with, conservation behaviors would be capable of achieving a higher rate of behavioral change than was seen in this study.

It could be argued that these communities' pre-existing pro-environmental attitudes, high levels of income, and education may have conferred a greater willingness to adopt new behaviors than seen in other communities and that these results therefore do not necessarily apply to the wider population. Since the harmful effects of climate change are of personal interest to everyone and most Americans have yet to make meaningful improvements in how they use energy at home, I contend that people who are less educated and less financially secure than the participants of this study would be just as eager to gain useful environmental knowledge of this type, especially if attaining this knowledge were coupled with an opportunity to reinforce connections with their community and serve the greater good. As long as there is a community to rally people around and to rely on to activate and leverage social norms to influence behaviors, I believe this intervention could serve people of varying environmental attitudes and socioeconomic and educational backgrounds and achieve meaningful results.

When attempting to motivate energy conservation behaviors, this study showed that it is important to design an intervention that offers a mix of behaviors that require a range of effort and financial cost. It was the low cost, high repeating behaviors that were the most popular, partly because many of the high cost behaviors presented in the intervention had been previously adopted by a large number of participants. I also contend that performing low cost, high repeating actions (for example, turning off the 
lights when leaving a room or using a personal water bottle) were popular because they are relatively easy to do, and they provided a quick way to reinforce participants' good intentions and self-esteem. Therefore, while they do not lead to significant energy savings, including "easy" behaviors in an intervention may make it more likely that participants will seek additional behaviors to adopt—including more challenging, highimpact ones - in order to continue the boost it provides to their self-esteem, an issue for future research to explore. Including high investment behaviors in the intervention (for example insulating an attic or buying an energy-efficient appliance), was also shown to be important both because those behaviors tend to produce higher energy savings overall and because their adoption, even if only among a small proportion of a community, has the potential to be especially motivating to others contemplating the adoption of those behaviors. The fact that a few households in most of the intervention and pilot study communities purchased fuel-efficient vehicles is another demonstration that the intervention was effective, and that including high investment, high impact behaviors is important, even if the majority of participants will choose to pursue low investment behaviors.

Central to using a community-based intervention of this type is having a group of individuals dedicated to providing shared leadership for the effort that inspires participation, models the desired behaviors, and provides encouragement and support to fellow community members engaged in the effort. Any information campaign can educate and inform; it is the social connection to that information that makes it come alive and inspires action. Luckily, many organizations have begun forming "green 
teams" to address group interest in supporting environmental practices, which makes future interventions feasible for those who want to replicate this approach, as ready-made teams would be available. Moreover, intervention participants identified the following most motivating features of the community-based campaign to be those that were directly tied to the Green Team's efforts: the community launch, Green Team communications, and knowledge about how many other households had pledged to join the campaign. What these three features had in common was they each promoted social norms, albeit relying on different behavior change strategies, which underscores the important role that social norms played in the intervention's success.

The overarching goal that drove the development of this intervention model was my belief that harnessing the power of community to motivate behavioral change in the individual might prove to be an effective approach. Indeed, this intervention, which exemplifies an empowering community setting, provides a useful opportunity to fill a gap in the research about community-based approaches. This community-based intervention model offers advantages over other types of programs designed to influence behaviors because it can also influence community betterment and drive meaningful social change. The improved sense of well-being that results from participating in an intervention that gives participants a sense of purpose and specific actions to perform is noteworthy, especially considering how hopeless many feel in the face of an uncertain future for our climate. As Maton noted, empowered community members show themselves to have higher levels of "political efficacy, civic skills, leadership, and community engagement" (Maton 2007, 14). This bodes well for the future of the environmental movement, if such 
communities can expand their focus to include initiatives that influence the public debate about our nation's energy practices.

These findings suggest an important step forward in understanding how to motivate people using community-based interventions that result in measurable and lasting behavior change. Future designers of interventions are advised to adopt the basic components of a successful intervention as established in this study. They should include the creation of a launch event to set the tone of the intervention and articulate the shared vision of fighting climate change; an empowered Green Team to provide leadership, credibility, and social support for behavior change; core activities in the form of clear behavior challenges for the community to strive for; and feedback about the collective accomplishments of the group to further stimulate motivation. If a model could be developed and introduced at a grassroots level around the nation that uses existing communities to engage participation of its members, inspire commitment, and motivate durable change in our use of fossil fuels, it becomes possible to imagine that our collective concern about the environment can be used to slow climate change while we still can.

\section{FUTURE RESEARCH}

Because the communities participating in the intervention were self-selected based on their interest in environmental matters generally, and therefore were a convenience sample and not necessarily representative of the broader population, it would be helpful to measure the effectiveness of this model in communities that have no 
self-defining environmental interest. Since this study used a control group that was too small to provide a sufficient population of participants to derive completely meaningful comparisons to the intervention group, it is recommended that future research testing the effectiveness of this model first conduct extensive pilot-testing to locate an adequate control sample. Online survey use offers many advantages over paper surveys, but the reliability of survey responses remains of some concern. For that reason, it would be useful to corroborate reports of adopted behaviors by looking at pre- and postintervention electricity bills. While the Follow Up Survey used in this research solicited this information from participants, only three people were willing to provide it, far too few to provide conclusive evidence of the intervention's effectiveness. Therefore, obtaining permission to access electricity bills directly from electricity providers ahead of time may ensure that this important data will be available to confirm reports of energy savings. Similarly, measuring environmental attitudes pre- and post-intervention would provide important information about the environmental concerns of the communities generally, how participants' attitudes changed during the course of the intervention, and how they compare to national trends, which are measured routinely by various polling organizations and academic institutions around the country.

Given the urgency of the climate change crisis and the need to dramatically curtail our collective greenhouse gas emissions, further research is needed to identify the ideal length of an intervention to maximize and sustain the highest rate of participation possible, as the five-month period of this model showed that survey fatigue was difficult to overcome. It may be impractical to expect other interventions to be rolled out over 
such a long period and consume the time and energy of a Green Team to the degree that the one used in this study did. While some community members inevitably complained about the length of the campaigns presented in this study, many more were interested in trying to repeat their community's campaign the following year, to help drive people to deepen their habits and educate new families that did not participate the first time. In addition, while this intervention has been successfully employed in churches, schools, and workplaces, it had less success in residential neighborhoods and has not been attempted in apartment complexes or any other type of community. Therefore, developing ways to adapt this intervention to suit a variety of community types would be useful so that it could have a wider reach. In particular, it would be interesting to attempt an intervention in low-income communities where a greater level of environmental education may be needed, but where I suspect the empowerment that would come from taking collective action for the environment would be well received. 


\section{REFERENCES}

Abrahamse, Wokje, Linda Steg, Charles Vlek, and Talib Rothengatter. 2005. A review of intervention studies aimed at household energy conservation. Journal of Environmental Psychology 25, no. 3 (September): 273-291.

Advameg, Inc. City-data.com: Menlo Park, California. http://www.city-data.com/ city/Menlo-Park-California.html (accessed December 4, 2011).

Advameg, Inc. City-data.com: Palo Alto, California. http:/www.city-data.com/ city/Palo-Alto-California.html (accessed December 4, 2011).

Berk, Richard A., Daniel Schulman, Matthew McKeever, and Howard E. Freeman. 1993. Measuring the impact of water conservation campaigns in California. Climatic Change 24, no. 3 (July): 233-248.

Biel, Anders, and John Thøgersen. 2007. Activation of social norms in social dilemmas: A review of the evidence and reflections on the implications for environmental behavior. Journal of Economic Psychology 28, no. 1 (January): 93-112.

Brandon, Gwendolyn, and Alan Lewis. 1999. Reducing household energy consumption: A qualitative and quantitative field study. Journal of Environmental Psychology 19, no. 1 (March): 75-85.

Burn, Shawn M. 1991. Social psychology and the stimulation of recycling behaviors: The block leader approach. Journal of Applied Social Psychology 21, no. 8 (April): 611-629.

Carmichael, Lachlan. 2012. U.S. launches coalition to fight climate change. Inquirer News, World. March 18. http://newsinfo.inquirer.net/147205/ us-launches-coalition-to-fight-climate-change (accessed March 18, 2012).

Christens, Brian D., N. Andrew Peterson, and Paul W. Speer. 2011. Community participation and psychological empowerment: Testing reciprocal causality using a cross-lagged panel design and latent constructs. Health Education \& Behavior 38, no. 4 (April): 339-347.

Cialdini, Robert B. 2005. Basic social influence is underestimated. Psychological Inquiry 16, no. 4:158-161.

Cialdini, Robert B., and Noah J. Goldstein. 2004. Social influence: Compliance and conformity. Annual Review of Psychology 55, no. 1:591-621. 
Cialdini, Robert .B., and Melanie R. Trost. 1998. Social influence: Social norms, conformity, and compliance. In The handbook of social psychology, ed. D.T. Gilbert, S.T. Fiske, and G. Lindzey, 151-192. New York: McGraw-Hill.

Committee on America's Climate Choices. 2011. America's climate choices. Washington, D.C.: National Academies Press.

De Leon, Iser G., and R. Wayne Fuqua. 1995. The effects of public commitment and group feedback on curbside recycling. Environment and Behavior 27, no. 2 (March): 233-250.

Dietz, Thomas, Gerald T. Gardner, Jonathan Gilligan, Paul C. Stern, and Michael P. Vandenbergh. 2009. Household actions can provide a behavioral wedge to rapidly reduce US carbon emissions. PNAS: Proceedings of the National Academy of Sciences 106, no. 44 (November 3): 18452-18456.

Encyclopedia of Mental Disorders. Intervention/Definition. Encyclopedia of Mental Disorders. http://www.minddisorders.com/Flu-Inv/Intervention.html (accessed March 2, 2012).

Gardner, Gerald T., and Paul C. Stern. 2008. The short list: The most effective actions US households can take to curb climate change. Environment: Science and Policy for Sustainable Development 50, no. 5 (September): 12-25.

Giddens, Anthony. 1991. Modernity and self-identify: Self and society in the late modern age. Stanford, CA: Stanford University Press.

Gôckeritz, Susanne, P. Wesley Schultz, Tania Rendón, Robert B. Cialdini, Noah J. Goldstein, and Vladas Griskevicius. 2010. Descriptive normative beliefs and conservation behavior: The moderating roles of personal involvement and injunctive normative beliefs. European Journal of Social Psychology 40, no. 3 (April): 514-523.

Griskevicius, Vladas, Robert B. Cialdini, and Noah J. Goldstein. 2008. Social norms: An underestimated and underemployed lever for managing climate change. International Journal of Sustainability 9, no. 3:5-13.

Grodzinska-Jurczak, M., P. Tomal, M. Tarabula-Fiertak, K. Nieszporek, and A.D Read. 2006. Effects of an educational campaign on public environmental attitudes and behaviour in Poland. Resources, Conservation and Recycling 46, no. 2 (February): 182-197. 
Henry, Gary T., and Craig S. Gordon. 2003. Driving less for better air: Impacts of a public information campaign. Journal of Policy Analysis and Management 22, no. 1 (Winter): 45-56.

Hult, Margareta, and Sven-Ake Lennung. 1980. Towards a definition of action research: A note and bibliography. Journal of Management Studies 17, no. 2 (1980): 241-250.

Hegerl, Gabriele C., Francis W. Zwiers, Pascale Braconnot, Nathan P. Gillett, Yong Luo, Jose A. Marengo Orsini, Neville Nicholls, Joyce E. Penner, and Peter A. Stott. 2007. Understanding and attributing climate change. In Climate change 2007: The physical science basis. Contribution of Working Group I to the Fourth Assessment Report of the Intergovernmental Panel on Climate Change, ed. S. Solomon, D. Qin, M. Manning, Z. Chen, M. Marquis, K.B. Averyt, M. Tignor, and H.L. Miller, 663-745. Cambridge, UK: Cambridge University Press. http://www.ipcc.ch/publications_and_data/ar4/wg1/en/ch9.html (accessed September $5,2011)$.

Johnson, Adam. 1999. Social desirability, anonymity, and Internet-based questionnaires. Behavior Research Methods, Instruments \& Computers 31, no. 3 (September): 433-438.

Kantola, S. J., G. J. Syme, and N. A. Campbell. 1982. The role of individual differences and external variables in a test of the sufficiency of Fishbein's model to explain behavioral intentions to conserve water. Journal of Applied Social Psychology 12, no. 1 (February): 70-83.

Kaiser, Florian G. 1998. A general measure of ecological behavior. Journal of Applied Social Psychology 28, no. 5 (March): 395-422.

Krosnick, Jon. 2007. Concern soars about global warming as world's top environmental threat. ABC News/Washington Post/Woods Institute Survey. http://woods.stanford.edu/docs/surveys/GW_2007_ABC_News_Release.pdf (accessed March 22, 2011).

Krosnick, Jon A., and Bo MacInnis. 2011. National survey of American public opinion on global warming. Stanford University with Ipsos and Reuters. http://woods.stanford.edu/docs/surveys/ Global-Warming-Survey-Stanford-Reuters-September-2011.pdf (accessed March 11, 2012).

Leiserowitz, Anthony, Edward Maibach, Connie Roser-Renouf, Nicholas Smith, and Jay D. Hmielowski. 2011a. Climate change in the American mind: Americans' actions to conserve energy, reduce waste, and limit global warming in November 2011. George Mason University Center for Climate Change Communication. 
http://environment.yale.edu/files/BehaviorNovember2011.pdf (accessed March 5, 2012).

-----. 2011b. Climate change in the American mind: Americans' global warming beliefs and attitudes in November 2011. George Mason University Center for Climate Change Communication. http://environment.yale.edu/climate/files/

ClimateBeliefsNovember2011.pdf (accessed March 5, 2012).

-----. 2011c. Climate change in the American Mind: Public support for climate \& energy policies in November 2011. George Mason University Center for Climate Change Communication. http://environment.yale.edu/climate/files/

PolicySupportNovember2011.pdf (accessed March 5, 2012).

Maton, Kenneth. 2008. Empowering community settings: Agents of individual development, community betterment, and positive social change. American Journal of Community Psychology 41 (March): 4-21.

McKenzie-Mohr, Doug, and William Smith. 1999. Fostering sustainable behavior: An introduction to community-based social marketing. British Columbia: New Society Publishers.

Nolan, Jessica M., P. Wesley Schultz, Robert B. Cialdini, Noah J. Goldstein, and Vladas Griskevicius. 2008. Normative social influence is underdetected. Personality and Social Psychology Bulletin 34, no. 7 (July): 913-923.

O'Riordan, Timothy. 2001. From environmentalism to sustainability. Scottish Geographical Journal 115, no. 2 (June): 151-165.

Osbaldiston, Richard, and Kennon M. Sheldon. 2003. Promoting internalized motivation for environmentally responsible behavior: A prospective study of environmental goals. Journal of Environmental Psychology 23, no. 2 (June): 349-357.

Pelletier, Luc G., and Elizabeth Sharp. 2008. Persuasive communication and proenvironmental behaviours: How tailoring and message framing can improve the integration of behaviours through self-determined motivation. Canadian Psychology 49, no. 3 (August): 210-217.

Peters, Glen P, Gregg Marland, Corinne Le Quéré, Thomas Boden, Josep G. Canadell, and Michael R. Raupach. 2012. Rapid growth in $\mathrm{CO} 2$ emissions after the 2008-2009 global financial crisis. Nature Climate Change 2, no. 2 (February): 2-4.

Rocky Mountain Institute. 2008. Free things that cost nothing and save cash. Energy Efficiency. Rocky Mountain Institute. http://www.rmi.org/sitepages/pid206.php (accessed August 24, 2008). 
Shippee, Glenn, and W. Larry Gregory. 1982. Public commitment and energy conservation. American Journal of Community Psychology 10, no. 1 (February): 81-93.

Siero, Frans W., Arnold B. Bakker, Gerda B Dekker, and Marcel T.C. van den Burg. 1996. Changing organizational energy consumption behavior through comparative feedback. Journal of Environmental Psychology 16, no. 3 (September): 235-246.

Spaargaren, G., and B. Van Vliet. 2000. Lifestyles, consumption and the environment: The ecological modernisation of domestic consumption. Environmental Politics 9, no. 1 (Spring): 50-75.

Solomon, S., D. Qin, M. Manning, Z. Chen, M. Marquis, K.B. Avery, M. Tignor and H.L. Miller, eds. 2007. Contribution of Working Group I to the Fourth Assessment Report of the Intergovernmental Panel on Climate Change. Cambridge, UK: Cambridge University Press.

Staats, Henk, Paul Harland, and Henk A.M. Wilke. 2004. Effecting durable change: A team approach to improve environmental behavior in the household. Environment and Behavior 36, no. 3 (May): 341-367.

Steg, Linda, and Charles Vlek. 2009. Encouraging pro-environmental behaviour: An integrative review and research agenda. Journal of Environmental Psychology 29, no. 3 (September): 309-317.

Stern, Paul C. 2000. Toward a coherent theory of environmentally significant behavior. Journal of Social Issues 56, no. 3 (September): 407-424.

Syme, Geoffrey J., Blaire E. Nancarrow, and Clive Seligman. 2000. The evaluation of information campaigns to promote voluntary household water conservation. Evaluation Review 24, no. 6 (December): 539-578.

Javna, John. 2006. 30 simple energy things you can do to save the earth. N.p.: The Earth Works Group. Distributed by PG\&E.

Thøgersen, John. 2006. Norms for environmentally responsible behavior: An extended taxonomy. Journal of Environmental Psychology 26, no. 4 (December): 247-261.

Vedung, Evert. 1999. Constructing effective government information campaigns for energy conservation and sustainability: Lessons from Sweden. International Planning Studies 4, no. 2 (Spring): 237-251. 
Vining, Joanne, and Angela Ebreo. 2002. Emerging theoretical and methodological perspectives on conservation behavior. In New handbook of environmental psychology, eds. R. Bechtel and A. Churchman, 541-558. New York: Wiley.

Walker, Richard. 2007. The country in the city: The greening of the San Francisco Bay Area. Seattle: University of Washington Press.

Watts, Simon, and Lyndsay Halliwell, eds. 1996. Essential environmental science: Methods and techniques. New York: Routledge Press.

Weinsberg, Herbert F., Jon A. Krosnick, and Bruce D Bowen. 1996. An introduction to survey research, polling, and data analysis. 3rd ed. Thousand Oaks, CA: Sage Publications.

Wilke, Lindsay A., and Paul W. Speer. 2011. The mediating influence of organizational characteristics in the relationship between organizational type and relational power: An extension of psychological empowerment research. Journal of Community Psychology 39, no. 8 (November): 972-986. 


\section{Appendix A \\ Intervention Survey Questions By Topic and Type}

\begin{tabular}{|c|c|}
\hline Type & Survey and Questions \\
\hline & Things You Plug In \\
\hline LR & Raise your refrigerator/freezer temperature \\
\hline$L^{a}{ }^{a}$ & Unplug unused or "off" appliances \\
\hline HI & Replace worn-out refrigerator with efficient one \\
\hline HI & Replace worn-out dishwashing machine with efficient one \\
\hline HI & Replace worn-out washing machine with efficient one \\
\hline HI & Recycle your second refrigerator or freezer \\
\hline LR & Make your refrigerator more efficient \\
\hline LR & Ensure air seals are airtight \\
\hline LR & Clean the coils \\
\hline LR & Wash dishes more efficiently \\
\hline LR & Use the "energy saver" or "light wash" option \\
\hline LR & Select the "air-dry" setting or open the door for drying \\
\hline LR & Always run a full load \\
\hline LR & Use your home office more efficiently \\
\hline LR & Use a laptop instead of a desktop computer \\
\hline$L^{a}{ }^{a}$ & Plug equipment into powerstrips and turn them off when not in use \\
\hline LR & Stop using your screen saver \\
\hline LR & Use your computer's sleep mode when away $<1$ hour \\
\hline $\mathrm{LR}^{\mathrm{a}}$ & Turn off the computer when away $>1$ hour \\
\hline LR & Turn off the computer monitor when away $>15$ minutes \\
\hline LR & Turn off the printer when not in use \\
\hline \multirow[t]{2}{*}{ LR } & Turn off the copier when not in use \\
\hline & Your Consumer Footprint \\
\hline $\mathrm{LR}^{\mathrm{a}}$ & Eat food grown locally \\
\hline$L^{a}$ & Eat organic food \\
\hline $\mathrm{LR}^{\mathrm{a}}$ & Eat less than three meat meals per week \\
\hline LR & Follow a vegetarian diet \\
\hline $\mathrm{LR}^{\mathrm{a}}$ & Shrink your garbage: Throw less away \\
\hline $\mathrm{LR}^{\mathrm{a}}$ & Precycle: Buy items with least packaging \\
\hline LR & Buy in bulk, avoid single-serving items \\
\hline$L^{a}{ }^{a}$ & Reduce junk mail \\
\hline LR & Use less paper (e.g. use recycled paper, print/copy on both sides, pay bills online) \\
\hline LR & Use cloth bags, not paper or plastic \\
\hline $\mathrm{LR}^{\mathrm{a}}$ & Use a portable mug for coffee/tea, not paper cups \\
\hline LR & Use a personal water bottle filled at the tap \\
\hline
\end{tabular}


Appendix A table continued

\begin{tabular}{|c|c|}
\hline Type & Survey and Questions \\
\hline LR & Use reusable goods (e.g. rechargeable batteries, plastic party plates), not disposables \\
\hline $\mathrm{LR}^{\mathrm{a}}$ & Use cloth (e.g. napkins, dishtowels, diapers), not paper/disposables \\
\hline LR & Fix broken items, not replace them \\
\hline LR & Donate unwanted items, not trash them \\
\hline LR & Recycle mixed paper \\
\hline LR & Recycle glass, plastic (\#1-\#7), aluminum and metal \\
\hline LR & Recycle plastic bags \\
\hline LR & $\begin{array}{l}\text { Recycle hazardous waste: motor oil, paints, batteries, fluorescent lamps (e.g. CFLs), } \\
\text { electronics, expired medications, etc. }\end{array}$ \\
\hline LR & Recycle food and yard waste \\
\hline LR & Be a minimalist, buy and keep only what you need \\
\hline LR & Buy quality goods that will last, not cheap ones that need replacing \\
\hline \multirow[t]{2}{*}{$\mathrm{LR}^{\mathrm{a}}$} & Use up your food \\
\hline & Winter Heat \\
\hline $\mathrm{HI}$ & Switch to using compact fluorescent bulbs from incandescent bulbs \\
\hline HI & Install a programmable thermostat \\
\hline HI & Stop air leaks: caulked and weatherstripped \\
\hline HI & Install insulation \\
\hline HI & Seal leaks in air ducts \\
\hline HI & Install double-paned windows \\
\hline HI & Apply low-emissivity window films \\
\hline HI & Install skylights or sun tunnels \\
\hline $\mathrm{LR}^{\mathrm{a}}$ & Turn off the lights when away \\
\hline $\mathrm{LR}^{\mathrm{a}}$ & Turn down the thermostat when away or asleep \\
\hline $\mathrm{LR}^{\mathrm{a}}$ & Use a space heater \\
\hline \multirow[t]{2}{*}{ LR } & Use curtains to trap heat and allow daylight \\
\hline & Hot Water \\
\hline LR & Lower your water heater temperature \\
\hline $\mathrm{HI}$ & Install low-flow showerheads \\
\hline HI & Install faucet aerators \\
\hline $\mathrm{HI}^{\mathrm{a}}$ & Insulate your water pipes \\
\hline HI & Insulate your water heater \\
\hline HI & Replace your old water heater with an energy efficient model \\
\hline HI & Purchase a tankless water heater \\
\hline HI & Purchase a solar hot water system \\
\hline $\mathrm{LR}^{\mathrm{a}}$ & Take shorter showers \\
\hline $\mathrm{LR}^{\mathrm{a}}$ & Wash clothes in cold water \\
\hline LR & Wash a full load \\
\hline LR & Run your pool or spa more efficiently \\
\hline
\end{tabular}


Appendix A table continued

\begin{tabular}{|c|c|}
\hline Type & Survey and Questions \\
\hline & Transportation \\
\hline HI & Keep your car tuned \\
\hline LR & Keep your tires properly inflated (maximum recommended pressure) \\
\hline $\mathrm{LR}^{\mathrm{a}}$ & Turn off the engine instead of idling, if parking $>20$ seconds \\
\hline LR & Travel at $60 \mathrm{mph}$ on the highway \\
\hline LR & Frequent businesses \& restaurants close to home \\
\hline LR & Combine errands to keep trips to a minimum \\
\hline LR & Shop on-line \\
\hline LR & Choose slow shipping \\
\hline LR & Conduct banking business on-line \\
\hline LR & Drive your most fuel-efficient car \\
\hline LR & Participate in a carsharing program \\
\hline $\mathrm{LR}^{\mathrm{a}}$ & Take public transportation or schoolbus instead of driving/being driven \\
\hline $\mathrm{LR}^{\mathrm{a}}$ & Carpool instead of driving \\
\hline $\mathrm{LR}^{\mathrm{a}}$ & Walk instead of driving/being driven \\
\hline LR & Bike instead of driving/being driven \\
\hline LR & Work from home instead of driving/being driven \\
\hline $\mathrm{HI}^{\mathrm{a}}$ & $\begin{array}{l}\text { Bought a more efficient vehicle (Originally: "If you bought a more efficient vehicle } \\
\text { (car, scooter, etc) since [the intervention/study began], congratulations! What did you } \\
\text { buy?" Responses of cars purchased were converted to "Did it" responses. }\end{array}$ \\
\hline LR & $\begin{array}{l}\text { Chose not to fly (Originally: "If you chose not to fly as a result of [the intervention/ } \\
\text { study] how many total person-miles did your family save?" Responses of \# of miles } \\
\text { were converted to "Did it." }\end{array}$ \\
\hline $\mathrm{HI}$ & $\begin{array}{l}\text { Offset travel-related miles (Original question: "If you chose to offset your travel-related } \\
\text { CO2 emissions by purchasing carbon offsets because of the [intervention][this study], } \\
\text { how many miles did you offset? Responses of \# of miles were converted to "Did it." }\end{array}$ \\
\hline
\end{tabular}

${ }^{a}$ Denotes questions used in the Follow Up Survey 


\section{Appendix B \\ First Monthly Survey}

How did you do with the Things You Plug In challenges?(One survey per household please.)

\section{How did you do with these one-time actions to reduce energy used by your home} appliances?

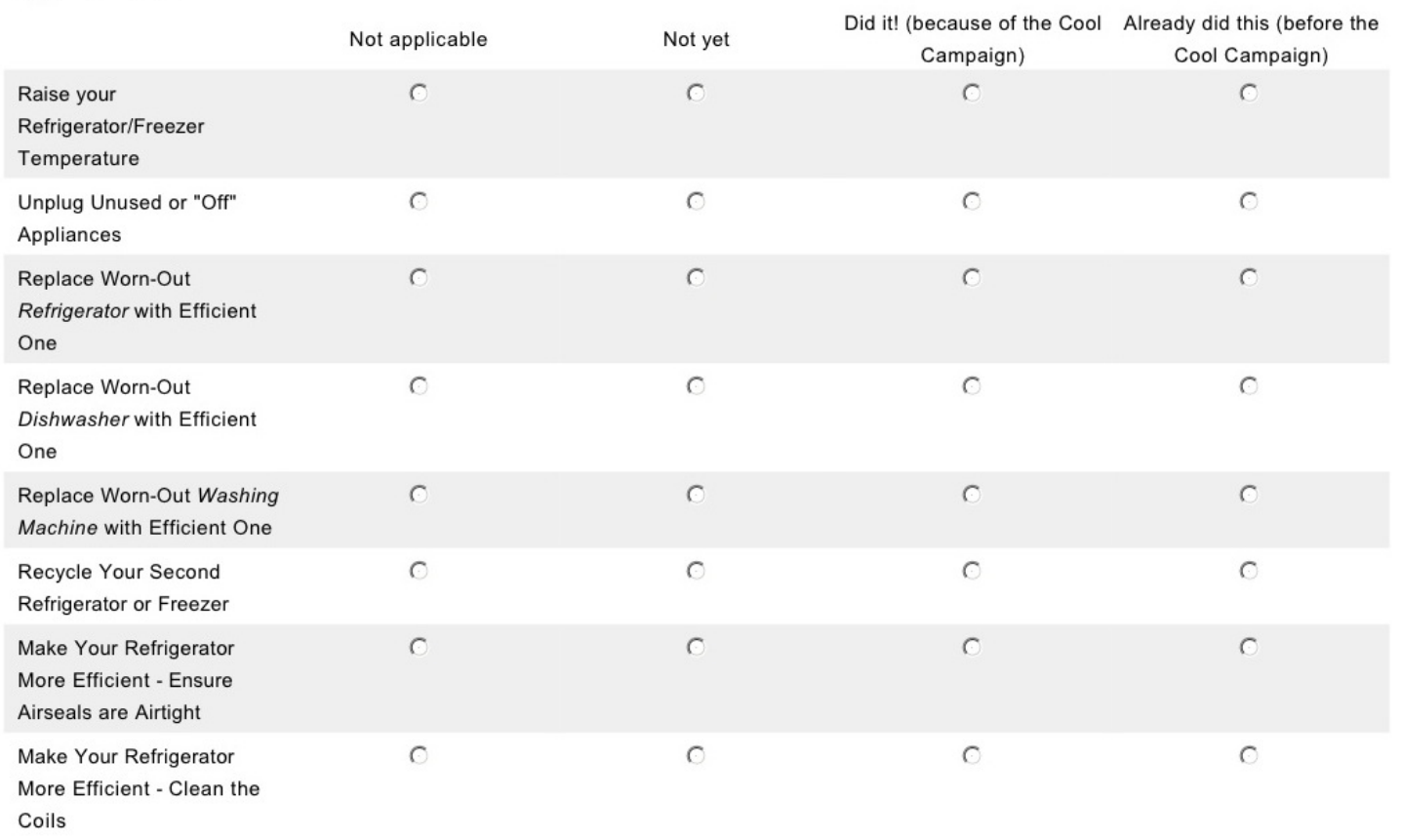

2. How did you do adopting new habits to more efficiently wash dishes?

$\begin{aligned} & \text { Use the "Energy Saver" or } \\ & \text { "Light Wash" option }\end{aligned}$
$\begin{aligned} & \text { Select the "Air-Dry" Setting } \\ & \text { or Open the Door for Drying }\end{aligned}$
$\begin{aligned} & \text { Always Run a Full Load } \\ & \text { Niwe Applicable }\end{aligned}$

3. If you did adopt or strengthen these habits, how often do you perform them? (Skip actions you answered "Already Doing" in Question 2.)

Use the "Energy Saver" or
"Light Wash" option




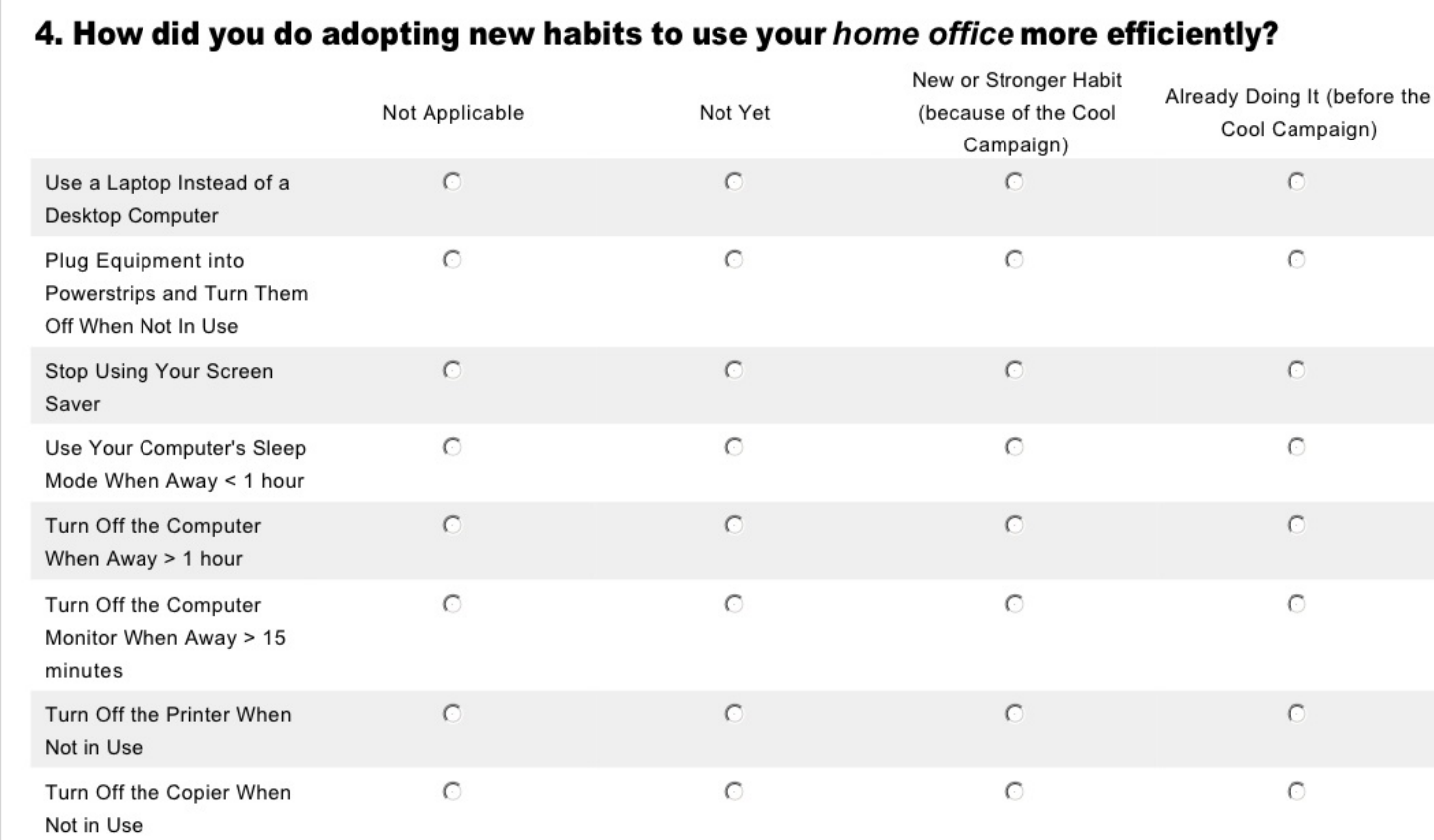

\section{If you did adopt or strengthen these habits, how often do you perform them? (Skip actions you answered "Already Doing" in Question 4.)}

Use a Laptop Instead of a
Desktop Computer
Plug Equipment into
Powerstrips and Turn Them
Off When Not In Use
Stop Using Your Screen
Saver
Use Your Computer's Sleep
Mode When Away< 1 hour
$\begin{aligned} & \text { Turn Off the Computer } \\ & \text { When Away }>1 \text { hour }\end{aligned}$
$\begin{aligned} & \text { Turn Off the Computer } \\ & \text { Monitor When Away }>15 \\ & \text { minutes }\end{aligned}$
$\begin{aligned} & \text { Turn Off the Printer When } \\ & \text { Not in Use }\end{aligned}$
$\begin{aligned} & \text { Turn Off the Copier When } \\ & \text { Not in Use }\end{aligned}$

Note: The third page of the Things You Plug In study that posed the question "Any other comments about the Cool Campaign" and provided information for informed consent was not included here to save paper. 
For this survey of the Cool Campaign only, we are asking a few extra questions to help us get to know your community and improve the program. As is true for all Cool Campaign surveys, your answers are anonymous.

7. 1. How many persons living in your household are the following ages?

Under 18

$18-29$

$30-39$

$40-49$

$50-64$

$65+$

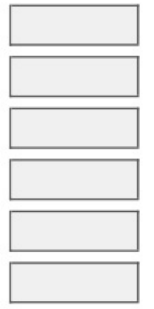

8. 3. Do you own or rent?

$\ulcorner$ Own

$\ulcorner$ Rent

Other (please specify)

9. Do you live in a house, apartment, or townhome/condominium

House

Apartment

Townhome/Condominium

Other (please specify)

\section{What is your annual household income?}

A Above $\$ 150,000$

C. $\$ 100,000-\$ 149,000$

C $\$ 80,000-\$ 99,000$

( $\$ 60,000-\$ 79,000$

C $\$ 40,000-\$ 59,000$

C $\$ 20,000-\$ 39,000$

Less than $\$ 20,000$ 


\section{What is the highest level of education you have completed?}

Less than High School

High School or equivalent

Vocational/Technical School

Some College

4-year College

Master's Degree

Doctorate Degree

Professional Degree (MD, JD, etc.)

\section{How much do you agree or disagree with the following statements?}

"I closely follow current
events in the local and
national news."
"Climate change (aka
global warming) is one of
the most important issues
facing the world right now."
"I am concerned about
climate change, but don't
know what I can do about
it."
"In terms of energy use, my
household is at least as
"green" as most other
households."
"often think about how I can
reduce my impact on the
planet (energy use,
resource use, or other)."




\section{Appendix C \\ Monthly Survey Results Graph}

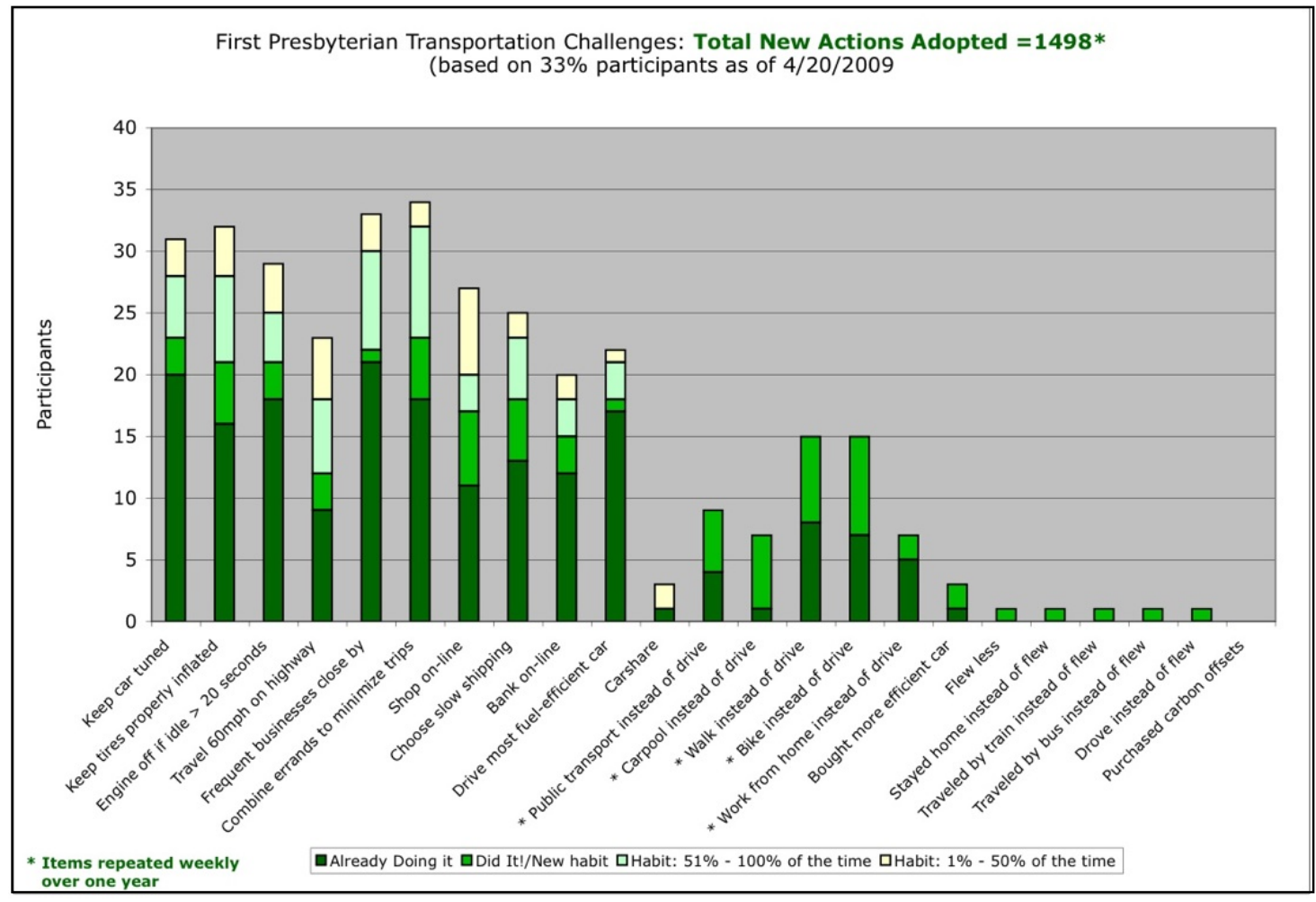




\title{
Appendix D \\ Follow Up Survey for Intervention Group
}

\author{
Final Cool Campaign Feedback Questionnaire \\ Welcome to the Final Cool Campaign Questionnaire \\ One year ago you joined a six month Cool Campaign to help you and your family reduce your home energy use. This \\ survey seeks your feedback about your experiences with the campaign and its long-term impact on your attitudes and \\ behaviors. \\ Your responses are anonymous, but please use the same computer to answer this survey as you used during the \\ Campaign to help us link the surveys together. \\ 1. Did you pledge your commitment to participate in your community's Campaign, whether \\ during the launch event or at a later time? \\ Yes, I pledged at the launch event \\ Yes, I pledged after the launch event

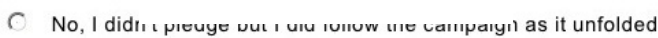 \\ No, I didn't participate in the pledge nor pay attention to the campaign
}

\section{Please indicate your level of participation during your community's Campaign. Check all} boxes that apply:

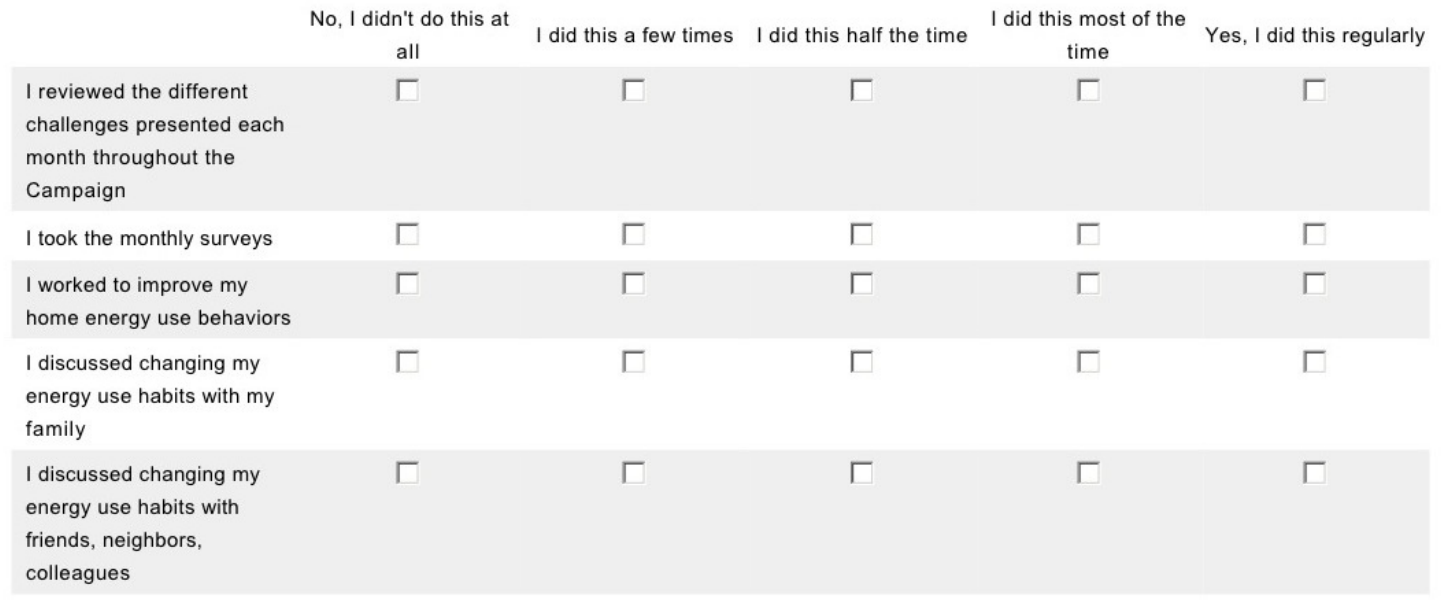

What habits have you continued... 


\section{Final Cool Campaign Feedback Questionnaire}

3. Please indicate which habits you have continued to perform or which you have newly adopted since the end of your community's Campaign:

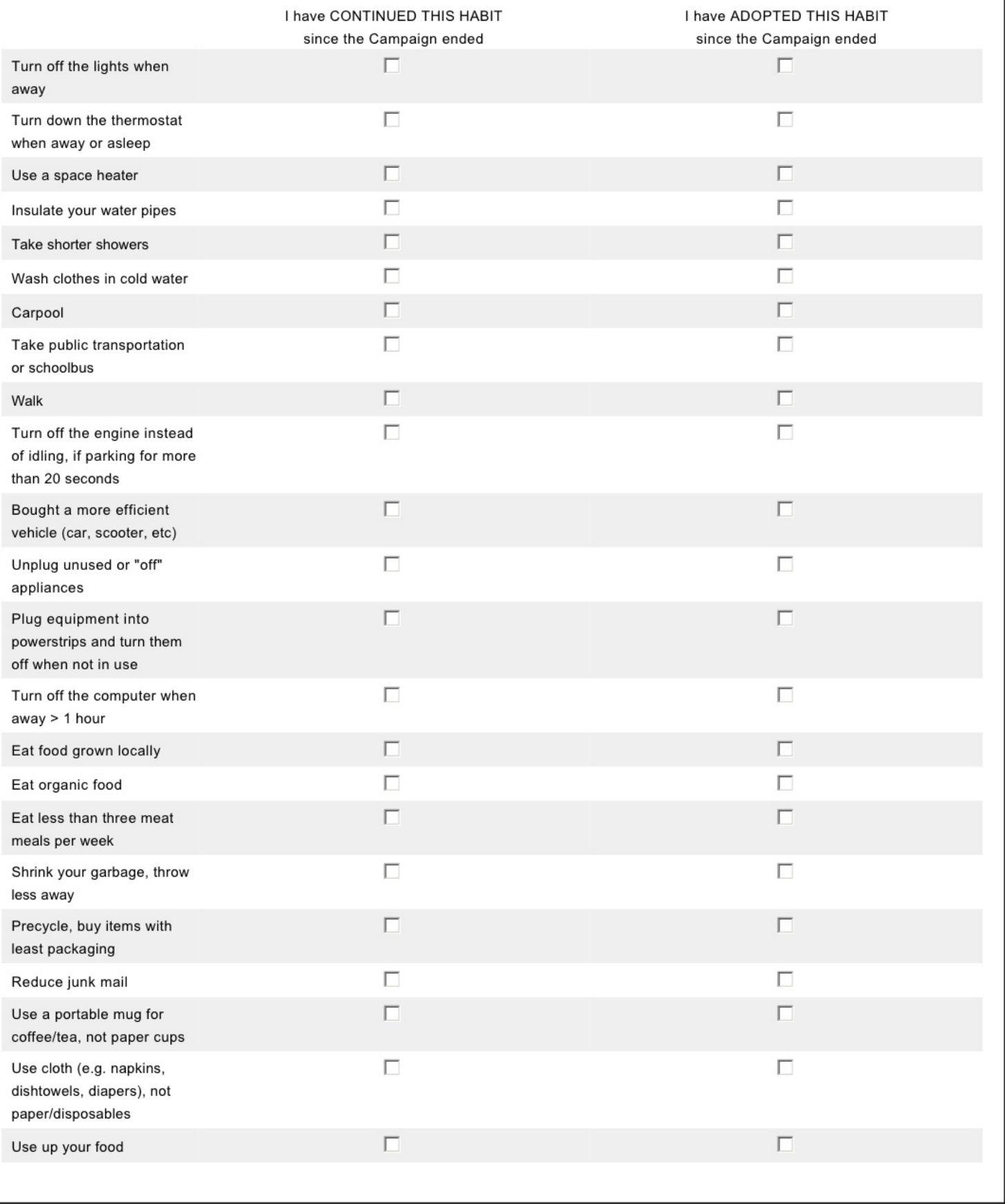




\section{Final Cool Campaign Feedback Questionnaire}

\section{Please indicate HOW OFTEN you are currently performing these habits/actions:}

\begin{tabular}{|c|c|c|c|c|c|}
\hline & $\begin{array}{l}\text { Not at all, } \\
\text { this is not a habit }\end{array}$ & $\begin{array}{l}\text { About } 25 \% \\
\text { of the time }\end{array}$ & $\begin{array}{l}\text { About } 50 \% \\
\text { of the time }\end{array}$ & $\begin{array}{l}\text { About } 75 \% \\
\text { of the time }\end{array}$ & $100 \%$ of the time \\
\hline $\begin{array}{l}\text { Turn off the lights when } \\
\text { away }\end{array}$ & $\Gamma$ & $\Gamma$ & $\Gamma$ & $\Gamma$ & $\Gamma$ \\
\hline $\begin{array}{l}\text { Turn down the thermostat } \\
\text { when away or asleep }\end{array}$ & $\Gamma$ & \ulcorner & \ulcorner & \ulcorner & \ulcorner \\
\hline Use a space heater & Г & $\Gamma$ & $\Gamma$ & Г & $\Gamma$ \\
\hline Insulate your water pipes & $\Gamma$ & $\Gamma$ & $\Gamma$ & Г & $\Gamma$ \\
\hline Take shorter showers & $\Gamma$ & $\Gamma$ & $\Gamma$ & $\Gamma$ & $\Gamma$ \\
\hline Wash clothes in cold water & \ulcorner & \ulcorner & \ulcorner & Г & Г \\
\hline Carpool & $\Gamma$ & $\Gamma$ & $\Gamma$ & $\Gamma$ & Г \\
\hline $\begin{array}{l}\text { Take public transportation } \\
\text { or schoolbus }\end{array}$ & \ulcorner & \ulcorner & Г & \ulcorner & \ulcorner \\
\hline Walk & $\Gamma$ & $\Gamma$ & $\Gamma$ & $\Gamma$ & $\Gamma$ \\
\hline $\begin{array}{l}\text { Turn off the engine instead } \\
\text { of idling, if parking for more } \\
\text { than } 20 \text { seconds }\end{array}$ & $\Gamma$ & Г & \ulcorner & $\Gamma$ & \ulcorner \\
\hline $\begin{array}{l}\text { Bought a more efficient } \\
\text { vehicle (car, scooter, etc) }\end{array}$ & Г & $\Gamma$ & Г & $\Gamma$ & $\Gamma$ \\
\hline $\begin{array}{l}\text { Unplug unused or "off" } \\
\text { appliances }\end{array}$ & \ulcorner & \ulcorner & $\Gamma$ & Г & \ulcorner \\
\hline $\begin{array}{l}\text { Plug equipment into } \\
\text { powerstrips and turn them } \\
\text { off when not in use }\end{array}$ & Г & $\Gamma$ & $\Gamma$ & Г & $\Gamma$ \\
\hline $\begin{array}{l}\text { Turn off the computer when } \\
\text { away }>1 \text { hour }\end{array}$ & $\Gamma$ & $\Gamma$ & \ulcorner & $\Gamma$ & \ulcorner \\
\hline Eat food grown locally & $\Gamma$ & $\Gamma$ & $\Gamma$ & $\Gamma$ & $\Gamma$ \\
\hline Eat organic food & $\Gamma$ & \ulcorner & $\Gamma$ & \ulcorner & \ulcorner \\
\hline $\begin{array}{l}\text { Eat less than three meat } \\
\text { meals per week }\end{array}$ & $\Gamma$ & $\Gamma$ & $\Gamma$ & $\Gamma$ & $\Gamma$ \\
\hline $\begin{array}{l}\text { Shrink your garbage, throw } \\
\text { less away }\end{array}$ & \ulcorner & \ulcorner & Г & Г & \ulcorner \\
\hline $\begin{array}{l}\text { Precycle, buy items with } \\
\text { least packaging }\end{array}$ & $\Gamma$ & $\Gamma$ & Г & Г & $\Gamma$ \\
\hline Reduce junk mail & \ulcorner & \ulcorner & $\Gamma$ & \ulcorner & \ulcorner \\
\hline $\begin{array}{l}\text { Use a portable mug for } \\
\text { coffee/tea, not paper cups }\end{array}$ & $\Gamma$ & $\Gamma$ & $\Gamma$ & $\Gamma$ & $\Gamma$ \\
\hline $\begin{array}{l}\text { Use cloth (e.g. napkins, } \\
\text { dishtowels, diapers), not } \\
\text { paper/disposables }\end{array}$ & \ulcorner & \ulcorner & Г & \ulcorner & $\Gamma$ \\
\hline Use up your food & $\Gamma$ & $\Gamma$ & $\Gamma$ & $\Gamma$ & $\Gamma$ \\
\hline
\end{tabular}

Note: Frequency data was not included in the results to keep the overall scope of this research project to a manageable size. 


\section{Final Cool Campaign Feedback Questionnaire}

5. How effective was your community's Campaign in EDUCATING YOU about the importance of taking individual daily action to fight Global Warming?

Not At All Effective

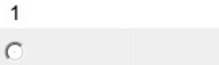

6. How much did your your community's Campaign MOTIVATE YOU to change your habits to reduce your home energy use?

Not Motivated At All By

Extremely Motivated

This

2

By This

c

C

6

7. How much did the knowledge that your community was united in a campaign to reduce their energy use MOTIVATE YOU to change your energy habits?

Not Motivated At All By

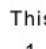

$$
1
$$$$
\text { C }
$$

2

$c$

8. How much did the knowledge that reducing energy use has been gaining popularity around the country MOTIVATE YOU to change your energy habits?

Not Motivated At All By This$$
1
$$$$
\text { C }
$$
$c$
Extremely Motivated

By This

5

What else has motivated you to change your energy use? 


\section{Final Cool Campaign Feedback Questionnaire}

9. To the best of your memory, how much did each of the following MOTIVATE YOU to adopt energy-reduction behaviors DURING the Campaign?

\begin{tabular}{|c|c|c|c|c|c|}
\hline & $\begin{array}{l}\text { Motivated By } \\
\text { This } \\
1\end{array}$ & 2 & 3 & 4 & $\begin{array}{c}\text { Extremely Motivated } \\
\text { By This } \\
5\end{array}$ \\
\hline $\begin{array}{l}\text { Campaign launch in your } \\
\text { community }\end{array}$ & 0 & 0 & 0 & 0 & 0 \\
\hline Pledge display/gesture & 0 & 0 & 0 & 0 & 0 \\
\hline $\begin{array}{l}\text { Knowing how many other } \\
\text { households in your } \\
\text { community had pledged to } \\
\text { join the campaign }\end{array}$ & 0 & 0 & 0 & 0 & 0 \\
\hline Campaign website & 0 & 0 & 0 & 0 & 0 \\
\hline $\begin{array}{l}\text { Green team } \\
\text { communications about the } \\
\text { campaign }\end{array}$ & 0 & C & 0 & 0 & 0 \\
\hline $\begin{array}{l}\text { Green team outreach } \\
\text { events }\end{array}$ & 0 & 0 & 0 & 0 & 0 \\
\hline Taking the monthly surveys & 0 & $\sigma$ & 0 & 0 & 0 \\
\hline $\begin{array}{l}\text { Reviewing monthly survey } \\
\text { results showing how many } \\
\text { households were changing } \\
\text { their habits }\end{array}$ & 0 & 0 & 0 & 0 & 0 \\
\hline Campaign wrap event & 0 & 0 & 0 & 0 & 0 \\
\hline $\begin{array}{l}\text { Discussions with other } \\
\text { community members about } \\
\text { the Campaign generally or } \\
\text { specific challenges }\end{array}$ & 0 & 0 & 0 & 0 & 0 \\
\hline $\begin{array}{l}\text { Firsthand knowledge of the } \\
\text { efforts of other campaign } \\
\text { households to reduce their } \\
\text { energy use }\end{array}$ & 0 & 0 & 0 & 0 & 0 \\
\hline
\end{tabular}

Other (please specify) 


\section{Appendix E \\ Open-ended Comments from All Surveys}

\begin{tabular}{|c|c|c|}
\hline Comment Type & Survey & Comment \\
\hline \multirow[t]{4}{*}{ General } & Hot Water & $\begin{array}{l}\text { I guess now we have to save water, as well as energy, and } \\
\text { money... }\end{array}$ \\
\hline & $\begin{array}{l}\text { Things You } \\
\text { Plug In }\end{array}$ & $\begin{array}{l}\text { I responded to this e-mail because the link was easily accessible in } \\
\text { the e-mail! It's got to be easy! (sorry, it's sad but true). }\end{array}$ \\
\hline & Winter Heat & $\begin{array}{l}\text { It's still early in the campaign, but we are interested to see what } \\
\text { other members are doing that perhaps we are not. }\end{array}$ \\
\hline & Hot Water & $\begin{array}{l}\text { I wish } \mathrm{i} \text { could think of a nice way of telling upstairs neighbor to } \\
\text { stop showering for } 20 \text { minutes!! }\end{array}$ \\
\hline Suggestion & $\begin{array}{l}\text { Things You } \\
\text { Plug In }\end{array}$ & $\begin{array}{l}\text { What about use of washing machine? Type of washing machine? } \\
\text { How many loads can you eliminate in one month? How many } \\
\text { reside in your household? }\end{array}$ \\
\hline \multirow[t]{10}{*}{$\begin{array}{l}\text { Reported New } \\
\text { Habits }\end{array}$} & $\begin{array}{l}\text { Consumer } \\
\text { Footprint }\end{array}$ & $\begin{array}{l}\text { Because of the Cool Campaign I rounded up all of the cloth bags I } \\
\text { had and now keep them in both cars and use them all the time. }\end{array}$ \\
\hline & & $\begin{array}{l}\text {... I won't take a reusable container to a party or reception, nor } \\
\text { pull out my own napkin at a restaurant using paper napkins. And if } \\
\text { I forget to tell the pizza delivery order taker NOT to include paper } \\
\text { napkins, I don't take them out of the bag and hand them back to } \\
\text { the delivery person (who would just throw them away I am } \\
\text { sure)...Make the best choices that are feasible in the situation, and } \\
\text { don't alienate people unnecessarily. }\end{array}$ \\
\hline & & Showering at the Y saves energy at home! \\
\hline & Hot Water & $\begin{array}{l}\text { We installed two tankless heaters and one energy efficient water } \\
\text { heater for the radiant heating system. }\end{array}$ \\
\hline & & $\begin{array}{l}\text { I wash full loads when I can, but it isn't always possible. I } \\
\text { normally use warm water for washing clothes, cold for rinsing. I } \\
\text { use shortest times possible. }\end{array}$ \\
\hline & & $\begin{array}{l}\text { Because of your suggestions, I had SJ Water come out and do a } \\
\text { water audit...Thanks! }\end{array}$ \\
\hline & & $\begin{array}{l}\text { Went from hot water washing to warm/cold Could not go straight } \\
\text { cold / cold yet }\end{array}$ \\
\hline & & $\begin{array}{l}\text { Looking into installing some kind of pump to get hot water across } \\
\text { the house to baths. Wasting a lot of water now waiting for the hot } \\
\text { water to arrive. }\end{array}$ \\
\hline & & $\begin{array}{l}\text { We hope, this year, to install a solar system for our home, and } \\
\text { then, if possible, buy an electric car next time we need to change } \\
\text { cars. }\end{array}$ \\
\hline & Transportation & $\begin{array}{l}\text { Contribution to carbon fund every month offsets unknown \# of } \\
\text { miles flown. }\end{array}$ \\
\hline
\end{tabular}


Appendix E table continued

\begin{tabular}{|c|c|c|}
\hline Comment Type & Survey & Comment \\
\hline & & $\begin{array}{l}\text { We hope to install a tankless water heater at our cabin, but found } \\
\text { that it was very difficult to change to a tankless at our SJ house } \\
\text { due to the placement of the existing water heater. At least we will } \\
\text { wrap it. }\end{array}$ \\
\hline & Winter Heat & $\begin{array}{l}\text { I appreciate your doing this. I am still thinking about doing some } \\
\text { of the things suggested for February... like getting the air ducts } \\
\text { checked for leaks... and I'd love to get sun tunnels or sky lights, } \\
\text { but that will require lots of convincing for my husband! But it's on } \\
\text { my list to work on. }\end{array}$ \\
\hline & $\begin{array}{l}\text { Things You } \\
\text { Plug In }\end{array}$ & $\begin{array}{l}\text { Have not used dishwasher this month - waiting for parts. Will } \\
\text { shop for a more efficient one if parts do not show up. }\end{array}$ \\
\hline & & $\begin{array}{l}\text { When using just a small amount of water to wash a few dishes or } \\
\text { to wash my face before bedtime, I heat the water with an electric } \\
\text { kettle instead of running the water to get it hot. What is the } \\
\text { difference between sleep saver and sleep mode? And computer } \\
\text { guru says it is better for the computer not to be turning it off and } \\
\text { on all the time. }\end{array}$ \\
\hline & $\begin{array}{l}\text { Follow Up } \\
\text { Survey }\end{array}$ & $\begin{array}{l}\text { It's a great program. I was pretty "dark green" to begin with, but } \\
\text { was still able to make some significant changes (mainly having to } \\
\text { do with power-strips, turning off computers and accessories). I've } \\
\text { definitely been better about local, organic food. This didn't come } \\
\text { up in the survey, but I'm currently working on installing a native } \\
\text { garden in part of my yard. }\end{array}$ \\
\hline \multirow[t]{4}{*}{ Complaint } & Winter Heat & Once again, most of these actions aren't possible for renters... \\
\hline & & Many of the things on this list I cannot do because I rent. \\
\hline & $\begin{array}{l}\text { Things You } \\
\text { Plug In }\end{array}$ & $\begin{array}{l}\text { Need to acknowledge the fact that renters (like me) don't have all } \\
\text { the options to swap out inefficient appliances that homeowners } \\
\text { do... }\end{array}$ \\
\hline & Transportation & $\begin{array}{l}\text { these questions are unnecessarily complicated. This might turn off } \\
\text { any otherwise motivated person. You should be able to say N/A } \\
\text { and move on...I just had to put in a nominal number to complete } \\
\text { the survey }\end{array}$ \\
\hline \multirow[t]{9}{*}{ Thanks or Praise } & $\begin{array}{l}\text { Consumer } \\
\text { Footprint }\end{array}$ & $\begin{array}{l}\text { great, thanks for setting up the program. We got a lot from it and } \\
\text { will continue the changes we made with the program. }\end{array}$ \\
\hline & Winter Heat & A great program - glad that our church could use it. \\
\hline & & Great idea, great follow through! \\
\hline & & So glad we're doing this \\
\hline & & $\begin{array}{l}\text { I think it's a great idea and like the fact that the church has taken } \\
\text { an active part in this campaign. Thank you to those of you who } \\
\text { have taken leadership in this project. }\end{array}$ \\
\hline & & It's cool! \\
\hline & & Keep up the good work. \\
\hline & & Good general resources. \\
\hline & & Great idea! Hope we can keep it up! \\
\hline
\end{tabular}


Appendix E table continued

\begin{tabular}{|c|c|c|}
\hline Comment Type & Survey & Comment \\
\hline \multirow[t]{9}{*}{ Thanks or Praise } & Winter Heat & $\begin{array}{l}\text { Extremely interesting and an easy way to discover what can be } \\
\text { done. }\end{array}$ \\
\hline & & Thanks for the reminders \\
\hline & & $\begin{array}{l}\text { Think it is a great idea and everyone should try to something to } \\
\text { reduce the use of electricity. }\end{array}$ \\
\hline & & Good job, [lead Green Team member] and group! \\
\hline & Transportation & Yes, let's keep the dialogue/info sharing ongoing. \\
\hline & & We are GOOD!! \\
\hline & & Great job! \\
\hline & $\begin{array}{l}\text { Things You } \\
\text { Plug In }\end{array}$ & Thanks for doing this! I'm already on the email group list. \\
\hline & & Great suggestions. \\
\hline
\end{tabular}

